Eng. Adriano Salomão loriatti

\title{
ESTUDO DA DINÂMICA DE LAVADORA DE EIXO VERTICAL UTILIZANDO SISTEMAS MULTICORPOS
}

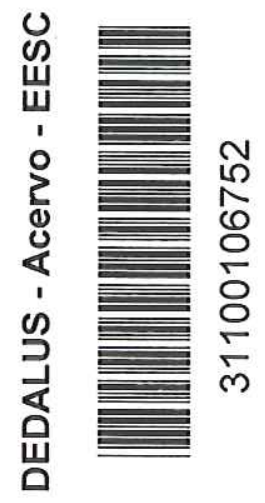

Dissertação apresentada à Escola de Engenharia de São Carlos da Universidade de São Paulo, como parte dos requisitos para a obtenção do Título de Mestre em Engenharia Mecânica.

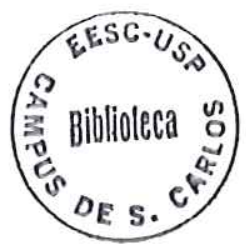

ORIENTADOR: Prof. Dr. Álvaro Costa Neto

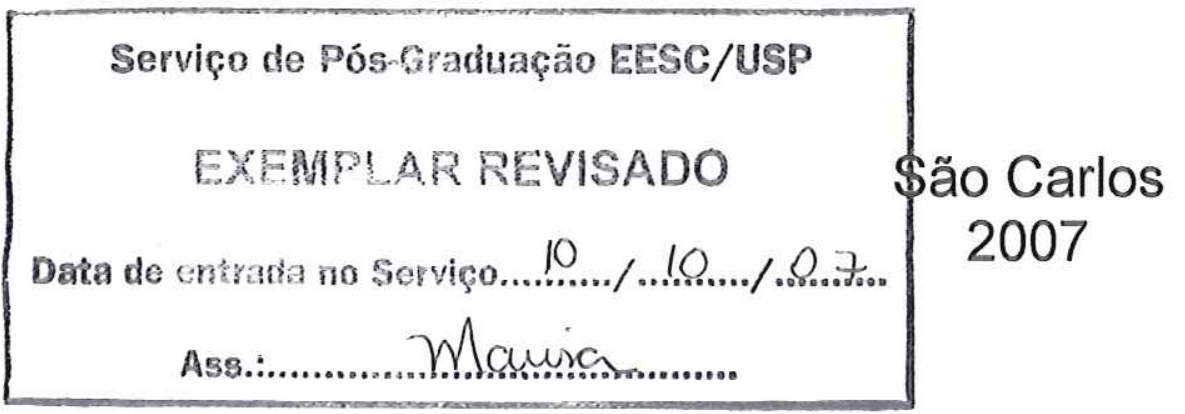




\section{FOLHA DE JULGAMENTO}

Candidato: Engenheiro ADRIANO SALOMÃO IORIATTTI

Dissertação defendida e julgada em 28/06/2007 perante a Comissão Julgadora:

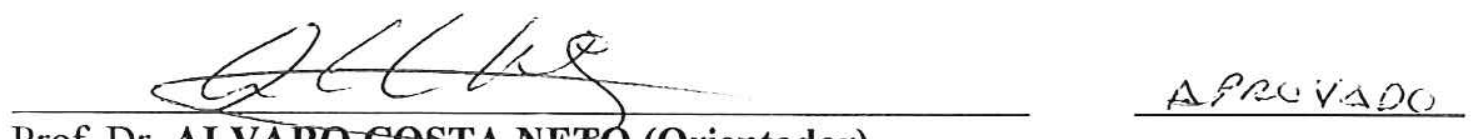

Prof. Dr. ALVARO COSTA NETO (Orientador)

(Escola de Engenharia de São Carlos/USP)

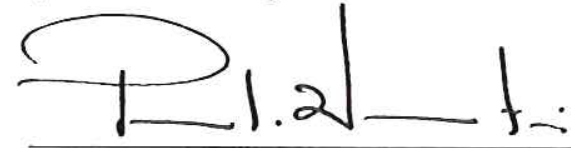

Prof. Titular PAULO SERGIO VAROTO

\#provado

(Escola de Engenharia de São Carlos/USP)

$i 1$

Dr. WLADDMIR ALEX MAGALHÃES BARCHA

APROVADO

(Whirlpool S.A.)

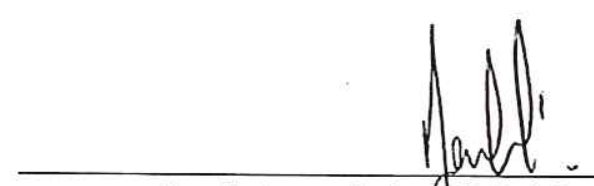

Prof. Associado JONAS DE CARVALHO

Coordenador do frograma de Pós-Graduação em Engenharia Mecânica

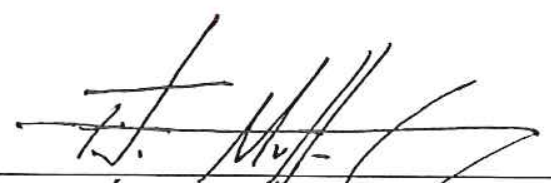

Prof. Associado FÁBIO MOULLER GUERRINI Vice-Presidente da Comissão da Pós-Graduação da EESC em Exercício 
Aos meus pais e irmãos, com carinho 


\section{AGRADECIMENTOS}

Ao Prof. Dr. Álvaro pela orientação e amizade.

Aos meus amigos, em especial ao Érico Munhoz e Wladimir Barcha pelas dicas.

A Whirlpool SA Eletrodomésticos, que me deu a oportunidade de realizar este trabalho.

A Deus, pela vida. 


\section{SUMÁRIO}

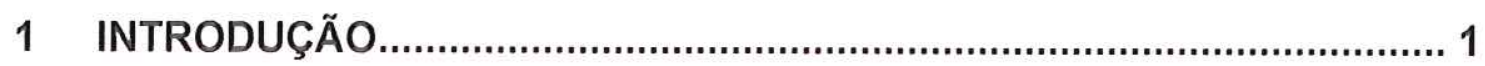

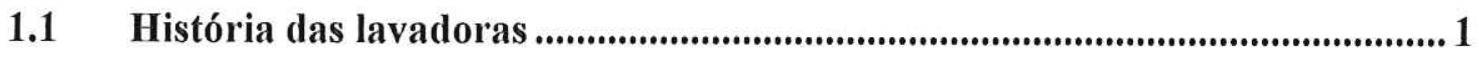

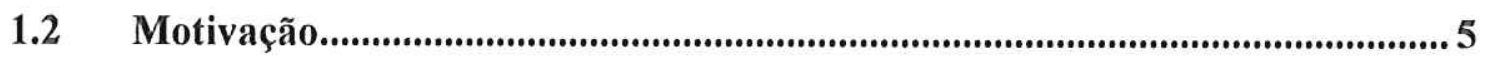

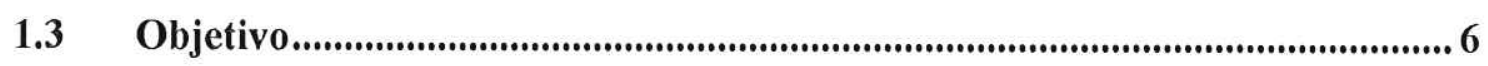

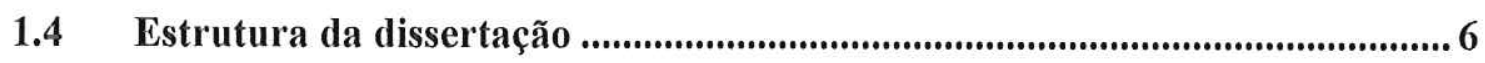

2 REVISÃO BIBLIOGRÁFICA ............................................................ 8

2.1 Modelamento dinâmico de lavadoras.................................................................. 8

3 BALANCEADORES DINÂMICOS ................................................... 18

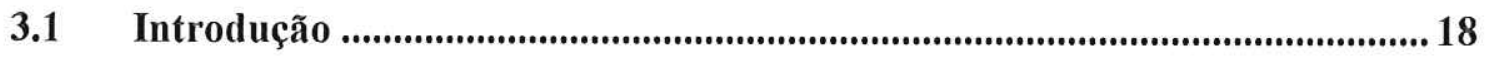

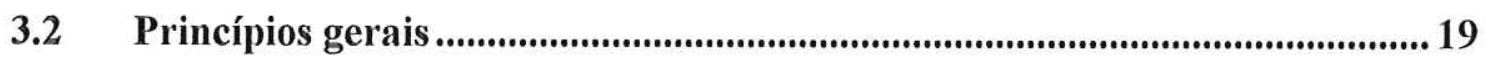

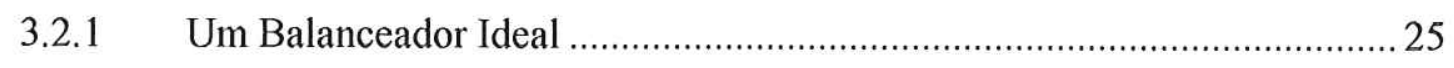

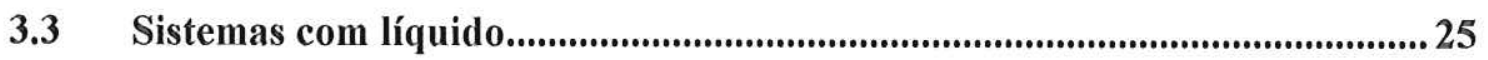

3.3.1 O anel de balanceamento de Leblanc .......................................................... 25

3.3.2 O balanceador de Leblanc modificado ....................................................... 33

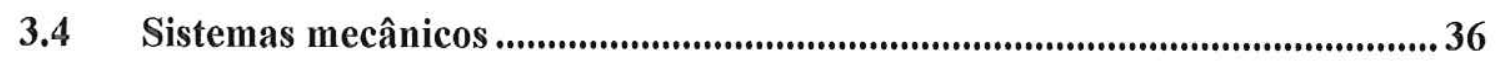

3.4.1 Pêndulo, anel e balanceadores de esferas .................................................... 36

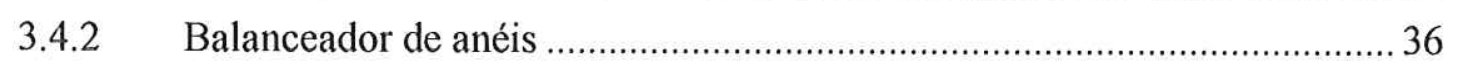

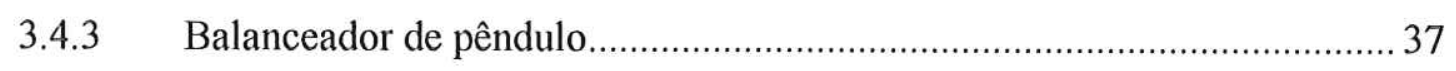

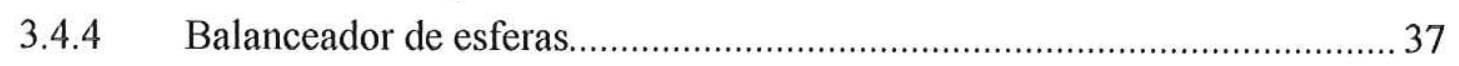

3.4.5 O balanceador combinado ................................................................... 41

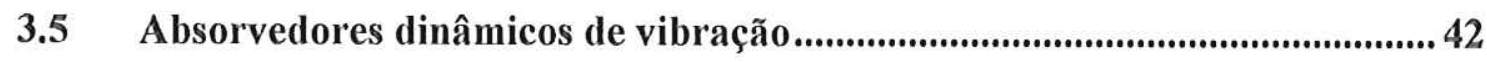

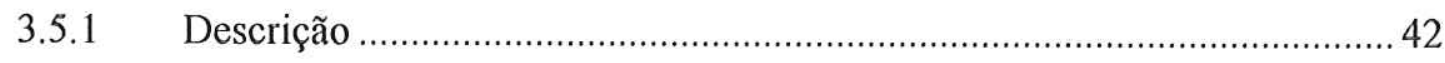

3.5.2 Sistema primário (1 GDL) …................................................................... 43

3.5.3 Princípio de funcionamento de um sistema primário com um AV............. 44

4 TEORIA DE MULTICORPOS …............................................................ 48

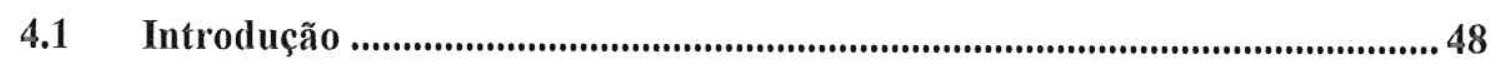




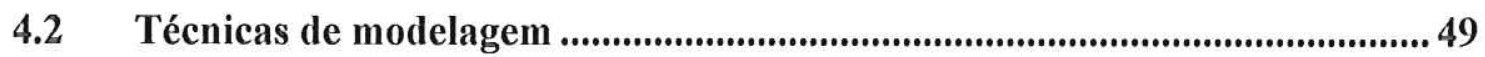

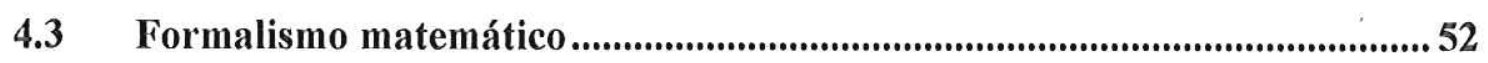

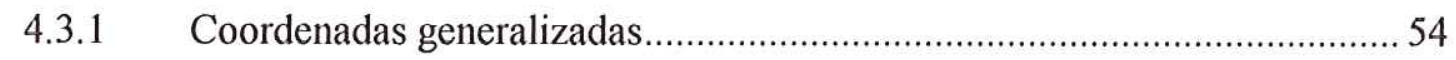

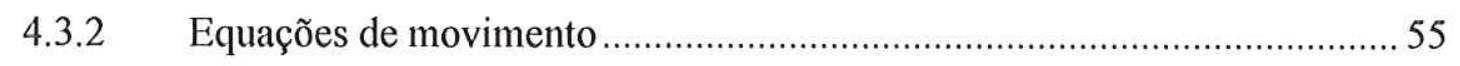

4.3.3 Juntas no ADAMS ................................................................................... 58

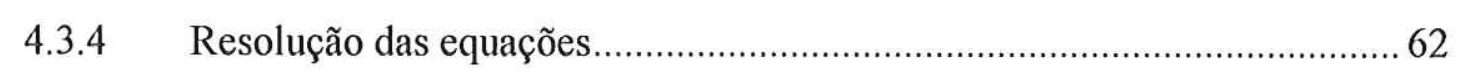

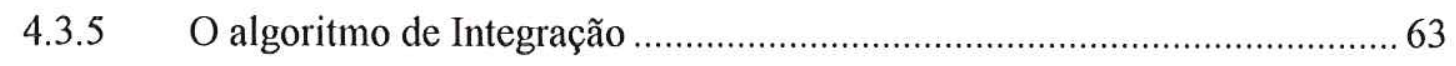

5 CONSTRUÇÃO DE MODELO MULTICORPOS E VALIDAÇÃO .............69

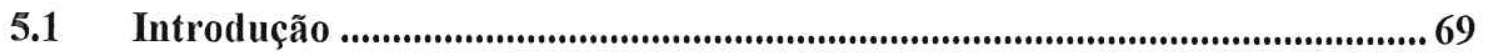

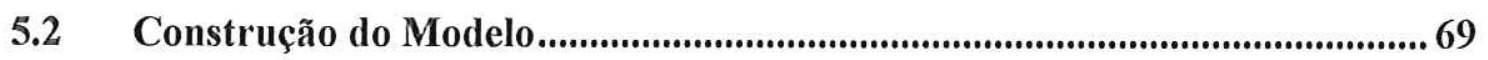

5.3 Análise experimental e validação do Modelo .............................................. 75

5.3.1 Equipamentos e forma de medição ............................................................... 75

5.4 Resultados de Deslocamento Medidos ............................................................79

5.4.1 Análise experimental no domínio do tempo ............................................. 79

5.4.2 Análise Experimental no Domínio da Freqüência......................................... 84

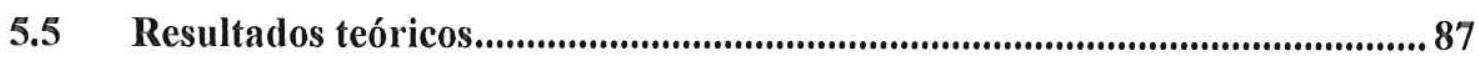

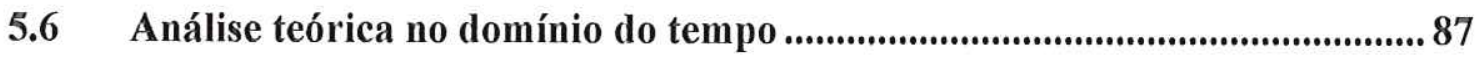

5.7 Análise teórica no domínio da freqüência ............................................... 92

5.8 Discussão e validação do modelo teórico ........................................................... 93

6 COMPORTAMENTO TEÓRICO DINÂMICO VIA MULTICORPOS ......... 99

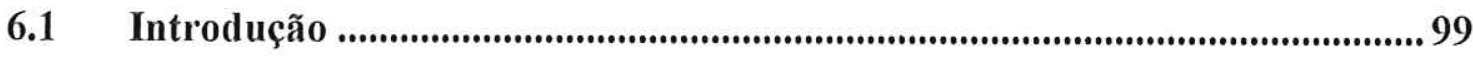

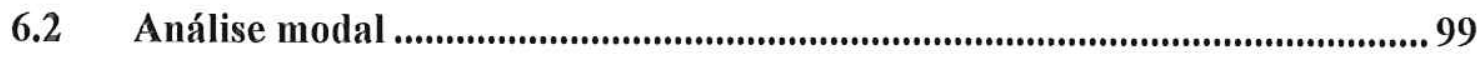

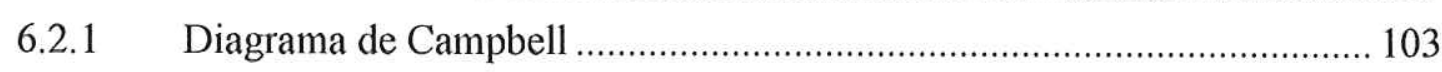

6.3 Performance da lavadora contra deslocamento ........................................ 104

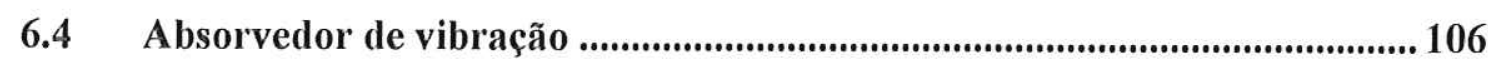

7 RESULTADOS E CONCLUSÕES ................................................... 109 


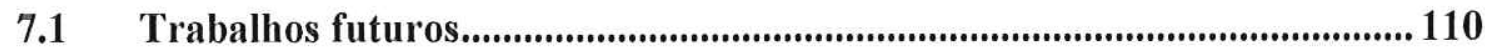
REFERÊNCIAS BIBLIOGRÁFICAS .....................................................111 


\section{LISTA DE FIGURAS}

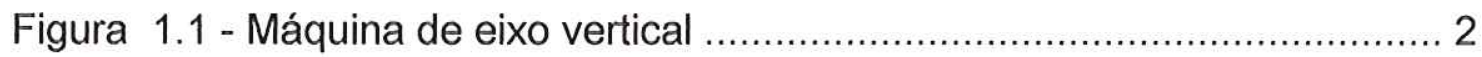

Figura 1.2 - Máquina de eixo horizontal .................................................... 3

Figura 2.1 - Design de suporte com nó fixo (Non-translating Fixed node Design - NTFN) - Fonte: (BAGAPALLI, 1987) . 10

Figura 2.2 - Design de suporte com nó livre ("Translating Free Noded Design - TFN") - Fonte: (BAGAPALLI, 1987) ...................... 11

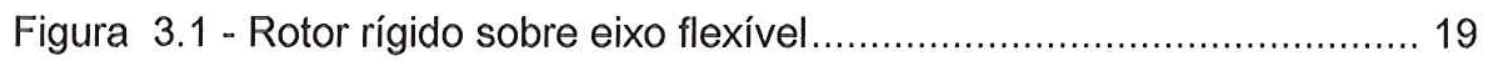

Figura 3.2 - Extrator centrifugo....................................................... 21

Figura 3.3 - Diagrama de forças de equilíbrio......................................... 22

Figura 3.4 - Excentricidade versus rotação .............................................. 23

Figura 3.5 - Anglo de fase entre excentricidade e massa desbalanceada versus razão de rotação ............................... 24

Figura 3.6 -Balanceador de Leblanc numa máquina de eixo horizontal ......... 27

Figura 3.7 -Representação gráfica do volume de fluido otimizado ................. 30

Figura 3.8 - Força de restauração versus excentricidade ............................ 32

Figura 3.9 - Centróide do fluido em um anel-hidro: a) e $<e_{\max }$ b) e $>$

$e_{\max } \quad$ c) e $\gg>e_{\max }-$ Fonte: Adatsdo de S. Bae et.al (2002) ....................... 33

Figura 3.10 - O anel modificado de Leblanc............................................ 33

Figura 3.11 -Força de Restauração em função da excentricidade em um balanceador de múltiplas câmaras......

Figura 3.12 - Sensibilidade de um anel de múltiplas câmaras versus anel de câmara simples ................................................ 35

Figura 3.13 - Esquema de balanceador (a) de anel (b) de pêndulo ............... 36

Figura 3.14 - Balanceador de esferas ............................................. 38

Figura 3.15 - Diagrama de corpo livre de uma esfera............................... 39

Figura 3.16 -Balanceador combinado ................................................. 41

Fligura 3.17 - Absorvedores mecânicos de vibração utilizados em lavadoras de eixo vertical e horizontal.Fonte: Haar (1999) 42

Figura 3.18 - Sistema Primário de 1 GDL................................................. 43

Figura 3.19 - Função de Resposta em freqüência para sistema primário 
Figura 3.20 - Absorvedor de vibração 45

Figura 3.21 - Resposta em freqüência para o sistema primário e combinado. 46

Figura 4.1 - Representação Topológica de Sistemas Multicorpos.

Fonte: Barbosa (1999) 50

Figura 4.2 - Lei de Newton e seus Princípios. Fonte: (BARBOSA, 1999) 53

Figura 5.1 - Etapa de Construção do Modelo MBS-Fonte Adams reference manual (1992) ................................................. 70

Figura 5.2 - Exemplo de componente e seu tensor de massa e inércia.......... 71 Figura 5.3 - Modelo Multicorpos da Lavadora BRASTEMP 24" em

ADAMS 72

Figura 5.4 - Modelo ilustrativo de suspensão de copo. Fonte: Park (2006) 73

Figura 5.5 -Rampa de aceleração 75

Figura 5.6 - Modelo em EF do pé de uma lavadora para caracterização de rigidez 75

Figura 5.7-Deslocamento do tanque de uma lavadora de eixo horizontal em centrifugação. Fonte: Türkay (1992) 76

Figura 5.8 -Design mostrando acelerômetro utilizado 77

Figura 5.9-Resposta em freqüência do acelerômetro B\&K 4506B.................. 78

Figura 5.10 - Carta de calibração do acelerômetro B\&K 4506B ..................... 78

Figura 5.11 - Ilustração do sistema de coordenadas utilizado .......................... 80

Figura 5.12 - Deslocamento superior do tanque na direção $X$........................... 80

Figura 5.13 - Deslocamento superior do tanque na direção $Y$............................ 81

Figura 5.14 - Órbita superior do tanque experimental ..................................... 81

Figura 5.15 - Raio da órbita superior experimental........................................ 82

Figura 5.16 - Deslocamento inferior experimental do mecanismo na direção X 82

Figura 5.17 - Deslocamento inferior experimental do mecanismo na direção $Y$ 83

Figura 5.18 - Órbita inferior experimental do mecanismo ............................... 83

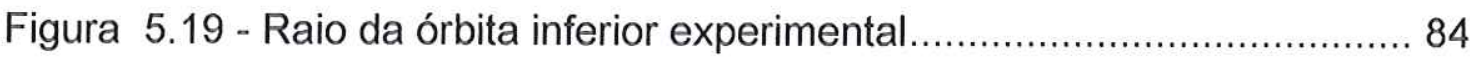

Figura 5.20 - Diagrama em cascata para deslocamento superior X. 
Experimental - Vista ISO. 85

Figura 5.21- Diagrama em cascata para o deslocamento superior $X$.

Experimental -Vista frontal. 86

Figura 5.22 - Diagrama em cascata para o deslocamento superior X.-

Experimental -Vista superior. 86

Figura 5.23 - Rampa de aceleração utilizada no ADAMS 87

Figura 5.24 - Deslocamento teórico superior do tanque na direção $X$ 88

Figura 5.25 - Deslocamento teórico superior do tanque na direção $Y$ 88

Figura 5.26 - Órbita superior teórica do tanque 89

Figura 5.27 - Raio da órbita teórica superior do tanque. 89

Figura 5.28 Deslocamento teórico inferior do mecanismo $X$.......... 90

Figura 5.29 - Deslocamento teórico inferior do mecanismo $Y$. 90

Figura 5.30 - Órbita inferior teórica do mecanismo. 91

Figura 5.31 - Raio teórico da órbita inferior do mecanismo 91

Figura 5.32 - Diagrama em cascata para o deslocamento superior em X - Teórico

Figura 5.33 - Diagrama em cascata para o deslocamento superior em Y - Teórico. 92

Figura 5.34 - Diagrama em cascata para o deslocamento inferior em Y - Teórico.

Figura 5.35 - Detalhe construtivo de anel-hidro, mostrando sua estrutura interna de aletas 95

FIGURA 5.36 órbita inferior do conjunto na direção $\mathrm{X}$ e $\mathrm{Y}$

respectivamente - resultados teóricos vs.

experimentais 96

FIGURA 5.37 órbita superior do conjunto na direção $X$ e $Y$

respectivamente - resultados teóricos vs.

experimentais

Figura 5.38 - Diagrama em cascata para deslocamento superior em $X$

- Experimental 98

Figura 5.39 - Diagrama em cascata para deslocamento superior em X-Teórico. 98

Figura 6.1 - Modo Pendular $1-0.58 \mathrm{~Hz}$. 100

Figura 6.2 - Modo Pendular $2-0.58 \mathrm{~Hz}$ 100 


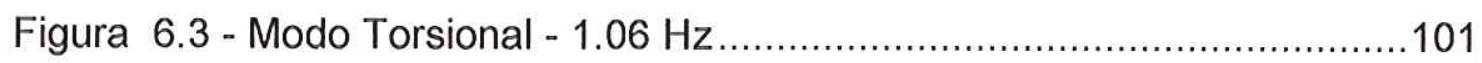

Figura 6.4 - Modo Vertical de solicitação das molas traseiras - $2.4 \mathrm{~Hz}$.........101

Figura 6.5 -Modo Vertical de solicitação das molas laterais $2.19 \mathrm{~Hz}$..............102

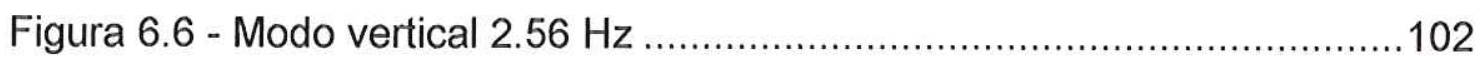

Figura 6.7 - Diagrama de Campbell do modelo teórico da lavadora .............104

Fligura 6.8 - Força residual nos pés e tendência de andar. .........................105

Figura 6.9 - Patente Maytag mostrando absorverdor de vibração em lavadoras - Fonte: Haar (1999) .................................106

Figura 6.10 - Absorvedor de vibração aplicado ao modelo da lavadora ........107

Figura 6.11 - Absorvedor de vibração - vista de topo...................................107

Figura 6.12 - Absorvedor de vibração de uma máquina de eixo horizontal Maytag ........................................................ 108

Figura 6.13 - Deslocamento lateral do gabinete .......................................108

Figura 7.1 - Resultados comparativos - Teórico versus Experimental ..........109 


\section{LISTA DE TABELAS}

Tabela 5.1 Verificação do Modelo ADAMS

Tabela 5.2 - Raio de deslocamento superior e inferior da lavadora.

Dados experimentais

Tabela 5.3 - Raio de deslocamento superior e inferior da lavadora.

Dados teóricos

Tabela 5.4 Resultados comparativos - Teórico versus Experimental 


\section{LISTA DE ABREVIATURAS E SIGLAS}

ABNT - Associação Brasileira de normas Técnicas

ADAMS - Automatic Dynamic Analysis of Mechanical Systems

AV - Absorvedor de Vibração

CAD - Computer Aided Design

CAE - Computer Aided Engineering

CG - Centro de Gravidade

DAE - Differential Algebraic Equation

GDL - Grau De Liberdade

MBS - Multibody System

NTFN - Non-Translating Fixed Noded Design

TFN - Translating Free Noded Design

TD - Tendência de deslocamento

FEA - Finite Element Analysis

EF - Elementos Finitos

STL - Estereolitografia 


\title{
RESUMO
}

\author{
IORIATTI, A. (2007). ESTUDO DA DINÂMICA DE LAVADORA DE EIXO \\ VERTICAL UTILIZANDO SISTEMAS MULTICORPOS \\ Dissertação (Mestrado) - Escola de Engenharia de São Carlos, \\ Universidade de São Paulo.
}

Recentemente, uma mudança de paradigma vem impactando toda a engenharia e manufatura na forma de se planejar, projetar, testar e construir produtos. A forma mais tradicional de desenvolvimento, que se caracterizava pelo processo seriado de múltiplos ciclos de design-construção-teste, vem sendo substituída gradativamente por processos de desenvolvimento guiados por simulação computacional. Decorrentes disto, os primeiros protótipos físicos são freqüentemente capazes de atingir os objetivos quando testados. Esta mudança, chamada também de projeto baseado em simulação, permite reduzir drasticamente o tempo de desenvolvimento de produtos e trazer a inovação para o mercado. Este trabalho apresenta uma forma computacional, via técnica de multicorpos, para se analisar a dinâmica de uma lavadora de eixo vertical. É proposto um protótipo virtual no software ADAMS, para estudo dinâmico de uma lavadora durante o processo crítico de centrifugação. $O$ modelo virtual é posteriormente confrontado com dados experimentais, para sua validação. Uma extensa pesquisa bibliográfica foi realizada, com a intenção de capturar as técnicas mais usuais de modelamento e estudo dinâmico em lavadoras, bem como de compreender melhor o papel de seus componentes durante o processo crítico de centrifugação.

Palavras-Chaves: Dinâmica de corpos rotativos, Modelamento de sistemas multicorpos, Lavadoras de Roupa, Balanceadores rotativos. 


\section{ABSTRACT}

IORIATTI, A. (2007). Dynamic Study of a top loader washing machine using Multibody System. São Carlos. 10p. Dissertação (Mestrado) - Escola de Engenharia de São Carlos, Universidade de São Paulo.

Recently a paradigm shift has impacted the engineering and manufacturing in the way of planning, designing, testing and building products. The most traditional way of product development, characterized by multiple cycles of design-build-test, has been substituted by a process based on computational simulation, where the first physical prototypes are capable of delivering the desired performance. This new way of developing products is called Simulation Based Design and allows organizations to reduce drastically the product lead time and bring innovation to the market. This work presents a computational way to analyze the dynamic behavior of a top load washing machine using Multibody System (MBS). It's proposed a virtual prototype developed in the ADAMS software, for dynamic study of a commercial washing machine during spin cycle. The virtual model is compared to experimental data for validation. An extensive research in the literature has been done in order to find the most usual ways of modeling and analyzing washing machine dynamics during spin.

Keywords: Dynamics of rotational machinery, Multibody system dynamics, washing machines, dynamic balancers. 


\section{Introdução}

\subsection{História das lavadoras}

A história das lavadoras de roupa automáticas é bastante recente. Os métodos anteriores de lavagem permaneceram essencialmente os mesmos por milhares de anos.

No século XIX, o processo de lavagem entrou inevitavelmente nos estágios de desenvolvimento econômico, cujo processo já tinha ocorrido com os produtores de sapatos e roupas durante a revolução industrial.

O processo de lavagem deixou de ser um trabalho artesanal para ser uma operação industrial, criando-se então lavanderias comerciais. Entretanto, os donos de lavanderias rapidamente encontraram concorrência nos fabricantes de lavadoras domésticas. Por ironia, as inovações criadas pelas lavanderias comerciais, visando aumento de produtividade e performance, inspiraram e possibilitaram o nascimento da indústria de lavadoras domésticas.

As primeiras máquinas imitavam o movimento das mãos humanas. Uma das primeiras tinha duas superfícies curvas com ranhuras, feito uma chapa de lavagem. As roupas eram alimentadas uma a uma na máquina, o que de certa forma desagradava os donos de lavanderias comerciais, devido à baixa eficiência.

Isto levou ao desenvolvimento de um sistema moderno de lavagem, no qual roupas submergiam em líquido detergente e eram agitadas em solução. Os primeiros sistemas deixavam a roupa de molho, que a seguir passavam por um processo de torção para extração de água. A primeira lavadora de roupas de forma semelhante à descrita acima foi criada por Schaefer em 1766 (TURKAY 1992,1993; VAN DEAR BRECKEL, 1987). Esta máquina era operada manualmente, movendo-se mecanicamente a solução constituída de roupa, água e detergente.

A ação mecânica esfregava o material a ser lavado, permitindo assim a limpeza do mesmo. Este processo foi empregado até a virada do século, 
quando a primeira lavadora de eixo horizontal ("front loader") com cesto rotativo e comandado por um motor elétrico apareceu no mercado (TURKAY, 1987).

A invenção da eletricidade foi sem dúvida a maior contribuinte para o desenvolvimento de lavadoras de roupa automáticas. Principalmente após a 2a Guerra, com a introdução das lavadoras automáticas, a indústria de eletrodomésticos ganhou impulso e estabeleceu-se de forma definitiva, tornando assim parte de nossas vidas. (CONRAD, 1994).

Hoje se encontram basicamente dois tipos de lavadoras de roupa no mercado: lavadora top loader ou de eixo vertical e front loader ou de eixo horizontal. As primeiras são mais freqüentes na América, bem como em países asiáticos. Já as segundas são mais populares no mercado europeu. A figura ilustra uma lavadora de eixo vertical e suas partes principais:

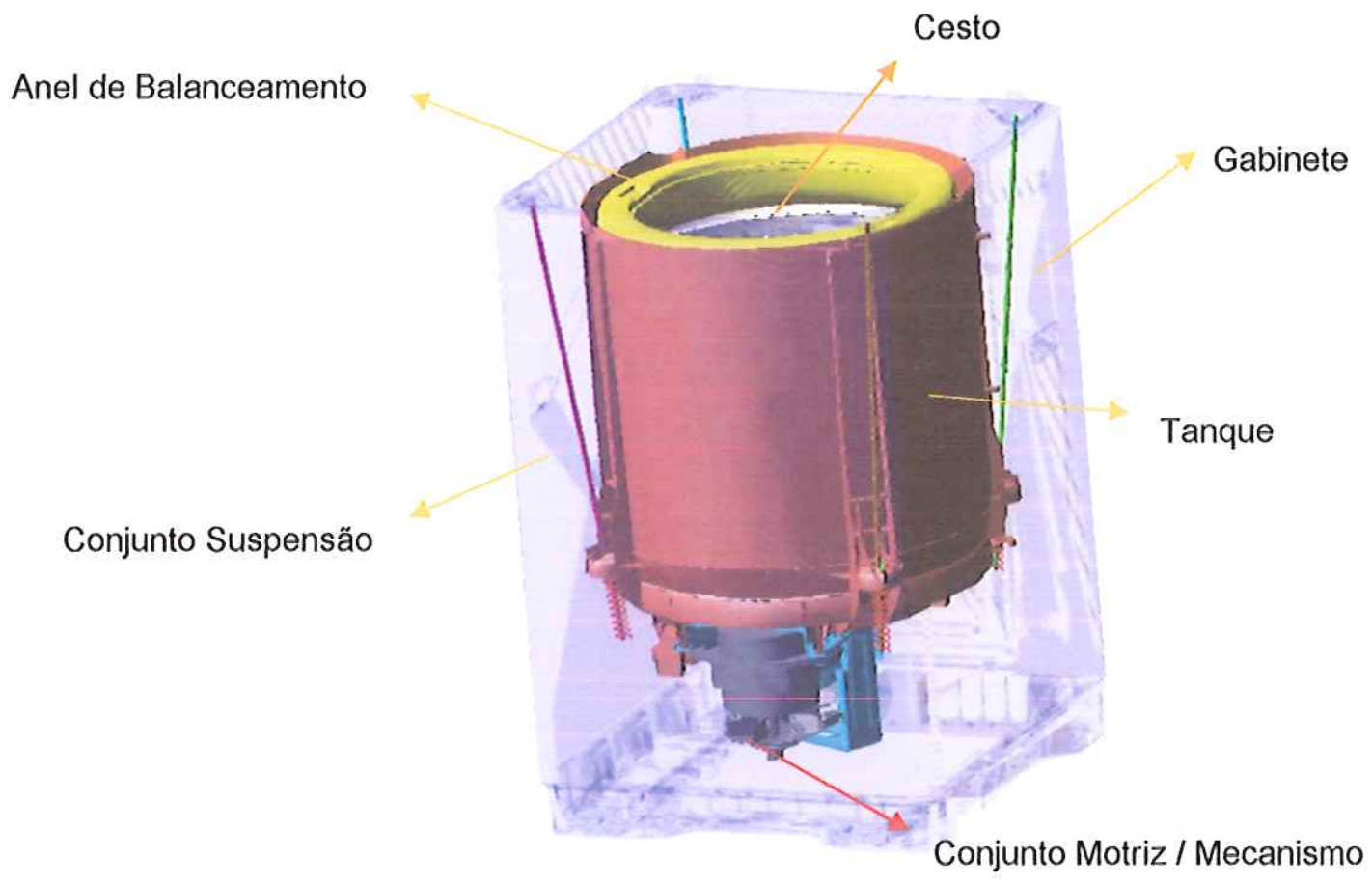

Figura 1.1 - Máquina de eixo vertical

A lavadora apresentada na Figura 1.1 é uma típica lavadora doméstica de eixo vertical muito popular no mercado brasileiro atualmente, cujos conjuntos e funções são descritas a seguir:

- Unidade de lavagem ou Conjunto Suspenso: composta por anel de balanceamento (responsável por balancear dinamicamente o cesto rotativo durante centrifugação, na presença de uma carga desbalanceada), pelo 
cesto (responsável por suportar a roupa durante a lavagem e a centrifugação), tanque (responsável por conter a solução de água e sabão ) e conjunto mecanismo (responsável pelo movimento de agitação na lavagem e centrifugação das roupas).

- Conjunto suspensão: responsável por sustentar a unidade de lavagem ou conjunto suspenso, fazendo a conexão com o gabinete, bem como amortecer e absorver os movimentos do conjunto suspenso.

- Gabinete: cuja função é dar suporte, proteção, bem como isolar todo o conjunto.

A Figura 1.2 ilustra uma típica lavadora de eixo horizontal ou "front loader".

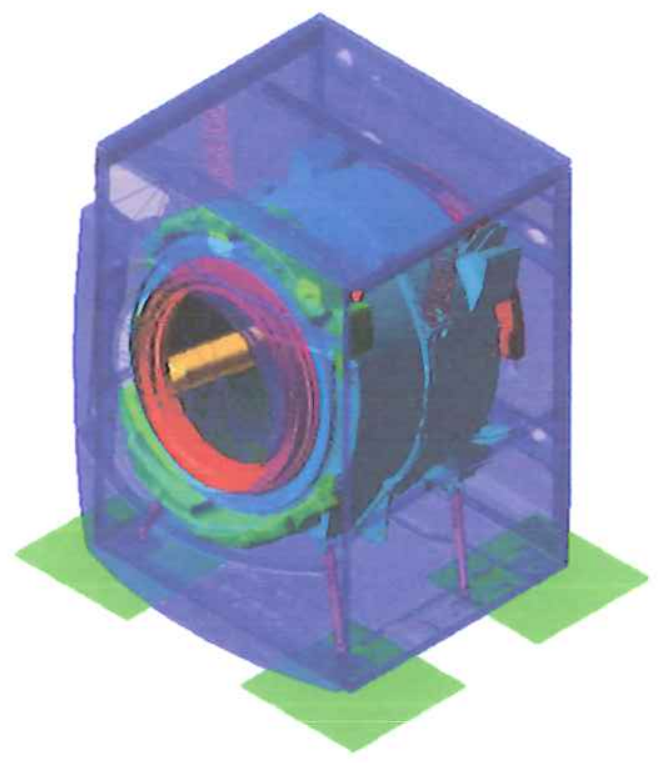

Figura 1.2 - Máquina de eixo horizontal

As principais funções de uma lavadora típica são lavar e secar a carga de roupa, geralmente por um processo de extração de água denominado também centrifugação. O processo de lavagem é realizado através do lento movimento alternado do cesto ao longo do eixo horizontal (no caso de lavadoras de eixo horizontal) ou através das oscilações do agitador (ou ainda impeler) ao longo do eixo vertical, contido dentro do cesto (lavadoras de eixo vertical). (TURKAY, 1993). 
Os grandes desafios de projeto de uma lavadora são comuns a todos os tipos, causados basicamente pela força centrífuga originada pela carga desbalanceada em rotação. Durante o ciclo de drenagem (centrifugação), há uma tendência da roupa acumular-se de um lado do cesto e conseqüentemente causar desbalanceamento durante rotação (BAGAPALLI, 1987; TURKAY, 1992). No projeto de uma lavadora, deve-se garantir que forças de desbalanceamento não sejam excessivamente transmitidas aos pés através de forças horizontais, de forma a fazerem toda a máquina se deslocar relativamente ao piso (walking phenomenon). Deve-se ainda limitar a mobilidade das partes internas, de forma que as partes não se choquem contra o gabinete (striking). Finalmente, é necessário ainda evitar que os pés percam contato com o solo (tipping). Baixos níveis de ruído e vibração são ainda requisitos claros de projeto de uma lavadora.

Para atender tais necessidades, necessariamente requer-se o uso de componentes balanceadores e minimizadores de vibração, como o uso de anéis de balanceamento, contra-peso, massas inerciais, bem como suspensões eficientes. Pretende-se, neste trabalho, descrever e estudar alguns desses componentes e seus efeitos na dinâmica da máquina.

A natureza competitiva das empresas e a demanda constante por produtos de alta qualidade, custos reduzidos e principalmente inovadores vem direcionando as empresas de ponta a investir pesado no desenvolvimento de produtos e em ferramentas que reduzam o tempo de desenvolvimento. Dentre estas ferramentas, destacam-se as ferramentas CAD (Computer Aided Design) e CAE (Computer Aided Engineering), bem como técnicas de experimentação e análise de dados. A Whirlpool SA Eletrodomésticos, na vanguarda desta tecnologia, utiliza extensivamente as técnicas de Elementos Finitos (EF) e Dinâmica de Multicorpos, bem como ferramentas Seis Sigma para planejamento e execução de experimentos, a fim de manter a alta qualidade e competitividade de seus produtos e trazendo sempre inovação ao mercado. As ferramentas permitem otimizações de design para redução de massa, o uso de materiais mais baratos e alternativos (como o extenso uso de materiais plásticos, por exemplo), a prevenção de falhas e a diminuição de gastos com protótipos reais, bem como estudos de conceito de forma rápida e precisa via 
simulação. Vale ressaltar ainda que a redução de peso em lavadoras é de crucial importância, não só em termos ambientais, mas também financeiros. Isto naturalmente tem um efeito direto na dinâmica da lavadora. O desafio de hoje está em se fazer componentes com alta eficiência e custos reduzidos, agregando-se com isso boa dose de engenharia.

\subsection{Motivação}

Recentemente, o processo de desenvolvimento de produtos vem sofrendo mudanças radicais. Sua forma mais tradicional, baseada na cultura da tentativa e erro e composta por inúmeros ciclos de design-construção-teste, vem sendo substituída gradativamente por uma forma de desenvolvimento muito mais enxuta, onde muitas vezes o primeiro protótipo físico já é capaz de atingir os objetivos de projeto, sem necessidade de retrabalho. Tudo isso se deve ao uso extensivo de ferramentas CAD/CAE no processo de desenvolvimento de produtos, que permite a criação de protótipos virtuais para estudo e otimização, reduzindo-se falhas, aumentando-se a performance e qualidade e principalmente reduzindo-se drasticamente 0 tempo de desenvolvimento de produtos.

O mercado de lavadoras domésticas no Brasil hoje não é diferente. A competição é extremamente acirrada, obrigando fabricantes a aumentar a qualidade, reduzir seus custos e principalmente inovarem freqüentemente. Os custos envolvidos referem-se aos recursos empregados durante o desenvolvimento de produto bem como o uso de componentes otimizados em massa e ainda materiais alternativos, mais baratos e leves, como o plástico. A redução de peso, como será vista posteriormente, tem implicação direta na performance dinâmica da lavadora. Aliado a isso, os consumidores exigem altos padrões de qualidade no produto, como durabilidade e performance em geral, incluindo-se neste quesito baixos níveis de ruído. Neste cenário, ferramentas computacionais que permitam estender o conhecimento sobre o produto, otimizar os componentes, prever e corrigir falhas precocemente e até mesmo reduzir ou eliminar a necessidade de protótipos reais são cruciais para que se prospere no mercado de lavadoras. Soma-se a isso a grande vantagem 
de se reduzir o tempo de desenvolvimento de produtos e trazer a inovação para o mercado.

\subsection{Objetivo}

No presente trabalho, procurou-se, através de uma boa pesquisa bibliográfica, dar uma visão geral sobre o comportamento dinâmico de uma lavadora, bem como a interação de seus componentes durante a fase de centrifugação das roupas.

Avaliaram-se os modelos analíticos apresentados na literatura, bem como as técnicas mais recentes de modelamento de multicorpos (MBS) aplicados em lavadoras.

Através da construção de um protótipo virtual representativo de uma máquina comercial BRASTEMP, foi possível estudar dinamicamente o comportamento da lavadora durante as fases de centrifugação, etapa crítica do ciclo de lavagem. Como próprio relatado por W. Schiehlen (1997), as técnicas de modelamento dinâmico via multicorpos, suportadas pelo desenvolvimento de computadores cada vez mais rápidos, estão transformando o que era um método puro de análise para uma ferramenta de sintetização para o engenheiro.

Foram ainda revisados alguns requisitos básicos de projeto de lavadoras, abordando técnicas comuns para evitar problemas de desbalanceamento, ruído e problemas de deslocamento (walking).

Buscou-se validar alguns dos resultados dos modelos teóricos propostos através do ensaio experimental de uma lavadora de eixo vertical, bem como otimizar alguns parâmetros de forma a melhorar performance dinâmica da lavadora em estudo.

\subsection{Estrutura da dissertação}

O presente documento, apresentado à Escola de Engenharia de São 
Carlos da Universidade de São Paulo como parte dos requisitos para a obtenção do título de Mestre em Engenharia Mecânica, está dividido nos capítulos abaixo:

- Capítulo 1: Introdução. Resume a história das lavadoras de roupa, descreve a motivação do trabalho e objetivos e por fim a estrutura da dissertação.

- Capítulo 2: Revisão bibliográfica. Mostra tópicos importantes relacionados ao desempenho dinâmico de lavadoras durante o processo crítico de centrifugação, técnicas de modelamento de lavadoras utilizadas e ainda a utilização de elementos balanceadores e desempenho de suspensões.

- Capítulo 3: Balanceadores dinâmicos.Este capítulo descreve especificamente o funcionamento de balanceadores dinâmicos, amplamente utilizados em lavadoras de eixo vertical e componentechave no desempenho dinâmico de lavadoras.

- Capítulo 4: Teoria de Multicorpos. Descreve de forma sucinta as origens da dinâmica de Multicorpos e a metodologia de equacionamento utilizada pelo software ADAMS.

- Capítulo 5: Construção de modelo Multicorpos e validação. Apresenta o modelo Multicorpos proposto bem como sua validação com dados experimentais

- Capítulo 6: Comportamento teórico dinâmico via Multicorpos. Utiliza-se o modelo proposto para estudo do comportamento dinâmico da lavadora.

- Capítulo 7: Resultados e conclusões : Resultados alcançados com o trabalho, proposição de idéias e melhorias para trabalhos futuros. 


\section{Revisão Bibliográfica}

\subsection{Modelamento dinâmico de lavadoras}

O número de trabalhos publicados que contemplam análise dinâmica teórica e experimental de lavadoras de roupa é restrito. Isto se deve em parte à política conservadora de fabricantes de lavadoras em querer divulgar seus resultados de pesquisa.

As referências abaixo contemplam alguns dos principais trabalhos publicados referentes ao tema. Em geral, os trabalhos estão focados no desempenho de diferentes conceitos de suspensão para máquinas de eixo vertical e horizontal, no modelamento de sistemas dinâmicos balanceadores para máquinas rotativas ou ainda no desempenho dinâmico da lavadora contra o fenômeno de deslocamento (walking) e ruído.

Com o intuito de atingir melhor desempenho na extração de água, os fabricantes de lavadoras vêm aumentando as rotações das máquinas gradativamente, a medida em que se desenvolvem conceitos de suspensão e de balanceamento mais eficientes. Sistemas de balanceamento são capazes de reduzir as forças centrífugas geradas pela carga de roupa desbalanceada, melhorando a performance dinâmica através da redução de ruído e vibração. Os métodos de balanceamento podem ser classificados em métodos ativos ou passivos de vibração.

Em 1916, Leblanc propôs um simples sistema dinâmico de balanceamento automático (THEARLE, 1950a). O sistema era composto por um anel concêntrico parcialmente cheio com líquido. $O$ anel, após a primeira freqüência crítica, tende a balancear a força desbalanceadora, através da migração do líquido no anel na direção oposta `a carga desbalanceada. Porém, o anel de Leblanc consegue cancelar apenas parte da excentricidade gerada pela massa desbalanceada. Isto é devido à distribuição do líquido existente dentro do anel, que se vale da excentricidade para se posicionar. O equacionamento do anel de Leblanc será estudado posteriormente no Capítulo 3.

Já os sistemas mecânicos conseguem eliminar todo desbalanceamento, 
tornando-os bastantes úteis para aplicação em rotores com altas velocidades. Basicamente, existem três tipos de sistemas de balanceamento mecânicos: o de esferas, o de pêndulo e o anel de balanceamento. Estes sistemas possuem uma vantagem básica sobre o anel de Leblanc, eles conseguem balancear completamente um sistema rotativo.

Thearle $(1950 a, b, c)$ escreveu uma série de três trabalhos relatando os princípios de funcionamento destes sistemas. No primeiro trabalho, Thearle (1950a) descreve o princípio de funcionamento de sistemas dinâmicos de balanceamento, em especial o anel de Leblanc. No segundo trabalho da série, Thearle (1950b) descreve o funcionamento de três sistemas mecânicos de balanceamento, o de esferas, o de pêndulo e o anel de balanceamento, e também os confronta com um sistema de balanceamento ideal. No terceiro e último trabalho da série, Thearle (1950c) propõe um sistema de balanceamento que é $100 \%$ efetivo no balanceamento.

O sistema de balanceamento de esferas é o sistema mecânico com maior aplicação em sistemas rotativos. Este sistema consiste de uma pista na qual rolam esferas. As esferas se posicionam de forma a balancearem o sistema, e conseqüentemente, são $100 \%$ efetivas até que atinjam o ponto de saturação.

Em 1981 Hisao Tatsumi aborda o problema de vibração e ruído em lavadoras domésticas de eixo horizontal (TATSUMI, 1981). Neste trabalho, o autor analisa os modos de vibrar de uma lavadora e desenvolve ainda uma nova teoria que combina balanceadores dinâmicos de líquido e esferas. Com isso, obteve-se uma redução de níveis de ruído de $65 \mathrm{~dB}$ para $55 \mathrm{~dB}$ durante o processo de extração de água na centrifugação. Foi proposto um modelo com seis graus de liberdade, cujo movimento é expresso por equações diferenciais de segunda ordem, obtidas por equações de Lagrange. Os resultados práticos comprovam a validade do modelo analítico. O autor aborda ainda a deflexão do cesto plástico e anel balanceador da lavadora como contribuinte para a perda de eficiência de balanceamento.

(TADEUSZ, 1985) e (KRAVCHENKO,1986) abordam o uso de balanceadores de esferas em eixos de alta rotação. A vantagem do uso de balanceadores de esferas, pêndulos ou roletes em comparação aos 
balanceadores com líquidos mais uma vez é reforçada.

Bagapalli (1987) aborda o modelamento de um sistemas de suspensão em lavadoras de eixo vertical. Conforme descrito no trabalho, a suspensão tem a finalidade de evitar que forças excessivas sejam transmitidas aos pés da lavadora, que poderiam fazer a máquina se deslocar. A suspensão tem ainda a função de evitar que o tanque se choque contra o gabinete. $O$ modelo matemático proposto consiste em descrever o sistema através de duas coordenadas de translação no plano horizontal e ainda rotação em relação a um nó.

No trabalho, Bagapalli analisa dois tipos de fixação:

- Design de suporte com nó fixo ou Non-translating Fixed Node Design (NTFN)

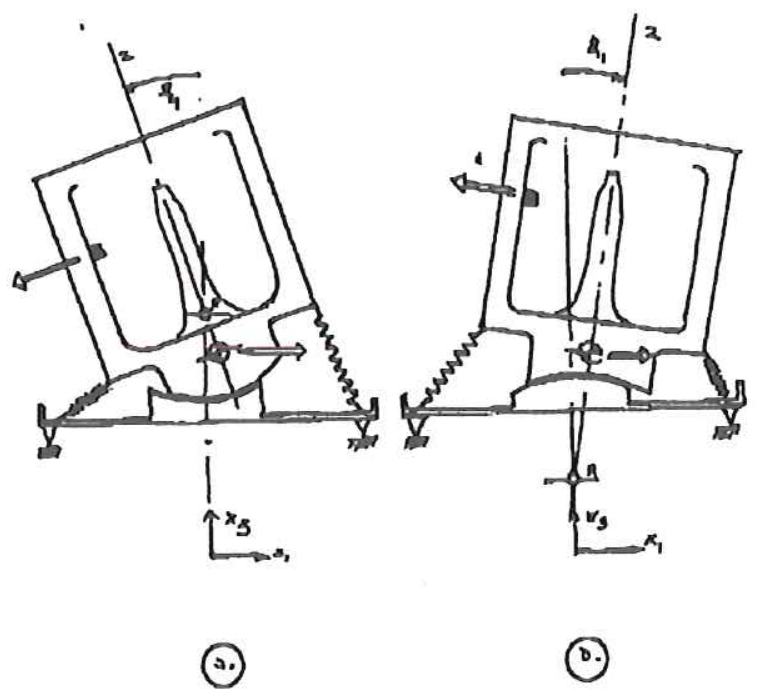

Figura 2.1 - Design de suporte com nó fixo (Non-translating Fixed node Design - NTFN) - Fonte:

(BAGAPALLI, 1987)

Neste design, a lavadora é forçada a rotacionar sobre um nó fixo, e nenhuma mobilidade de translação é permitida. Tal modelo transmite forças para o gabinete, podendo fazer com que a máquina se desloque. Este sistema é hiperestático, havendo apenas graus de liberdade de rotação. É obtido através de um suporte em forma de prato ou ainda em forma de redoma esférica. O sistema consiste ainda de molas que auxiliam em restringir as oscilações transientes. Há ainda amortecimento por atrito de Coulomb entre as 
duas superfícies esféricas de contato.

- Design de suporte com nó livre ou The Translating Free Noded Design (TFN)

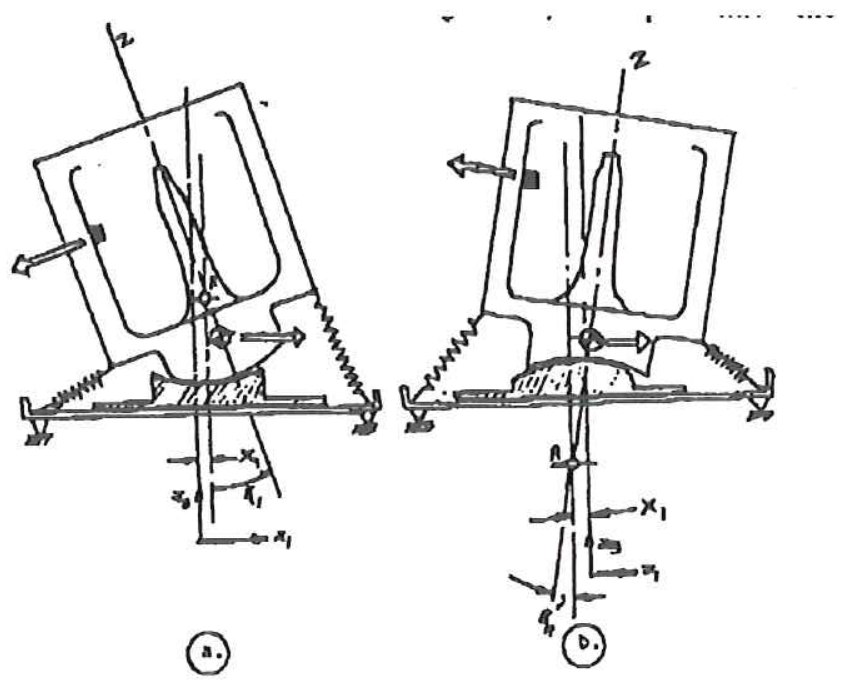

Figura 2.2 - Design de suporte com nó livre ("Translating Free Noded Design - TFN") - Fonte:

(BAGAPALLI, 1987)

$$
\mathrm{TD}=\mu^{*} \sum \mathrm{F}_{\text {vertical }}-\sum \mathrm{F}_{\text {horizontal }}
$$

Neste design, o sistema tem dois graus de liberdade de translação, e dois graus de liberdade de rotação. Este suporte permite que a máquina rotacione em relação a um nó fixo $A$, e ainda que translade no plano. Há ainda a presença de amortecimento de Coulomb entre as superfícies de contato, isto é, entre as superfícies esféricas e planas. Tal sistema quase não apresenta tendência para andar, uma vez que forças horizontais transmitidas ao gabinete serão controladas por mola e ainda limitadas pelo atrito entre as superfícies planas. O autor define ainda uma margem de segurança contra o fenômeno do "walking" ou tendência de deslocamento (TD), que consiste basicamente em monitorar as forças horizontais nos pés e subtrair da máxima força horizontal devido ao atrito com o solo. Matematicamente:

O modelo analítico foi comparado com o protótipo experimental, analisando-se o deslocamento do tanque e os resultados concordaram satisfatoriamente. 
Mostrou-se ainda que o design de nó fixo tem uma tendência maior para se deslocar. No design de nó livre esta tendência é grandemente minimizada.

(TURKAY et al,1992) descreve um modelo de simulação de uma lavadora de eixo horizontal, consistindo de uma suspensão com 3 molas helicoidais que suspendem o tanque e 2 amortecedores de atrito. O modelo foi a seguir validado através de experimentos. A aceleração foi medida experimentalmente e a seguir integrada duplamente para determinar o deslocamento do tanque.

O deslocamento do tanque foi medido durante o estado transiente bem como no estado de regime durante centrifugação, obtendo-se $11 \%$ e $5 \%$ de erro respectivamente.

Experimentos práticos através do uso de acelerômetros e martelo de impacto permitiram ainda conhecer as freqüências críticas de corpo rígido. Posteriormente, confirmou-se que as máximas amplitudes de vibração ocorrem com rotações muito próximas às freqüências críticas obtidas experimentalmente.

Em 1993, Türkay et al (TÜRKAY 1993a) apresenta os resultados de uma nova configuração de suspensão, usando-se todavia o mesmo algoritmo apresentado no trabalho anterior em (TÜRKAY et al,1992). Os resultados apresentam erros máximos de $10 \%$ e $14 \%$, para deslocamentos do tanque em transiente e regime, respectivamente, durante ciclo de centrifugação. Os resultados comprovam conseqüentemente a validade do modelo e o código de programa de simulação.

Em vista dos resultados obtidos nos trabalhos anteriores, Türkay propõe um modelo parametrizado para estudo e otimização de lavadoras (TURKAY et al, 1993b).

No design de qualquer lavadora, os objetivos são basicamente:

i. Ruído através da vibração das partes rotativas deve ser minimizado. Esta condição pode ser atingida minimizando-se as amplitudes pico a pico do estado de regime.

ii. A batida do tanque contra as partes não móveis deve ser evitada durante a ressonância. 
iii. A tendência de deslocamento (TD) deve também ser evitada. Isto acontece quando a força resultante horizontal transmitida ao pé do gabinete é maior que a força de atrito resultante na mesma direção, como já descrito na equação (2.1.1).

A máquina irá andar, portanto, se TD for maior que zero.

De acordo com os autores, o método de otimização para um problema de design é muito dependente do tipo de problema e da formulação de otimização. Os resultados deste estudo podem contribuir para a formulação e seleção de um método apropriado de otimização para projeto de uma suspensão de lavadoras.

Em geral, a escolha de uma função-objetivo num problema de otimização é uma decisão importante numa fase de formulação. Türkay et al propõe a minimização de uma função multi-objetiva, que aborda tanto a tendência de deslocamento quanto a minimização das órbitas do cesto no transiente e no regime.

Então, a função-objetivo minimizaria a soma da máxima amplitude vertical ou horizontal transiente, ao mesmo tempo em que minimizaria a função negativa da força dos pés, obtendo-se com isso robustez à tendência da máquina de andar.

Este trabalho permitiu de forma conclusiva realizar um trabalho de otimização da lavadora. Os resultados da simulação mostraram ainda que os deslocamentos no estado transiente são pouco sensíveis ao coeficiente de rigidez da mola k. O estudo mostra ainda, como já comentado por (BAGAPALLI, 1987), que enquanto as amplitudes de vibração estão diminuindo, a tendência para andar, ao contrário, está aumentando. Com isso, conclui-se que o sistema de suspensão não deve ser tão rígido de forma a evitar o fenômeno de deslocamento ou "walking", mas também não pode ser tão flexível a ponto de provocar grandes amplitudes de vibração.

Em (TÜRKAY; SÜMER e TAGCU, 1992), o modelamento matemático permitiu ganhar não só informações sobre o comportamento dinâmico da lavadora em estágios recentes de desenvolvimento, mas ainda o de inferir sobre a robustez do design na presença de tolerância de fabricação. De acordo 
com os autores, técnicas de modelamento computacional são ferramentas fundamentais disponíveis hoje para se atingir um entendimento completo do comportamento mecânico, elétrico, eletrônico ou híbrido. O desenvolvimento de um modelo de simulação válido, entretanto não é uma tarefa fácil, podendo levar um longo tempo para se obter resultados satisfatórios. Com isso, muitos fabricantes ainda optam por desenvolver protótipos na tentativa e erro.

Menores amplitudes de vibração durante o regime dinâmico podem ser atingidas através do ajuste de rigidez e das propriedades de amortecimento do sistema de suspensão, de acordo com a massa e propriedades estruturais da máquina. Ainda, o projetista deve assegurar que o tanque não toque o gabinete, enquanto a velocidade de rotação passa através da ressonância.

A máquina pode ainda deslocar-se contra o piso se a combinação de forças de desbalanceamento verticais e horizontais forem transmitidas ao gabinete, dependendo ainda do coeficiente de atrito entre solo e máquina. Com isso, a suspensão deve ser flexível suficiente para limitar a transmissão das forças de desbalanceamento ao gabinete, e ao mesmo tempo ser rígida o suficiente para evitar que o tanque bata contra outras partes não móveis.

Estes objetivos, combinados com a rigidez e amortecimento necessários para minimizar oscilações durante o regime dinâmico, tornam-se conflitantes para o problema de otimização.

Neste trabalho, procurou-se entender como as tolerâncias dimensionais dos componentes influenciam nas respostas listadas acima, de forma a propor tolerâncias maiores, que garantissem conseqüentemente uma redução de custo para componentes não críticos. Criou-se ainda uma tabela, capaz de relacionar o comportamento fora do esperado da máquina em teste na linha de produção com o componente fora do especificado.

Zuoxin (1991) descreve sobre o conceito do anel de Leblanc aplicado a lavadoras de roupas, também chamado de anel hidrocompensador, e propõe uma solução para um problema de instabilidade de uma lavadora durante a centrifugação através da formulação lagrangeana. Seu modelo de lavadora de eixo vertical utiliza seis graus de liberdade, onde o autor faz importantes considerações sobre quais parâmetros do anel de balanceamento fazem mais 
efeito na redução de vibração, bem como parâmetros inerentes ao design do tanque, capaz de reduzir o centro de gravidade do conjunto e conseqüentemente reduzir a vibração e ruído da lavadora.

Conrad (1994) apresenta uma revisão dos sistemas dinâmicos de balanceamento, dando ênfase na aplicação dos mesmos em lavadoras de roupas. O autor discute os critérios para utilização dos sistemas dinâmicos de balanceamento bem como as suas limitações. Finalmente, um novo tipo de sistema dinâmico de balanceamento é apresentado, o sistema de balanceamento elástico. As características fundamentais dos sistemas de suspensão de lavadoras de eixo vertical e horizontal são estudadas. O autor apresenta várias configurações de suspensão. Alguns dos modelos teóricos são confrontados com dados experimentais, apresentando boa correlação.

O autor ainda apresenta a teoria envolvida no fenômeno do deslocamento em lavadoras de eixo horizontal. O autor relaciona a velocidade máxima de rotação em função das características do sistema de suspensão.

Conrad e Soedel (1995) discutem o problema de deslocamento lateral utilizando modelos simples sem sistema de suspensão.

Conrad e Soedel (1998) discutem o procedimento genérico de controle de sistemas rotativos desbalanceados através da utilização de anéis de balanceamento.

Calejero (1998) desenvolve um programa com rotinas em FORTRAN-77 para descrever o comportamento dinâmico de lavadoras de eixo horizontal durante transiente e regime. O modelo apresenta três graus de liberdade e utiliza atrito de Coulomb em sua formulação. Este modelo é validado através de dados experimentais, permitindo a empresa FAGOR utilizá-lo para estudos dinâmicos e cinemáticos, antes mesmo de construir modelos reais de lavadoras.

Dong Won Kim et al (1999) aborda o estudo dinâmico e design de balanceadores de esfera na aplicação em aparelhos DVDs. O trabalho é suportado pelo software de modelamento multicorpos DADS, para se modelar o sistema de rotação e leitura. O autor consegue boa correlação com dados experimentais, bem como demonstra a eficiência do sistema balanceador de 
esferas no controle de vibração, possibilitando atingir altas velocidades de rotação.

Evangelos Papadopoulos (2001) aborda a dinâmica de uma lavadora de eixo horizontal. É abordado neste trabalho o fenômeno do deslocamento ou "walking", usando-se para isso um critério de margem de escorregamento semelhante ao proposto por Türkay et al (1992). Para ganhar mais estabilidade durante centrifugação, o autor propõe dois métodos passivos com a finalidade de aumentar as forças de atrito com o solo. O primeiro é a criação de vácuo entre os pés da lavadora e o solo, através do design de pés que funcionam como ventosas.

O segundo método é o armazenamento de água oriunda do enxágüe em container, de forma a aumentar a força normal nos pés da máquina devido ao aumento de massa do sistema.

Neste trabalho, o autor propõe ainda o uso de um balanceador ativo, composto de massas que exercem uma força centrífuga contrária à causada pela carga desbalanceada. É abordado o sistema de balanceamento de uma e de duas massas considerando-se o caso bidimensional. Tais massas balanceadoras devem ser posicionadas através de motores de passo ou outro atuador controlável, medindo-se previamente o estado da máquina através de sensores de vibração e de ângulo das massas balanceadoras. Os resultados obtidos são satisfatórios, porém há de se ressaltar que os custos aumentam significativamente ao se utilizar um balanceador ativo.

Recentemente, Susuk (2001) apresenta um modelamento em multicorpos de uma lavadora de eixo vertical, usando-se para isso o software ADAMS. O autor propõe ainda o uso de oito esferas simulando o efeito do anel hidrodinâmico na lavadora. A flexibilidade do cesto é representada por "lumped mass" com rigidez equivalente simulada via elemento "bushing". O modelo, segundo descrito, apresenta boa correlação com os testes práticos, apresentando erros da ordem de $18 \%$ para deslocamentos do cesto, se comparado com medições realizadas com acelerômetros. O autor conclui que o método de modelamento do ADAMS obtido pode ser utilizado para estimar as características de vibração da lavadora de acordo com as mudanças de 
parâmetros de design.

Bae et al (2001) apresenta a formulação analítica de um balanceador hidráulico aplicado numa lavadora de eixo vertical. São feitos estudos na forma construtiva do anel de balanceamento bem como no design da suspensão, cesto e tanque, visando estudar seus efeitos na resposta dinâmica do sistema. O autor conclui que a vibração é reduzida com o aumento de massa do anel, redução da taxa volumétrica ou ainda aumento do raio interno do mesmo. Conclui-se que o efeito do anel-hidro pode ser maximizado quando a densidade do fluido no balanceador hidráulico for grande. Esta é a razão porque a água salgada é mais eficiente do que água pura ou óleo. 


\section{Balanceadores dinâmicos}

\subsection{Introdução}

Devido à competitividade por preços baixos, fabricantes de lavadoras são fortemente guiados a reduzir o volume de materiais de lavadoras, utilizando-se para isso materiais mais leves e baratos como plástico. O plástico tem uma grande vantagem econômica sobre o aço, além de resistir à corrosão.

A redução de massa compromete também a performance dinâmica da lavadora, que apresenta maior tendência em se deslocar (fenômeno de deslocamento ou walking). Além disso, levantamento do pé (tipping), colisões do tanque contra o gabinete e aumento de ruído seriam fenômenos comuns apresentados em lavadoras com peso reduzido.

Naturalmente, é preferível evitar a fixação da lavadora numa fundação pesada a fim de isolar a vibração proveniente da mesma. Além disso, não se pode esperar que o consumidor tenha $\mathrm{o}$ hábito de distribuir a carga perfeitamente uniforme, de forma a obter um perfeito balanceamento.

A solução mais simples seria projetar lavadoras com baixa velocidade de centrifugação. Tal condição seria inaceitável, uma vez que o mercado exige lavadoras cada vez mais eficientes em sua capacidade de extrair água, produzindo ciclos mais curtos de lavagem e reduzindo ou eliminando as etapas de secagem.

Hoje se observa uma vasta extensão de lavadoras no mercado que dispõem de um sistema de balanceamento dinâmico, capaz de reduzir a vibração da máquina durante a fase de centrifugação. Neste capítulo, pretende-se discorrer sobre os sistemas de balanceamento mais comuns usados em lavadoras, descrever algumas de suas equações básicas de movimento e por fim tendências futuras sobre componentes utilizados para reduzir vibração das máquinas durante a centrifugação. 


\subsection{Princípios gerais}

Para se entender o princípio de funcionamento dos balanceadores automáticos, deve-se entender primeiramente a dinâmica de rotores. Um problema clássico que auxiliará no entendimento de balanceadores consiste em um rotor rígido montado sobre um eixo flexível, como ilustrado na Figura 3.1.

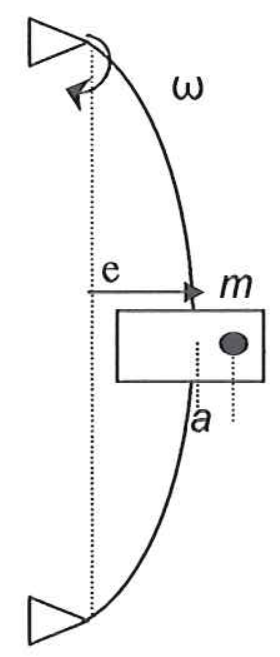

Figura 3.1 - Rotor rígido sobre eixo flexível

Consideremos um rotor de massa m e centrada a uma distância radial a do centro do eixo rotativo.

Fazendo o eixo girar sobre sua linha de centro, surge uma força centrífuga dada por $m \omega^{2} a$. Tal força ocasiona uma deflexão no eixo, que por sua vez reage oferecendo uma força que tende a alinhá-lo novamente. A força centrífuga resultante torna-se então $\mathrm{Fc}=\mathrm{m} \omega^{2} \mathrm{r}$, onde $\mathrm{r}$ é o raio com relação ao eixo de rotação. Adotando e como sendo a flecha gerada, pode-se escrever $r=a+e$.

A equação de restauração para um eixo de comprimento L será $k e$, onde $k$ é dada por 48El/L3 para uma viga em flexão. A equação para o sistema fica portanto: 


$$
m \omega^{2} R \cos \beta=\text { ke }
$$

Resolvendo a equação parae, tem-se:

$$
e=\frac{a\left(\frac{\omega}{\omega_{\mathrm{n}}}\right)^{2}}{1-\left(\frac{\omega}{\omega_{\mathrm{n}}}\right)^{2}}
$$

onde $\omega_{\mathrm{n}}=\sqrt{\frac{K}{m}}$.

Para $\omega \approx 0$, resulta em $e \approx 0$.

Para $\omega \approx \omega_{n}$, e tende a infinito.

Para $\omega>>\omega_{n}, \mathrm{e}=-a$, ou seja, o centro de gravidade coincide com o eixo de rotação.

Uma outra maneira de provar isto é substituindo o raio de giração $r$ na equação (3.2.2), obtendo:

$$
r=\frac{a}{1-\left(\frac{\omega}{\omega_{n}}\right)^{2}}
$$

Aplicando-se o limite para a equação (3.2.3), tem-se: 


$$
\lim _{\omega \rightarrow \infty} r=0
$$

Uma lavadora de roupas comporta-se de maneira semelhante à forma descrita acima de um rotor desbalanceado.

Como descrito ainda por Thearle (1950a), considera-se o sistema descrito pela Figura 3.2, representando um extrator centrífugo.

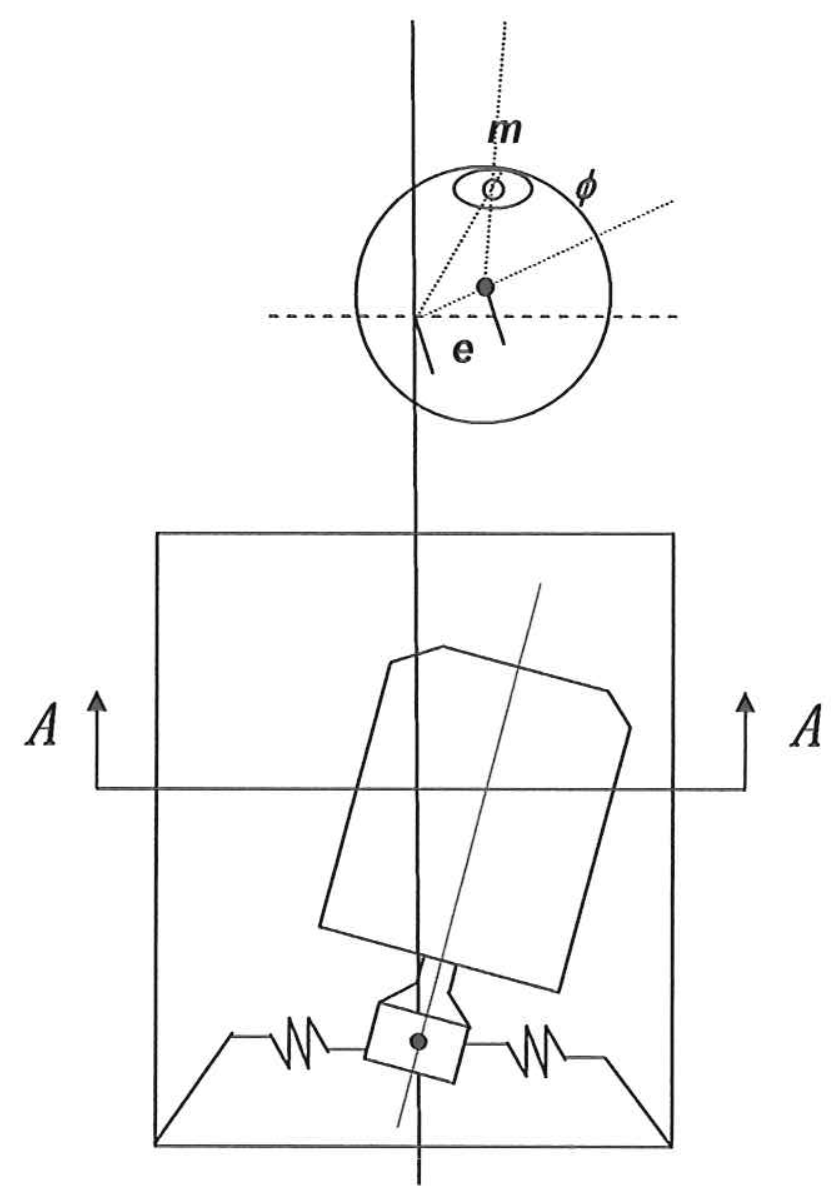

Figura 3.2 - Extrator centrifugo

Neste caso, o motor é montado na carcaça da máquina por meio de uma junta elástica. Há ainda um eixo que une o motor ao cesto, onde está localizada a carga desbalanceada. Considera-se a excentricidade como sendo o deslocamento radial do cesto, $\mathrm{m}$ a carga de roupa desbalanceada $\mathrm{e}$ finalmente a como a distância do centro do cesto à carga $\mathrm{m}$.

Neste sistema, estão presentes três vetores de força no diagrama de corpo livre do sistema. Tais forças são a força centrífuga da massa 
desbalanceada, as forças de mola do suporte e por último as forças de amortecimento. Assumiu-se neste caso um amortecimento viscoso e ainda, que tanto a força de mola quanto o amortecimento apresentam componentes de força equivalentes no plano de desbalanceamento. A força de mola age neste caso para restaurar o sistema radialmente na direção da excentricidade. Para uma excitação harmônica, as forças de amortecimento são ortogonais às forças elásticas.

O diagrama de forças da Figura 3.3 ilustra o que foi descrito acima:

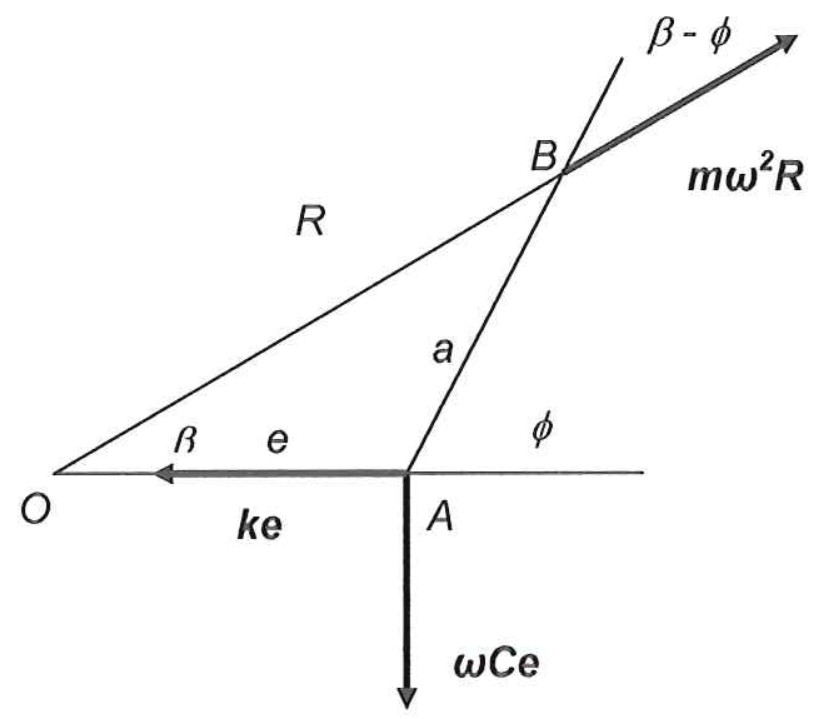

Figura 3.3 - Diagrama de forças de equilíbrio

Somando-se as forças na direção de $x$, resulta:

$$
m \omega^{2} R \cos \beta=k e
$$

Analogamente, tem-se em y: 


$$
\omega \mathrm{Ce}=\mathrm{m} \omega^{2} R \operatorname{sen} \beta
$$

Analisando o diagrama, obtém-se:

$$
\begin{gathered}
\omega \mathrm{Ce}=\mathrm{m} \omega^{2} a \operatorname{sen} \phi \\
\omega \mathrm{Ce}=\frac{\left(\frac{\omega}{\omega_{n}}\right)^{2}}{\sqrt{\left(1-\left(\frac{\omega}{\omega_{n}}\right)^{2}\right)^{2}+\left(2 \zeta\left(\frac{\omega}{\omega_{n}}\right)^{2}\right)^{2}}} \\
\tan \phi=\frac{R \operatorname{sen} \beta}{R \operatorname{sen} \beta-e}
\end{gathered}
$$

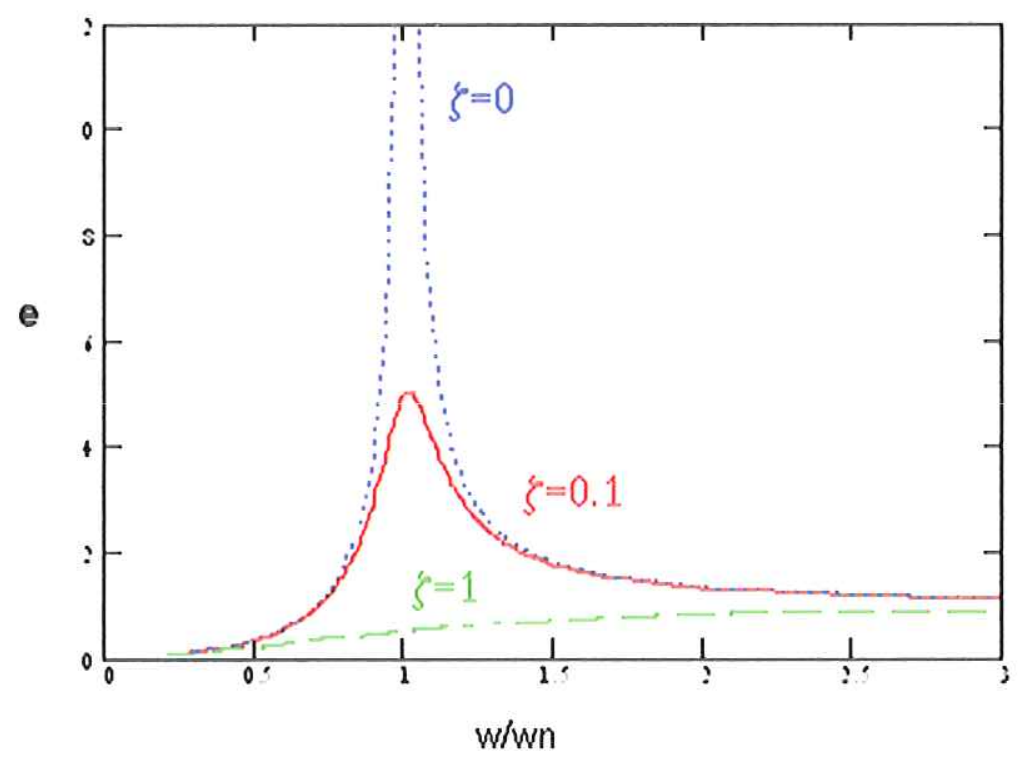

Figura 3.4 - Excentricidade versus rotação 


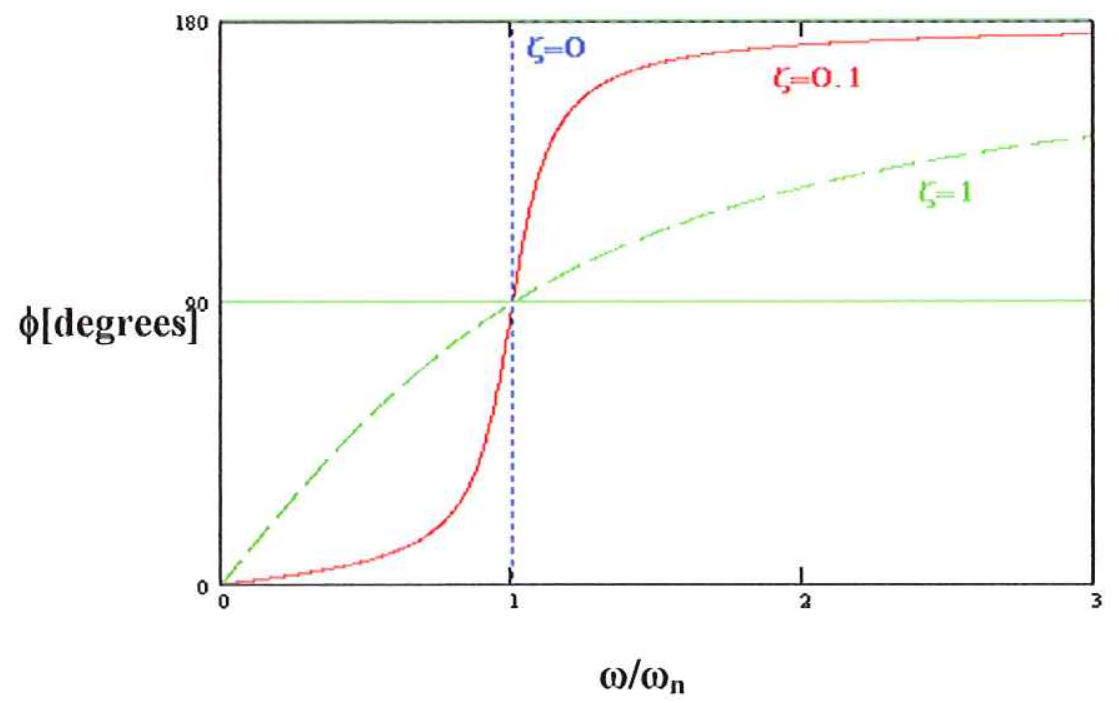

Figura 3.5 - Anglo de fase entre excentricidade e massa desbalanceada versus razão de rotação

As Figura 3.4 e Figura 3.5 mostram respectivamente a relação entre a excentricidade e a freqüência de rotação, bem como o ângulo de fase da carga desbalanceada e a freqüência de rotação.

O formato destas curvas, como notado, depende da quantidade de amortecimento $\zeta$. O ângulo de fase $\phi$, bem como a excentricidade e variam com a freqüência de rotação do motor.

O ângulo de fase $\phi$ é pequeno a baixas rotações e aumenta com a rotação. Ele atravessa o valor de 90 graus na rotação crítica e aproxima de 180 graus em altas rotações. A velocidade de aumento do ângulo de fase depende da quantidade de amortecimento, como observado. Para baixos coeficientes de amortecimento, esta mudança é muito abrupta na freqüência crítica.

Para velocidades de rotação abaixo da crítica, pode-se dizer que o rotor gira com o peso do lado de fora (heavy side out), enquanto que, acima da rotação crítica, a porção leve fica do lado de fora (light side out).

De acordo com a descrição do fenômeno acima, pode-se concluir que um balanceador automático, para ser efetivo em todas as freqüências de rotação, deve reagir de forma diferente em rotações abaixo e acima da crítica. 


\subsubsection{Um Balanceador Ideal}

Como descrito por Theale (1950a), um balanceador automático deve ter as seguintes características desejáveis:

"O balanceador deve ser completamente efetivo, corrigindo todo o desbalanceamento e não somente uma parte dele".

Considerando que a lavadora deve passar suave pela rotação crítica, o balanceador deve ser efetivo a velocidades abaixo da crítica. O dispositivo deveria agir continuamente para balancear o rotor enquanto aproxima-se da freqüência crítica, onde a máquina é mais sensível ao desbalanceamento.

Com a finalidade de compensar mudanças de desbalanceamento a altas rotações no processo de centrifugação, o balanceador deveria agir para balancear o rotor em rotações acima da crítica. Devido ao ângulo de fase variar de 180 graus, o balanceador deve ser sensível à rotação e ainda agir diferentemente em baixa e altas rotações.

A correção introduzida pelo balanceador deveria ser o mais próximo possível do plano radial do desbalanceamento.

As considerações acima são um bom guia para se projetar um anel de balanceamento. Entretanto, tais premissas são praticamente impossíveis de serem validadas na prática, como será mostrado a seguir.

\subsection{Sistemas com líquido}

\subsubsection{O anel de balanceamento de Leblanc}

Em 1916, Leblanc sugeriu um balanceador automático simples, baseado no fenômeno descrito acima, onde o rotor gira com a região mais leve do lado de fora (light side out) acima da rotação crítica.

O balanceador de Leblanc consiste basicamente de um anel anular concêntrico envolvendo o cesto da lavadora, parcialmente completo por líquido. A medida que o anel é deslocado, o líquido se redistribui e o centro de 
gravidade se move dependendo da quantidade desbalanceada. Tal anel foi originalmente cheio por um líquido pesado como o tetrabromometano, combinado por carbono tetraclorido ou mercúrio. Naturalmente, por motivos econômicos e ambientais, tais líquidos pesados foram substituídos por água ou água salina.

Como discutido anteriormente, pode-se concluir que este anel de balanceamento será efetivo apenas após a freqüência crítica $\omega>\omega_{n}$, onde há a mudança do ângulo de fase do sistema. Portanto, conclui-se que há uma desvantagem do efeito do anel-hidro sobre a dinâmica da lavadora abaixo da freqüência crítica. É desejável que lavadoras que tenham este tipo de balanceador tenham conseqüentemente uma baixa freqüência crítica.

Considerando o caso em que a máquina opera acima da freqüência crítica, o CG do líquido ficará conclusivamente no sentido oposto à carga desbalanceada.

De acordo com o diagrama da figura, tem-se: 


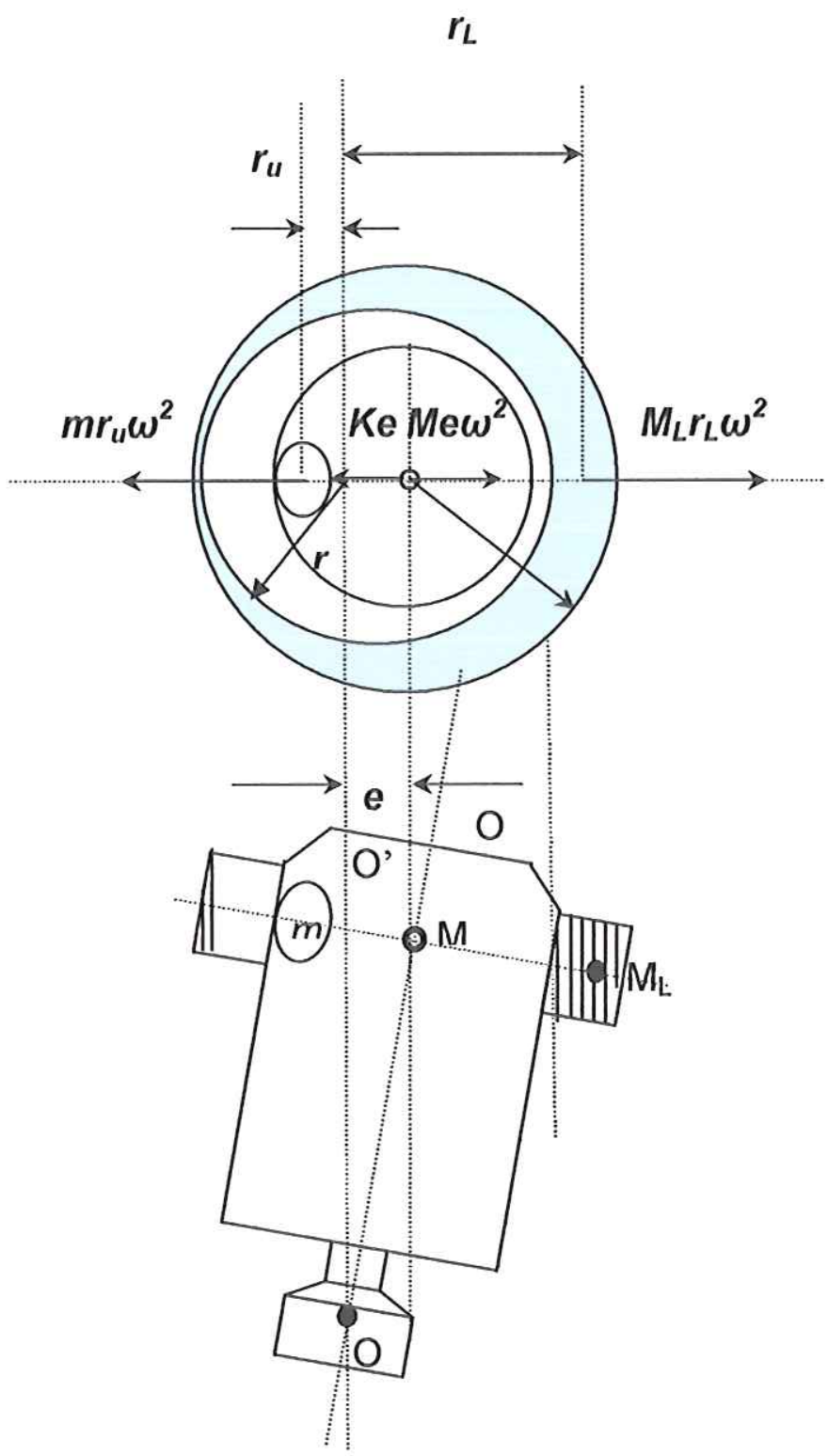

Figura 3.6 -Balanceador de Leblanc numa máquina de eixo horizontal

$$
\mathrm{mr}_{\mathrm{u}} \omega^{2}-k e=M e \omega^{2}
$$

A massa do líquido desbalanceado é dada por:

$$
\mathrm{Mr}_{\mathrm{L}}=\rho_{L} h \pi\left(R^{2}-r^{2}\right)
$$

$\mathrm{O}$ raio $\mathrm{rL}$ onde o centro de massa do líquido está localizado pode ser 
determinado através do equilíbrio de momentos de massa em relação ao eixo OO'. O anel-hidro pode ser idealizado como dois discos sólidos de líquido. Um disco com a densidade do líquido e o outro sem densidade.

Fazendo o equilíbrio em OO', tem-se:

$$
\mathrm{r}_{\mathrm{L}} \mathrm{M}_{\mathrm{L}}=\rho_{L} h \pi R^{2} e-\rho_{L} h \pi r^{2} * 0
$$

Das equações (3.3.2)) e (3.3.3), a excentricidade do sistema torna-se:

$$
\mathrm{r}_{\mathrm{L}}=\frac{e R^{2}}{R^{2}-r^{2}}
$$

Substituindo as equações (3.3.1) e (3.3.4), escreve-se a excentricidade e como:

$$
\mathrm{e}=\frac{m_{u} u_{u} \omega^{2}}{\left(M+\rho_{L} h \pi R^{2}\right) \omega^{2}-k}
$$

Para o caso em que não há dispositivo de balanceamento, a excentricidade torna-se:

$$
\mathrm{e}=\frac{m u^{r} u^{2}}{M \omega^{2}-k}
$$

Pode-se ainda expressar a razão de excentricidades como:

$$
\frac{e}{e_{o}}=\frac{M \omega^{2}-k}{\left(M+\rho_{L} h \pi R^{2}\right) \omega^{2}-k}
$$

Ou ainda: 


$$
\frac{e}{e_{o}}=\frac{\left(\frac{\omega}{\omega_{n}}\right)^{2}-1}{\left(1-\frac{\rho_{L} h \pi R^{2}}{M}\right)\left(\frac{\omega}{\omega_{n}}\right)^{2}-1}
$$

Onde $\omega_{\mathrm{n}}=\sqrt{\frac{K}{m}}$

Considerando que o ciclo de centrifugação atinge rotações muito superiores à rotação crítica, pode-se aproximar (3.3.5) por:

$$
\frac{e}{e_{o}}=\frac{1}{\left(1+\frac{\rho_{L} h \pi R^{2}}{M}\right)}
$$

De acordo com a expressão (3.3.6), conclui-se que a excentricidade nunca pode ser eliminada num balanceador dinâmico de Leblanc. De fato, o balanceador dinâmico de Leblanc só pode cancelar parte da excentricidade, uma vez que o líquido só se redistribui devido a tal excentricidade.

Balanceadores mecânicos dinâmicos, entretanto, podem eliminar todo o desbalanceamento e excentricidade, como mostrado a seguir. Tal sistema de balanceamento é muito utilizado para rotores de alta velocidade.

Define-se uma força de restauração para o balanceador de Leblanc, que pode ser escrita como:

$$
F_{R}=M_{L} r_{L} \omega^{2}
$$


$\mathrm{Ou}$

$$
F_{R}=\rho_{L} h \pi R^{2} \omega^{2} e
$$

Da equação (3.3.8) a massa equivalente do balanceador é um disco cheio, e a força de restauração é linearmente proporcional à excentricidade. Tais conclusões levam a considerar a hipótese de haver uma quantidade ótima de líquido e se há uma máxima excentricidade para o sistema de balanceamento.

A quantidade ótima de líquido pode ser determinada graficamente, como segue.

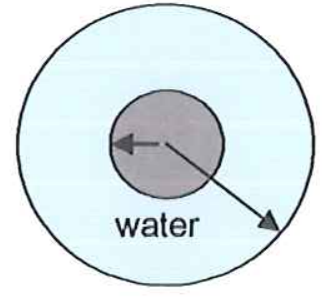

(A)

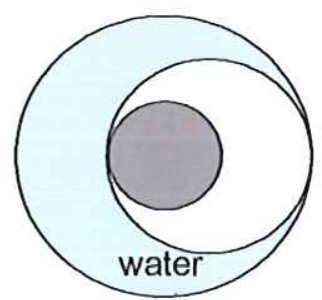

(C)

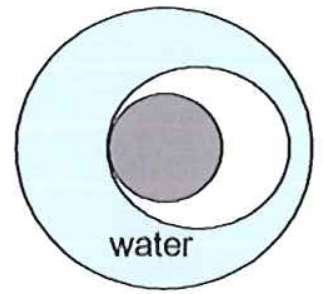

(B)

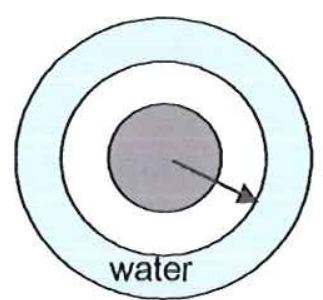

(D)

Figura 3.7 -Representação gráfica do volume de fluido otimizado

Na Figura 3.7(A), o disco está completamente cheio. Tal configuração impossibilita que o líquido desloque com a finalidade de contra-balancear o sistema. Na Figura 3.7(B), o anel está com um volume excedente mas não totalmente cheio. Isto permite que líquido fique ainda no lado oposto à porção 
balanceadora, que acaba reduzindo a capacidade balanceadora. $\mathrm{Na}$ Figura $3.7(\mathrm{C})$, o balanceador está com o volume de líquido otimizado, permitindo que todo o líquido se distribua de forma eficaz e balanceie o sistema de forma otimizada. O volume ótimo é mostrado novamente na Figura 3.7(D), e é dado por:

$$
\text { Vopt }=\pi h\left(\left(R_{o}\right)^{2}-\left(\frac{R_{o}+R_{i}}{2}\right)^{2}\right)
$$

A condição de volume ótimo de fluído dá ainda a máxima excentricidade efetiva do balanceador. Da Figura 3.7 (D), observa-se que quando o fluido é deslocado na condição extrema para uma quantidade otimizada, não há mais fluido remanescente na porção oposta à carga desbalanceada, definindo assim a máxima excentricidade $e_{\max }$ do sistema. Pode-se deduzir a máxima excentricidade como:

$$
e_{\max }=\frac{R_{o}-R_{i}}{2}
$$

Para excentricidades acima de $e_{\max }$ o sistema deveria se comportar como uma massa sólida desbalanceada, $\mathrm{M}_{\mathrm{L}}$. 
A Figura 3.8 mostra a força restauradora versus a excentricidade. A força restauradora acima da $e_{\max }$ é dada pela equação (3.3.7). Na condição de $e_{\max }$ o fluido moveu-se completamente oposto ao desbalanceamento. Para excentricidades maiores que $\mathrm{e}_{\max }$, a força de restauração é devido à adição da massa real ao invés da massa equivalente de um disco cheio. Como a massa real é menor que a massa equivalente de um disco cheio, a inclinação da força de restauração diminui como mostrado na Figura 3.8.

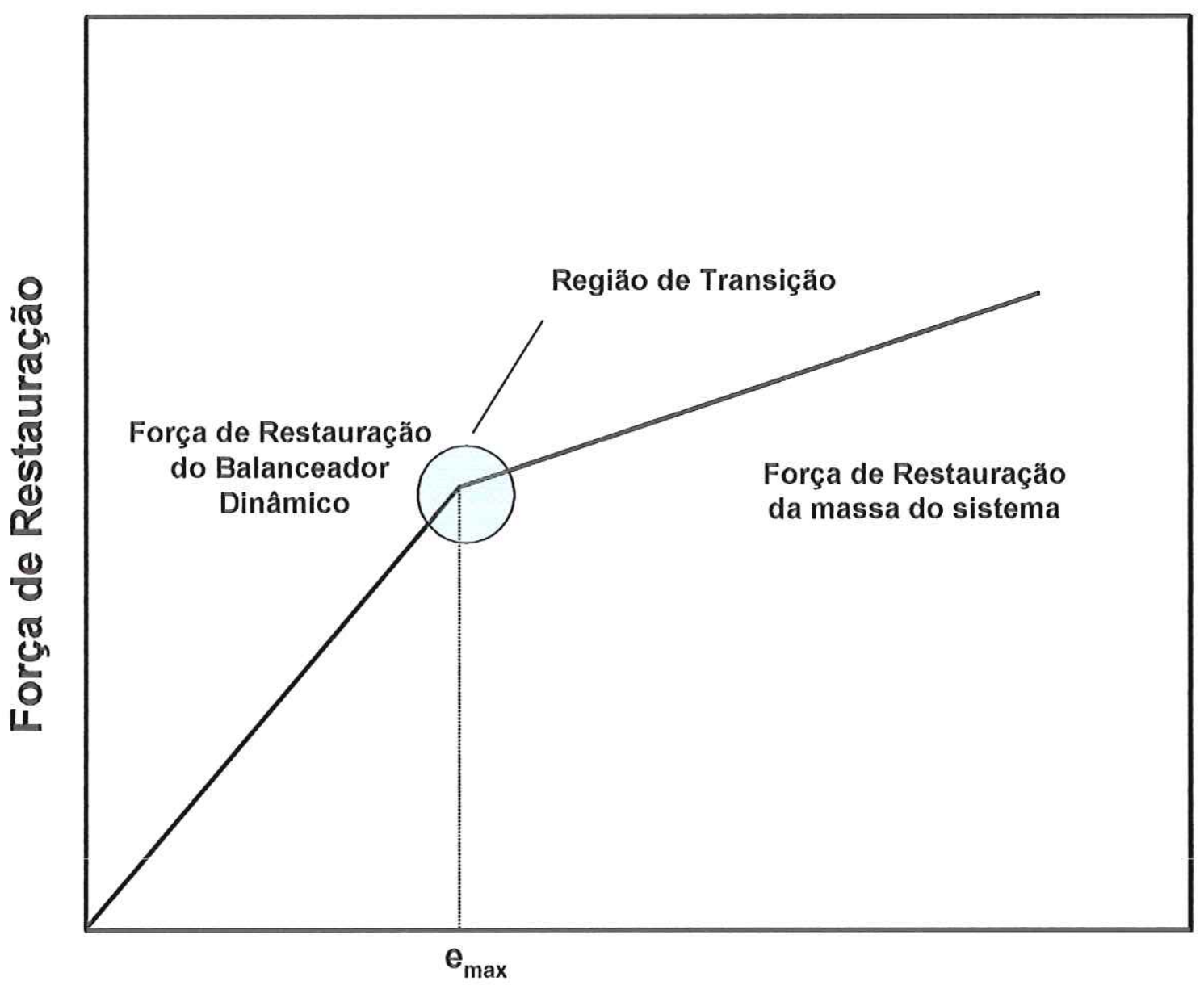

\section{Excentricidade}

Figura 3.8 - Força de restauração versus excentricidade

A Figura 3.9, adaptado de S. Bae et al (2002), ilustra o comportamento do fluído para diferentes excentricidades e. Para pequenas excentricidades, o fluído se comporta como ilustrado em (a). Quando a excentricidade é relativamente grande, isto é, e > $e_{\max }$ o fluído se comporta como ilustrado em (b). Já em (c), onde e \> emax, o fluído no anel move-se para o lado e se 
comporta como um corpo rígido.

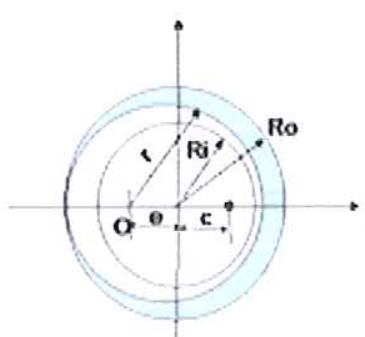

a)

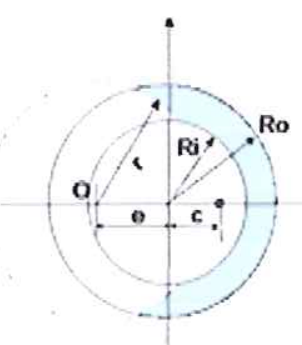

b)

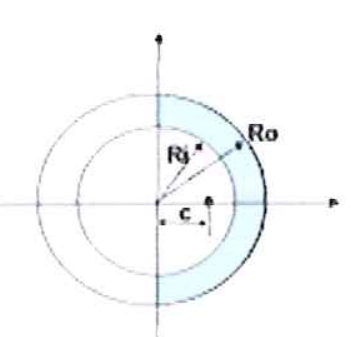

c)

Figura 3.9 - Centróide do fluido em um anel-hidro: a) e $\left\langle e_{\max }\right.$ b) e $>e_{\max } \quad$ c) e $\gg>>e_{\max }$-Fonte: Adatsdo de $s$. Bae et.al (2002)

\subsubsection{O balanceador de Leblanc modif́icado}

O balanceador de Leblanc modificado tem suas bases na equação(3.3.8). De acordo com a equação, a força restauradora de Leblanc é dependente apenas do raio externo e não da massa total do líquido. Assim, o anel de Leblanc modificado consiste simplesmente em múltiplas câmaras cheias parcialmente de líquido, como ilustrado (Figura 3.10):

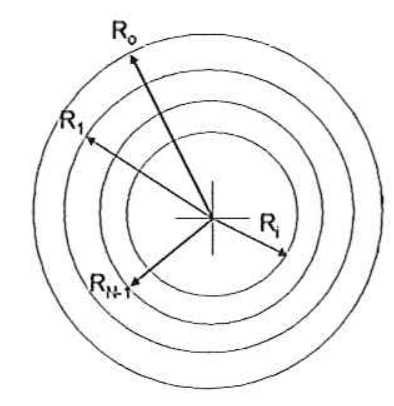

Figura 3.10 - O anel modificado de Leblanc

A força de restauração, neste caso, torna-se a adição consecutiva de raios externos. A força restauradora modificada torna-se então: 


$$
F_{R}=\rho_{L} h \pi\left(R_{O}^{2}+R_{1}^{2}+R_{2}^{2}+\ldots+R_{N-1}^{2}\right) \omega^{2} e
$$

Onde $\mathrm{N}$ é o número de câmaras.

De acordo com a equação acima, para $N \rightarrow \infty$, a força de restauração torna-se infinita. Tal condição torna-se fisicamente impossível, levando-nos a concluir que a expressão deve conter erros. Há uma espessura de parede entre cada câmara que, à medida que número de câmaras aumenta, o número de paredes também aumenta, levando a força de restauração à zero. A adição de espessura de parede na equação (3.3.11) resulta em:

$$
\left.F_{R}=\rho_{L} h \pi\left(R_{o}^{2}-t\right)^{2}+\left(R_{1}^{2}-t\right)^{2}+\left(R_{2}^{2}-t\right)^{2}+\cdots+\left(R_{N-1}{ }^{2}-t\right)^{2}\right) \omega^{2} e
$$

Assumindo-se tamanhos de câmaras iguais, a equação acima pode ser escrita como:

$$
F_{R}=\rho_{L} h \pi \omega^{2} e \sum_{j=0}^{N}\left(R_{o}-(t+\Delta j)\right)^{2}
$$

Onde $\Delta=\frac{R_{o}-R_{i}}{N}-1$ e $\Delta \geq 0$.

A força de restauração em função do número de câmaras até a excentricidade máxima é mostrada na Figura 3.11. 


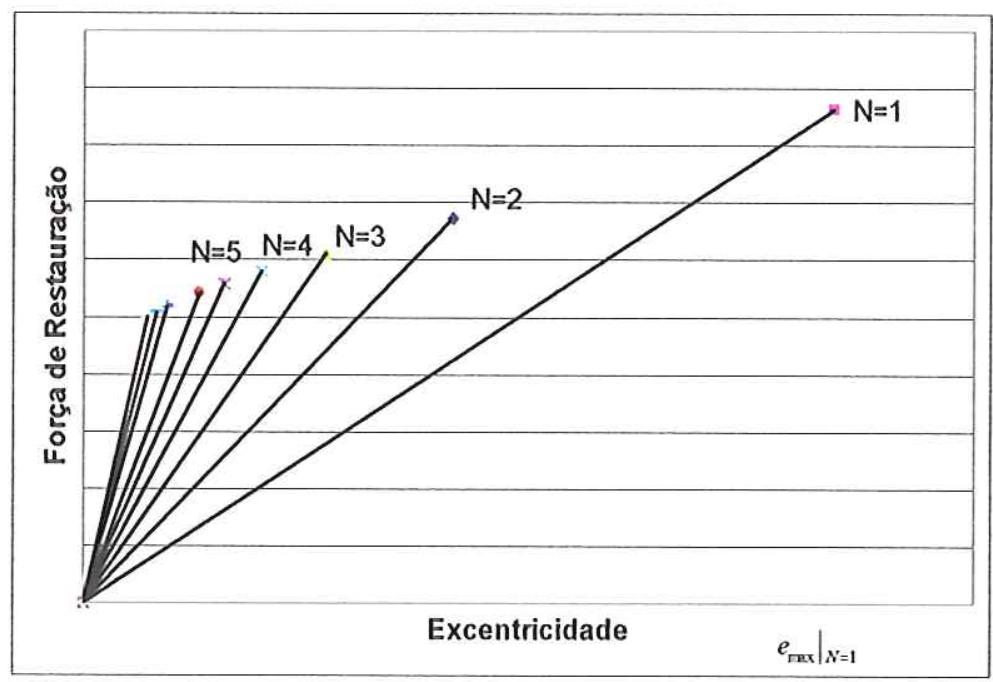

Figura 3.11 -Força de Restauração em função da excentricidade em um balanceador de múltiplas câmaras

Analisando a Figura 3.11, conclui-se que a força de restauração diminui com o número de câmaras. Há ainda uma região de "agrupamento" numa faixa de seis a dez câmaras. Além disso, a sensitividade do balanceador cresce com a adição de câmaras. Isto é ilustrado na Figura 3.12 geometricamente.

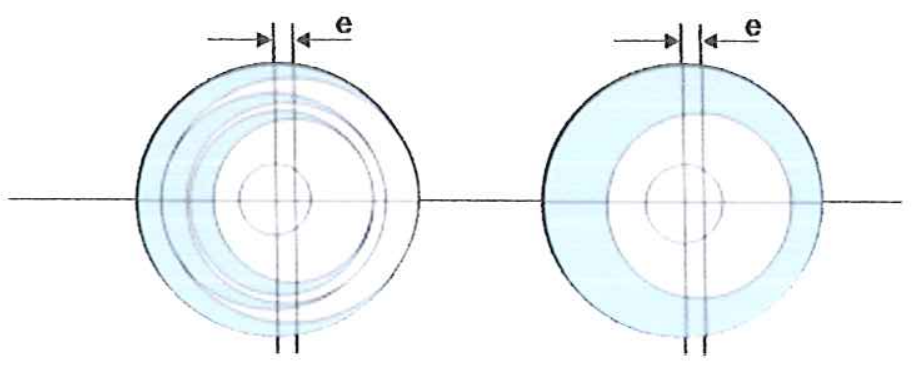

Figura 3.12 - Sensibilidade de um anel de múltiplas câmaras versus anel de câmara simples

A quantidade de líquido deslocado no anel com múltiplas câmaras é de $100 \%$ enquanto que num anel de câmara única somente uma parte do líquido foi deslocada. A vantagem de um anel de múltiplas câmaras não é a força de restauração total, como sugerido pela equação (3.3.11), mas sim o aumento da sensitividade do balanceador para deslocar o líquido para um lado, sobre o efeito de uma pequena excentricidade. Conseqüentemente reduz-se a excentricidade observada no sistema para uma certa carga desbalanceada. 


\subsection{Sistemas mecânicos}

\subsubsection{Pêndulo, anel e balanceadores de esferas}

Tentativas de atingir o balanceamento automático de máquinas rotativas, especialmente centrífugas, levaram ao surgimento de três sistemas de amortecimento principais de natureza mecânica. Tais mecanismos de balanceamento usam anéis, pêndulos e esferas para compensar o desbalanceamento do sistema.

\subsubsection{Balanceador de anéis}

A história deste dispositivo vem em torno do ano de 1877 quando Albert Fesca sugeriu a utilização de três anéis livres sobre o eixo de uma máquina centrífuga. EM 1916, Ledyard mostrou um número de anéis livres em torno de um cesto de uma centrífuga. (THEARLE, 1950a, 1950b).

A Figura 3.13 mostra um balanceador de anel (a) e de pêndulo (b).

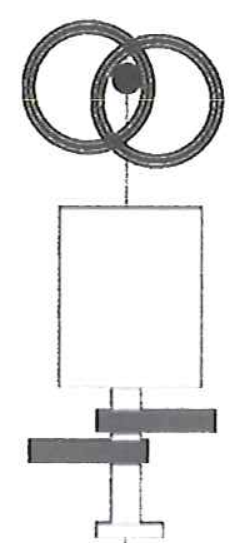

(a)

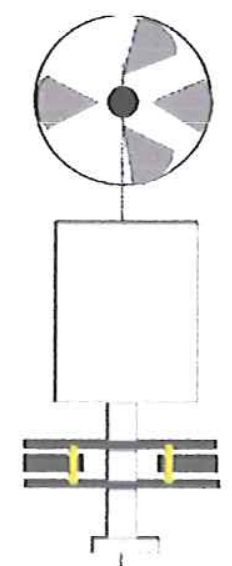

(b)

Figura 3.13 - Esquema de balanceador (a) de anel (b) de pêndulo

Entretanto, o balanceador de anel não é muito prático para aplicação em 
lavadoras de roupa, já que não pode ser preso no tanque externo da mesma. Além disso, o anel tem que ser fixado longe do plano de desbalanceamento, o que de certa forma prejudica o balanceamento. Outro aspecto desfavorável nos anéis é o atrito presente entre eles e a estrutura que suporta os mesmos. Este atrito faz com que o design dos discos torne-se bastante incômodo.

\subsubsection{Balanceador de pêndulo}

O balanceador de pêndulo é o sistema de transição entre o balanceador de anel e o balanceador de esferas, mostrado na Figura 3.13 (b). $\mathrm{O}$ atrito torna-se mais fácil de controlar neste sistema. As características principais deste tipo de balanceador são que os raios dos pivôs dos pêndulos são um limitante à compensação da excentricidade. Novamente, um limitante deste sistema é que não pode ser aplicado no tanque externo de uma lavadora, tornando-se de difícil aplicação na indústria de lavanderia. Entretanto, o sistema poderia ser acoplado logo abaixo do cesto sobre o eixo. A análise do balanceador de pêndulo segue a análise do balanceador de esferas e não será mostrado.

\subsubsection{Balanceador de esferas}

Balanceadores de esferas são extensamente usados em balanceamento de rotores de alta rotação, lavadoras e ainda DVD players (CONRAD, 1994; $\mathrm{KIM}$ et al, 1999). A grande vantagem dos balanceadores de esferas perante os anéis-hidro é que, para rotações acima da crítica, as esferas são capazes de balancear $100 \%$ da carga desbalanceada. Isto, claro, dentro de seus limites de capacidade e sensibilidade. A estabilidade de movimento pode ser garantida pela adição de óleo para amortecer oscilações das esferas.

Assumindo o regime e a condição em que $\omega \gg \omega_{n}$. Somando-se as forças radiais em regime como anteriormente, obtem-se: 


$$
m_{u} r_{u} \omega^{2}+k e=M e \omega^{2}+M_{B} r \omega^{2}
$$

A relação de localização das esferas no balanceador para as esferas individuais é dada por:

$$
M_{B} r=\sum_{j=1}^{N} m_{b j} r_{b j} \cos \beta_{j}
$$

Onde $M_{B}$ é a massa total e $N$ é o número de esferas. Da Figura 3.14 , a relação entre $r_{u}$ e e é:

$$
r_{u}=a-e
$$

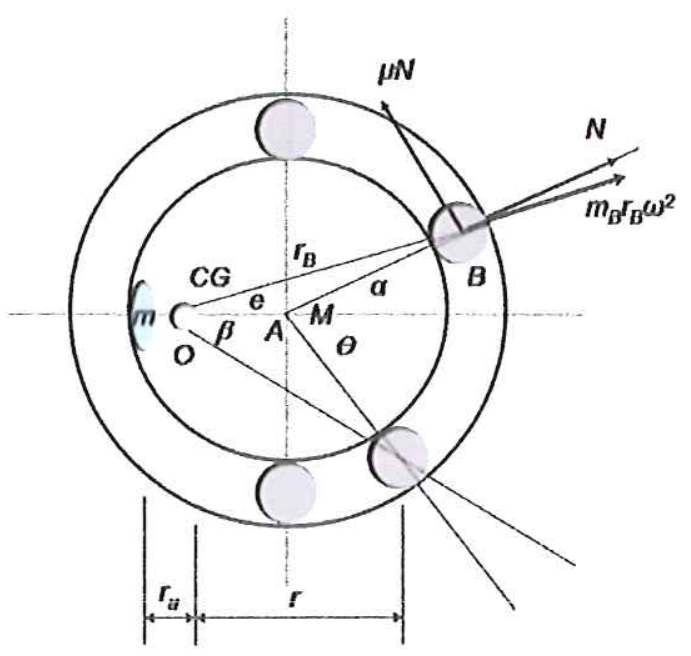

Figura 3.14 - Balanceador de esferas 


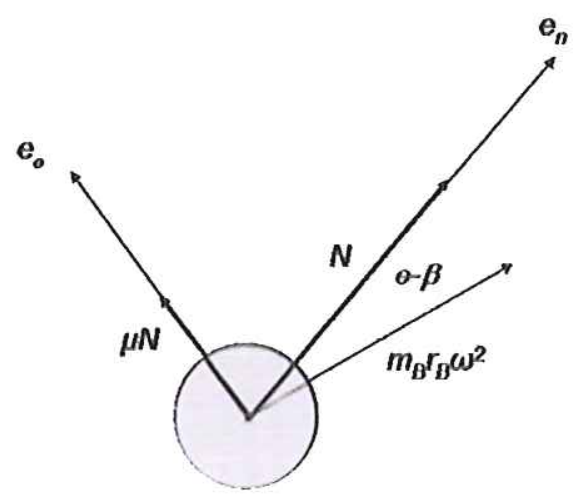

Figura 3.15 - Diagrama de corpo livre de uma esfera

Substituindo na equação (3.4.1), escreve-se a excentricidade como:

$$
e=\left(m_{u} a-M_{B} r\right) \frac{1}{\left(M+m_{u}\right)} \frac{\left(\frac{\omega}{\omega_{n}}\right)^{2}}{\left(\frac{\omega}{\omega_{n}}\right)^{2}-1}
$$

Onde $\left(\frac{\omega}{\omega_{n}}\right)^{2} \gg 1$

A equação mostra que a excentricidade pode ser zero, bastando que:

$$
m_{u} a-M_{B} r=0
$$

O raio do centro de gravidade do balanceador é:

$$
r=\frac{m_{u} a}{M_{B}}
$$

Pode-se ainda, da Figura 3.14, concluir que o máximo valor de $r$ pode ser dado por: 


$$
r_{\max } \approx r_{i}+\frac{d}{2}
$$

Considere agora o diagrama de corpo livre e de uma esfera, conforme Figura 3.15. Somando-se as forças nas direções normais e tangenciais, resulta:

$$
\begin{gathered}
N+m_{b} r_{b} \cos (\theta-\beta)=0 \\
\mu N-m_{b} r_{b} \operatorname{sen}(\theta-\beta)=0
\end{gathered}
$$

A equação (3.4.8) representa a porção das forças tentando trazer a esfera para o equilíbrio. Esta força tangencial será exercida até ser igual à força de resistência de atrito sobre a esfera. Se o atrito for desprezível, a força tangencial moverá a esfera até o perfeito balanceamento, e a força tangencial tornar-se-á igual a zero.

Entretanto, assumindo a presença da força de atrito, pode-se deduzir que:

$$
\operatorname{tg}(\theta-\beta)=\mu
$$

Ainda, o erro de posicionamento do anel de balanceamento depende do coeficiente de atrito, conforme mostrado acima. Entretanto, já que pode-se fazê-lo bem pequeno, afirma-se por conseqüência que o balanceador de esferas é $100 \%$ efetivo em balancear o sistema até sua máxima capacidade. Ainda, a força de restauração do balanceador de esferas é, antes da saturação, dado por:

$$
F_{R}=M_{B} r \omega^{2}
$$


ou

$$
F_{R}=m_{u} a \omega^{2}
$$

\subsubsection{O balanceador combinado}

O balanceador combinado apresenta características bastante favoráveis, como descrito por Tatsumi (1981). Este tipo de balanceador, também denominado balanceador duplo, combina os efeitos de balanceamento do balanceador de esferas com o balanceador com líquido. Tatsumi concluiu que o balanceador combinado pode reduzir efetivamente vibração e ruído na lavadora.

O princípio de funcionamento aproveita a ação do balanceador de esferas até a saturação. Abaixo deste ponto, o balanceador de esferas é capaz de eliminar totalmente a excentricidade da máquina até sua saturação. Acima deste ponto, o anel-hidro passa então a atuar atenuando a excentricidade causada por cargas desbalanceadas excessivas.

Esta combinação de anel-hidro e balanceador de esferas melhora a performance média da lavadora em comparação com o anel de Leblanc e ainda diminui o tamanho do balanceador de esferas.

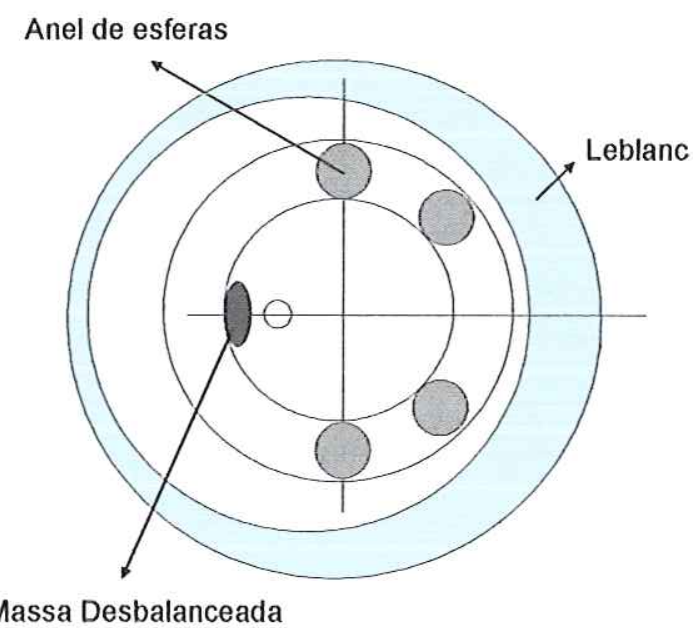




\subsection{Absorvedores dinâmicos de vibração}

\subsubsection{Descrição}

Alguns fabricantes utilizam absorvedores de vibração a fim de reduzir a vibração criada pelo sistema dinâmico da máquina. Um absorvedor de vibração consiste de uma massa e diversas molas que suspendem a massa numa determinada localização. Haar (1999) retrata o uso de absorvedores de vibração particularmente utilizados em lavadoras de roupa e secadoras no mercado americano. As figuras abaixo ilustram a aplicação dos mesmos.

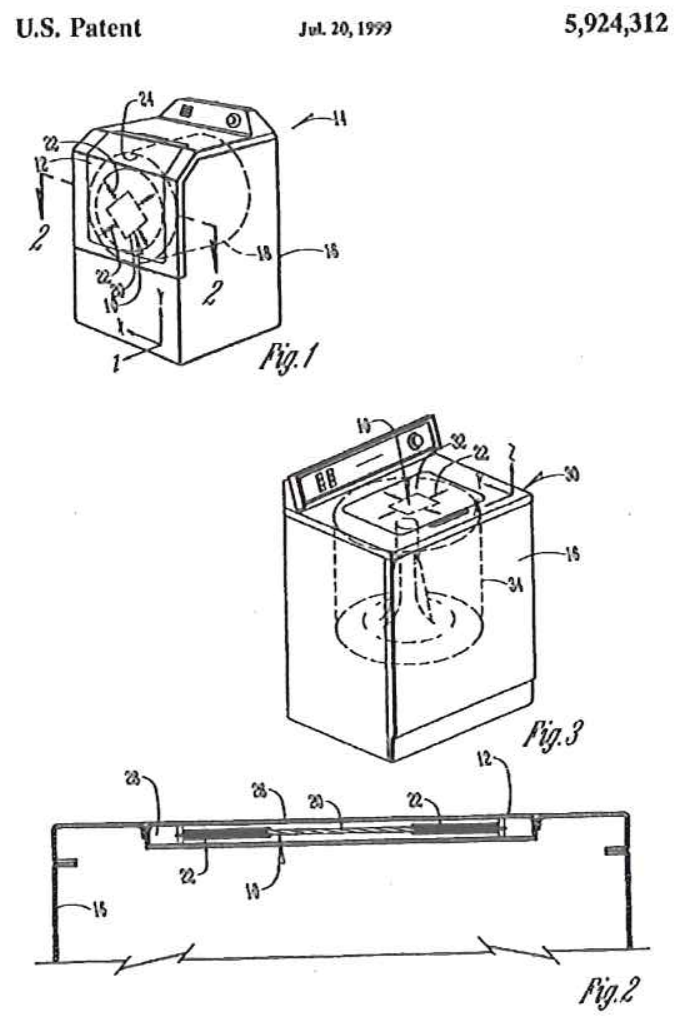

Fligura 3.17 - Absorvedores mecânicos de vibração utilizados em lavadoras de eixo vertical e horizontal.Fonte: Haar (1999)

Primeiramente, um sistema primário de um GDL será descrito e sua função de resposta em freqüência será examinada. Então, o impacto de se adicionar ao sistema um absorvedor de vibração será examinado. 


\subsubsection{Sistema primário (1 GDL)}

O sistema primário de interesse será simplificado a um sistema de um grau de liberdade, constituído de um sistema massa-mola-amortecedor. Este sistema é ilustrado abaixo:

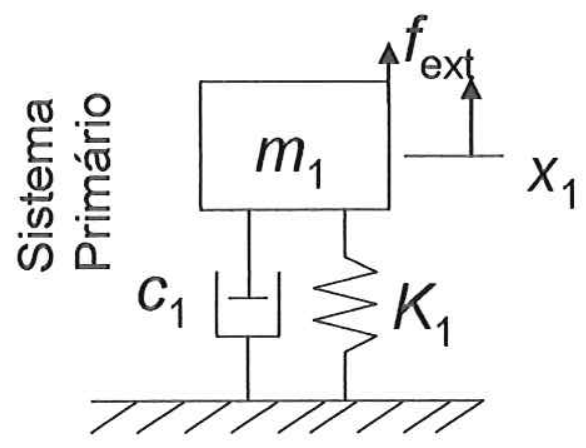

Figura 3.18 - Sistema Primário de $1 \mathrm{GDL}$

Onde:

$m_{1}:$ Massa suspensa 1

$c_{1}:$ Amortecimento viscoso 1

$k_{1}:$ Rigidez do sistema 1

$f_{\text {ext }}$ :Força externa aplicada ao sistema

$x_{1}$ : Deslocamento da massa 1

A equação de movimento do sistema é:

$$
m_{1} \ddot{x}_{1}+c_{1} \dot{x}_{1}+k_{1} x_{1}=f_{\text {ext }}(t)
$$

Através de manipulação da equação no domínio da freqüência, a resposta do sistema torna-se: 


$$
\frac{X_{1}}{F_{e x t}}=\frac{\frac{1}{k_{1}}}{1-\left(\frac{\omega}{\omega_{n, 1}}\right)^{2}+2 \zeta_{1}\left(\frac{\omega}{\omega_{n, 1}}\right) j}
$$

Onde $\omega_{n, 1}$ é a freqüência natural do sistema $1, \omega$ é a freqüência de entrada e $\zeta_{1}$ é o amortecimento crítico.

As figuras abaixo mostram a resposta em freqüência do sistema. Pode-se notar que há uma ressonância. Se esta freqüência de ressonância ocorrer próximo `a freqüência de operação, a resposta do sistema pode ser inaceitável dependendo do valor de amortecimento presente.

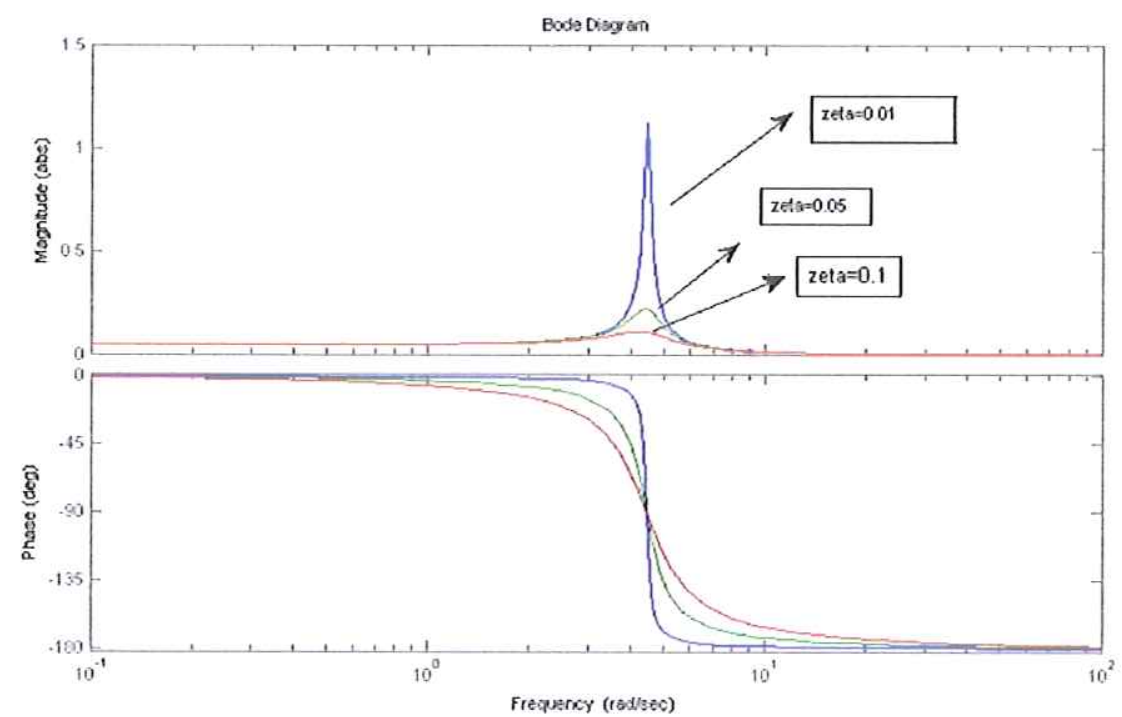

Figura 3.19 - Função de Resposta em freqüência para sistema primário

\subsubsection{Princípio de funcionamento de um sistema primário com um AV.}

Absorvedores de vibração (AV) vêm sendo discutidos desde o século 20. Estes dispositivos são empregados para reduzir a vibração do sistema através da transferência de energia para a massa absorvedora (TENTOR, 2001).

Adicionando um sistema massa-mola-amortecedor, a resposta combinada do sistema será diferente do sistema primário. Se o AV for 
escolhido de acordo com a freqüência de excitação, a massa primária terá menor resposta para excitação.

O sistema pode ser representado através do seguinte diagrama:

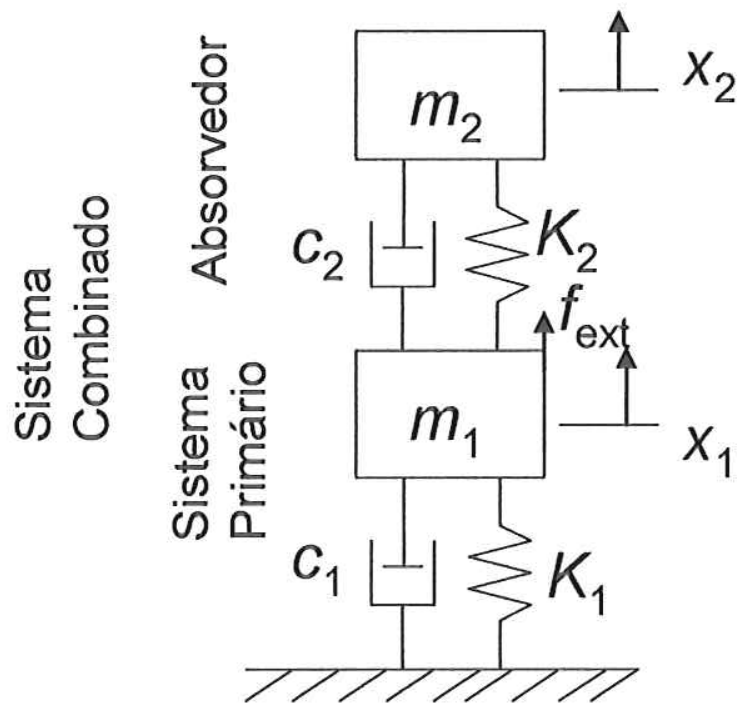

Figura 3.20 - Absorvedor de vibração

A equação de movimento resulta na matriz:

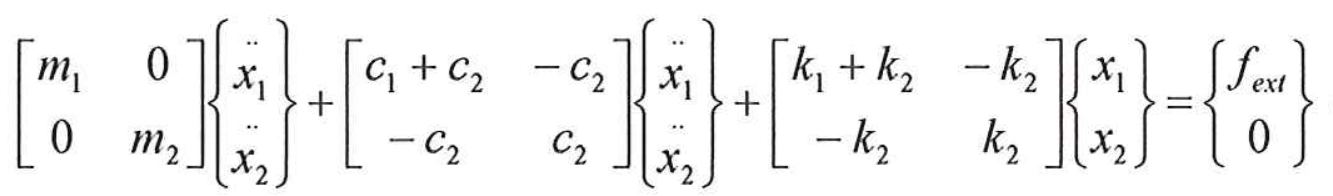

O sistema ainda pode ser reduzido usando a transformada de Laplace e assumindo condições iniciais nulas:

$$
X=\left(M s^{2}+C s+K\right)^{-1} F_{e x t}
$$

Na freqüência a ser absorvida, é desejado que o sistema combinado apresente um ponto de anti-ressonância. Neste ponto a inércia do absorvedor estará contrária à força de excitação. Isto resulta num mínimo deslocamento e o sistema primário apresenta ainda menor energia. 
A equação (3.5.4) representa o deslocamento da massa primária do sistema combinado:

$$
\frac{X_{1}}{F_{a t}}=\frac{\frac{1}{k_{1}}\left(\left(\frac{\omega_{n, 2}}{\omega_{n, 1}}\right)^{2}-\left(\frac{\omega}{\omega_{n, 1}}\right)^{2}-2 j \zeta_{2}\left(\frac{\omega_{n, 2}}{\omega_{n, 1}}\right)\left(\frac{\omega}{\omega_{n, 1}}\right)\right)}{\left\{\begin{array}{l}
\left(\frac{\omega}{\omega_{n, 1}}\right)^{4}-\left(\left(\frac{\omega_{n, 2}}{\omega_{n, 1}}\right)^{2}+4 \zeta_{1} \zeta_{2}\left(\frac{\omega_{n, 2}}{\omega_{n, 1}}\right)+\frac{k_{2}}{k_{1}}+1\right)\left(\frac{\omega}{\omega_{n, 1}}\right)^{2}\left(\frac{\omega_{n, 2}}{\omega_{n, 1}}\right)^{2}+ \\
\left.j\left(-\left(2 \zeta_{1}+2 \zeta_{2}+\frac{c_{2}}{\sqrt{k_{1} m_{1}}}\right)\left(\frac{\omega}{\omega_{n, 1}}\right)^{3}+\left(2 \zeta_{1}\left(\frac{\omega_{n, 2}}{\omega_{n, 1}}\right)^{2}+2 \zeta_{2}\left(\frac{\omega_{n, 2}}{\omega_{n, 1}}\right)\right)\left(\frac{\omega}{\omega_{n, 1}}\right)\right)\right\}
\end{array}\right.}
$$

A equação (3.3.5) é a FRF para o caso em que a ressonância do sistema primário é anulada. Isto acontece se a freqüência natural do absorvedor de vibração é ajustada para a freqüência primária do sistema $\left.\left(\frac{\omega_{n, 2}}{\omega_{n, 1}}\right)=1\right)$.

Isto é aplicável quando a ressonância original não é desejada. A figura Figura 3.21 ilustra a FRF combinada em comparação ao sistema primário. Apesar da ressonância original ser cancelada, duas novas ressonâncias são

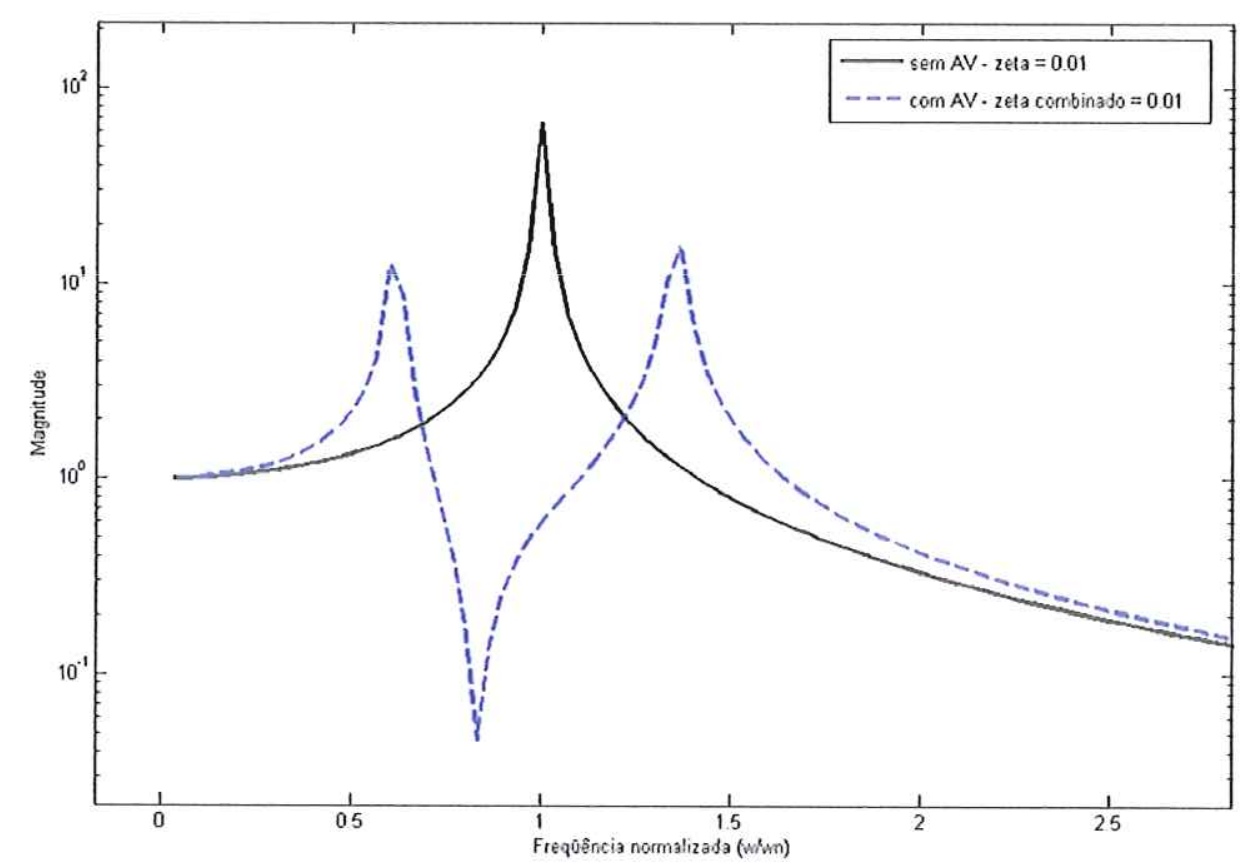

criadas.

Figura 3.21 - Resposta em freqüência para o sistema primário e combinado 
Uma vantagem do sistema é a redução da vibração perto da freqüência alvo. Além disso, este sistema mecânico se mostra simples, robusto e elegante. Como desvantagem pode-se citar sua banda de freqüência limitada. O sistema passou de uma ressonância para duas ressonâncias no sistema combinado. Se a freqüência de excitação variar durante operação, poderá haver deslocamentos inaceitáveis. Um absorvedor de vibração poderia resolver este problema.

$$
\frac{X_{1}}{F_{e x t}}=\frac{\frac{1}{k_{1}}\left(1-\left(\frac{\omega}{\omega_{n, 1}}\right)^{2}-2 j \zeta_{2}\left(\frac{\omega}{\omega_{n, 1}}\right)\right)}{\left\{\begin{array}{l}
\left(\frac{\omega}{\omega_{n, 1}}\right)^{4}-4\left(\zeta_{1} \zeta_{2}+\frac{k_{2}}{k_{1}}+2\right)\left(\frac{\omega}{\omega_{n, 1}}\right)^{2}+1+ \\
\left.j\left(-\left(2 \zeta_{1}+2 \zeta_{2}+\frac{c_{2}}{\sqrt{k_{1} m_{1}}}\right)\left(\frac{\omega}{\omega_{n, 1}}\right)^{3}+\left(2 \zeta_{1}+2 \zeta_{2}\right)\left(\frac{\omega}{\omega_{n, 1}}\right)\right)\right\}
\end{array}\right.}
$$

A faixa de deslocamento do absorvedor de vibração é dada pela relação de rigidez do sistema, da relação de massa entre o sistema primário e o absorvedor de vibração. No caso particular onde é anulada a ressonância original, a relação de rigidez $\left(\frac{k_{, 2}}{k_{1}}\right)$ é mostrada na equação (3.3.5). Nesta equação, $\left(\frac{\omega_{n, 2}}{\omega_{n, 1}}\right)=1$, de forma que, através de manipulação, a relação de rigidez e a relação de massa são equivalentes neste caso. Quanto menor esta relação, maior será o deslocamento da massa do AV. Isto pode ser visto como uma limitação de design na implementação de AVs. Um ajuste pode ser feito adicionando amortecimento ao absorvedor de vibração. Como discutido anteriormente, isto leva a uma resposta maior na freqüência a ser suprimida.

No capítulo 5 , será mostrado o uso de um absorvedor de vibração na lavadora em estudo neste trabalho. 


\section{Teoria de Multicorpos}

\subsection{Introdução}

Este capítulo tem por objetivo descrever de forma sucinta a teoria envolvida no modelamento matemático de Multicorpos. Tais formulações correspondem às técnicas utilizadas por softwares de MBS, notadamente o software ADAMS-MSC, utilizado neste trabalho.

Um sistema multicorpos pode ser definido como um sistema mecânico composto de corpos que são influenciados por forças e momentos. Estes corpos são interconectados uns aos outros por diferentes tipos de junta que restringem o movimento relativo dos corpos em diferentes direções (TISELL, 2000).

A técnica de multicorpos é extremamente importante na etapa de criação do produto, durante suas fases de desenvolvimento. Esta técnica permite determinar o movimento de sistemas mecânicos, através de deslocamentos, velocidades e acelerações, bem como extrair forças e carregamentos agindo no sistema, notadamente forças em rolamentos, fixações, forças em molas etc.

A modelagem em engenharia, assim como em qualquer ciência, necessita grande julgamento e conhecimento por parte do pesquisador, de forma a representar por equações matemáticas os fenômenos físicos relevantes que se pretende observar, assumir aproximações e simplificações não relevantes para o modelo em questão, assim como interpretar os resultados de forma coerente.

Independentemente do grau de complexidade, a modelagem passa pelos seguintes passos, como descrito extensivamente na literatura:

i. Descrição de um modelo físico do sistema que se pretende estudar, levando-se em conta os aspectos relevantes para a análise, bem como as simplificações.

ii. Obtenção das equações matemáticas que regem o sistema, baseado nas leis da física.

iii. Resolução das equações analiticamente ou numericamente, obtendo 
assim o comportamento do sistema baseado no modelo assumido.

iv. Verificação do resultado teórico do modelo e possível comparação com o modelo real, requerendo-se para isso grande conhecimento por parte do pesquisador a fim de julgar as respostas.

v. Modificar o modelo físico ou matemático, visando adequá-lo ao sistema real, ou ainda tomar decisões sobre o projeto, baseadas nos resultados obtidos.

Os softwares, neste sentido, são de extrema importância nas etapas ii e iii, pois permitem obter resultados satisfatórios com extrema velocidade, contribuindo assim para rápida tomada de decisão.

\subsection{Técnicas de modelagem}

Um sistema multicorpos (MBS - Multibody System) é um sistema mecânico composto por corpos que são influenciados por forças e momentos. Tais corpos são conectados entre si por juntas, que restringem o movimento relativo entre eles em diferentes direções.

Um MBS pode ser definido como um sistema mecânico com muitos graus de liberdade (COSTA, 1992).

Schiehlen (1997) faz uma análise histórica interessante sobre as origens de sistemas multicorpos, bem como suas perspectivas futuras.

A dinâmica de sistemas multicorpos é baseada na mecânica clássica, cuja descrição mais simples advém das equações de Newton, publicadas em 1686 para descrever o movimento de partículas. O conceito de corpo rígido foi introduzido posteriormente, em 1775 por Euler. Para o modelamento de juntas e restrições, Euler utilizou o princípio de corpo livre e forças de reação. Tais equações são conhecidas em multicorpos como equações de Newton-Euler.

Um sistema de corpos rígidos e suas restrições foram considerados por d'Alembert em 1743, onde se fez uma distinção entre forças aplicadas e forças de reação. Um formalismo mais elaborado das idéias de d'Alembert foi apresentado por Lagrange em 1778, que incorporou ainda o princípio de 
trabalhos virtuais. As equações de Lagrange são baseadas em princípios variacionais aplicados às energias potencial e cinética, incorporando as restrições cinemáticas e coordenadas generalizadas correspondentes.

Uma extensão do princípio de d'Alembert para sistemas holonômicos foi apresentada por Jourdain em 1913. Para sistemas não holonômicos, as variações relacionadas às velocidades de rotação e translação resultando em velocidades generalizadas são necessárias. Velocidades generalizadas, identificadas como velocidades parciais, foram introduzidas por Kane et al (1985). As equações de Kane representam basicamente uma descrição compacta de sistemas multicorpos (SCHIEHLEN, 1997).

A representação de um sistema multicorpos pode ser topológica, cuja representação irá mostrar as conexões (juntas) entre os corpos, bem como as forças externas aplicadas ao sistema.

A Figura 4.1 dá um exemplo de representação topológica.

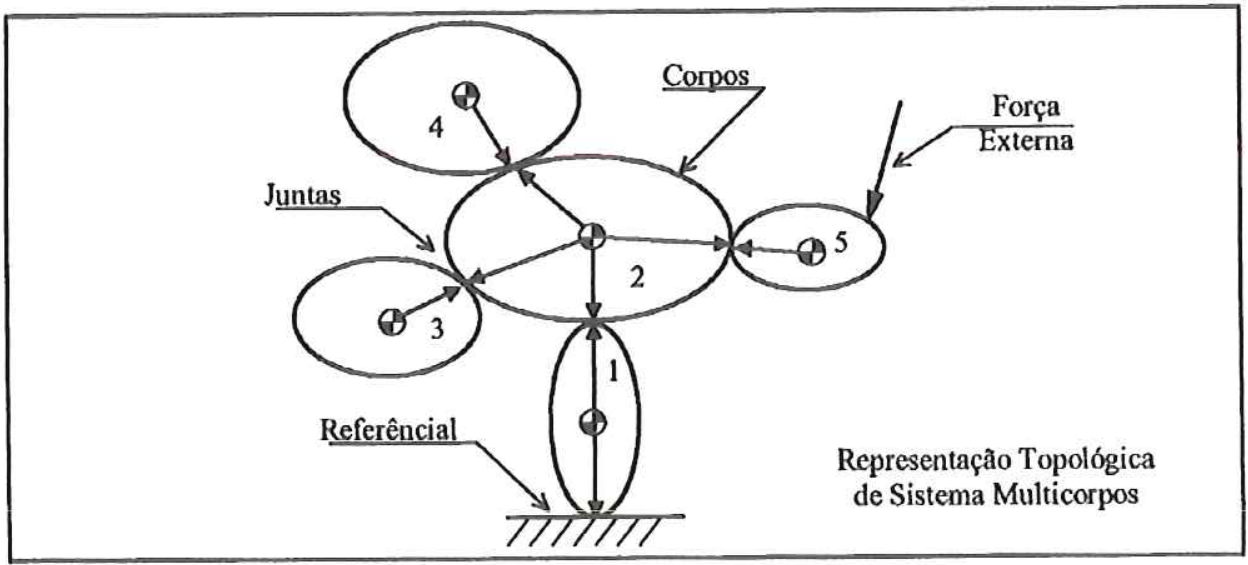

Figura 4.1 - Representação Topológica de Sistemas Multicorpos. Fonte: Barbosa (1999)

Os corpos são representados por elipses e possuem massa e momentos de inércia. As juntas estão associadas ao contato das elipses, nas quais atuam forças e momentos em direções e sentidos determinados pelo tipo de junta.

As forças externas são representadas por setas incidindo sobre o corpo e possuem direção e magnitude.

Com a finalidade de facilitar a descrição do sistema, os corpos podem ser considerados rígidos. Neste caso, somente seis coordenadas são 
necessárias para descrever completamente o estado de um corpo livre (três coordenadas de translação para a posição do centro de massa e três coordenadas de rotação para se determinar a orientação).

Estas coordenadas são funções do tempo e uma das funções primárias de uma análise multicorpos é determinar como tais variáveis variam no tempo.

Assumir um sistema de corpos rígidos geralmente implica ainda que a flexibilidade de determinados corpos seja representada por forças, notadamente molas de massa zero. Tais condições são válidas para o caso em que a flexibilidade dos corpos ou a massa das molas não influenciem consideravelmente a resposta dinâmica do sistema mecânico em questão.

Os movimentos de um MBS são governados por expressões matemáticas chamadas de equações dinâmicas do movimento. Estas equações são compostas de um conjunto de equações diferenciais, eventualmente acrescidas de algumas equações algébricas. As equações diferenciais são expressões das leis físicas (leis de Newton do movimento), descrevendo assim o movimento dos corpos, enquanto que as algébricas descrevem as restrições impostas pela geometria do sistema ou de seus movimentos, tais como conexões entre corpos adjacentes ou mesmo contato entre dois corpos.

Atualmente, programas multicorpos são capazes de gerar automaticamente as equações de movimento de sistemas complexos, permitindo ao pesquisador criar e estudar modelos com grande velocidade. Para isso, são necessárias apenas informações elementares sobre os corpos, com propriedades inerciais, bem como suas conexões ou restrições cinemáticas e leis de força.

Existem várias formas de se classificar a modelagem de multicorpos. $A$ mais usual é a classificação de acordo com o formalismo matemático e a natureza do algoritmo.

O desenvolvimento da modelagem de multicorpos por computador originou-se das comunidades de pesquisas espaciais e de máquinas e mecanismos. O programa ADAMS tem origem num trabalho proposto por Orlandea (1977), a fim de solucionar alguns problemas referentes a 
encadeamentos cinemáticos fechados e vínculos não holonômicos, presentes na área de transportes terrestres e que não apareciam com freqüência em aplicações espaciais. Uma revisão completa sobre o tema MBS foi apresentada por Schwertassek e Robertson em 1985. Mais recentemente, Kovalev e Savchenko (2001) sumarizaram uma seleção dos resultados mais importantes alcançados no século XX em dinâmica de corpos rígidos, baseada numa conferencia internacional para discussão do passado, presente e futuro de MBS.

\subsection{Formalismo matemático}

Os diversos métodos de formalismo matemático nas técnicas de MBS são todos baseados nas três leis fundamentais de Newton:

i. Todo corpo permanece em equilíbrio ou em movimento retilíneo uniforme, exceto se houver forças externas agindo sobre o corpo de forma a mudar seu estado.

ii. A mudança de movimento é proporcional à força aplicada e tem a direção da linha de ação da força.

iii. Para cada ação existe uma reação, de igual magnitude e sentido contrário. Ou as ações mútuas de qualquer dois corpos são sempre iguais e de sentidos opostos alongo da mesma linha.

As descrições típicas incluem as equações de Newton-Euler, equações de Lagrange, princípio de Jourdain, princípio de D'Alembert e assim por diante, conforme diagrama na Figura 4.2. 


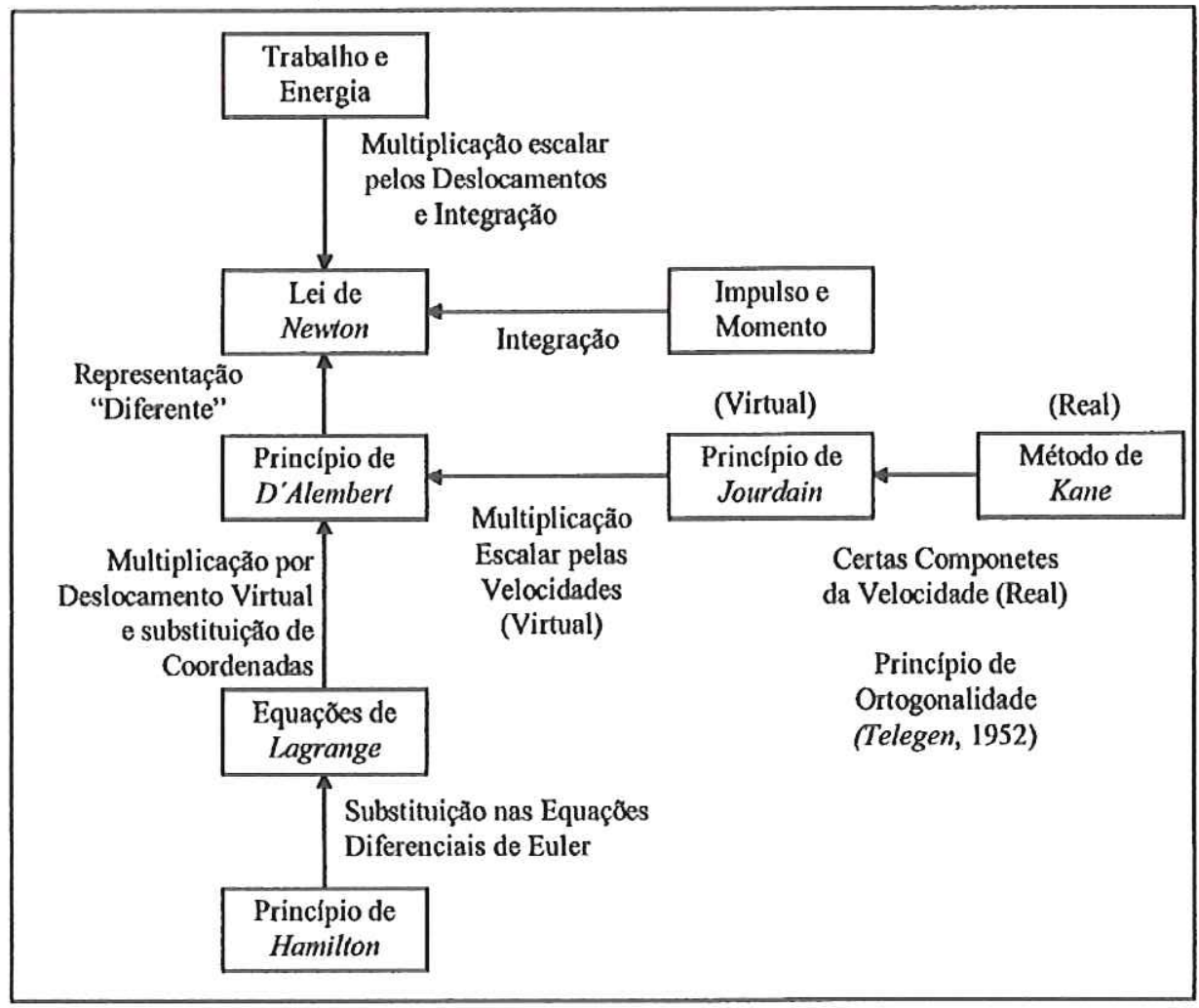

Figura 4.2 - Lei de Newton e seus Princípios. Fonte: (BARBOSA, 1999)

O objetivo da formulação de equações em MBS é obter eficiência e colocar as equações numa forma propícia para avaliação numérica.

O software ADAMS, utilizado nesta dissertação, utiliza o método Lagrangiano para formular as equações. Este programa é voltado para modelagem de sistemas tridimensionais com configuração arbitrária. A filosofia deste programa é baseada na adequação de variáveis e equações ao método numérico utilizado. Com esta finalidade, um conjunto redundante de equações é adotado, com quinze equações de primeira ordem para cada corpo, correspondentes às relações cinemáticas, equações dinâmicas e equações de energia.

Um algoritmo de Newton-Rapson é utilizado para solução da parte algébrica, ao passo que o método de Gear é utilizado para integração das equações diferenciais. Implementações numéricas (eliminação de Gauss e tratamento de matrizes esparsas) permitiram aumentar a eficiência do 
programa, uma vez que o número de equações geradas neste método é normalmente maior que em outros. A seção seguinte, baseada nas notas de (McCONVILLE; McGGRAPH, 1997), descreve o equacionamento utilizado no software ADAMS desenvolvido pela MDI.

\subsubsection{Coordenadas generalizadas}

No ADAMS, a posição de um corpo rígido é definido por 3 coordenadas cartesianas $x, y$ e $z$.

$$
\mathbf{p}=\left[\begin{array}{l}
x \\
y \\
z
\end{array}\right]
$$

A orientação de um corpo rígido é definido por um conjunto de 3 ângulos de Euler, correspondentes à seqüência de rotação 3-1-3: $\psi, \phi$ e $\theta$ respectivamente.

$$
\boldsymbol{\varepsilon}=\left[\begin{array}{l}
\psi \\
\phi \\
\theta
\end{array}\right]
$$

O conjunto de coordenadas generalizadas associadas com o corpo rígido i no ADAMS é denotado por:

$$
\mathbf{q}_{\mathrm{i}}=\left[\begin{array}{l}
\mathbf{p}_{\mathrm{i}} \\
\varepsilon_{\mathrm{i}}
\end{array}\right]
$$

A velocidade longitudinal e a velocidade angular são obtidas através da derivada das coordenadas generalizadas: 


$$
\begin{aligned}
& \mathbf{u}=\dot{\mathbf{p}} \\
& \varpi=\mathbf{B} \dot{\varepsilon} \equiv \mathbf{B} \zeta
\end{aligned}
$$

Onde

$$
\mathbf{B}=\left[\begin{array}{ccc}
\operatorname{sen} \phi \operatorname{sen} \theta & 0 & \cos \phi \\
\cos \phi \operatorname{sen} \theta & 0 & -\operatorname{sen} \phi \\
\cos \theta & 1 & 0
\end{array}\right]
$$

E $\varpi$ é a velocidade angular do corpo expressa no sistema de coordenadas locais do corpo. A equação (4.3.6) define a relação entre a velocidade angular do corpo, isto é, a característica intrínseca do corpo, e a nossa escolha de sistema de coordenadas generalizadas.

Para o sistema mecânico completo, contendo $n b$ corpos, o vetor com $n=6 * n b$ descreverá num certo instante de tempo a posição e a orientação de cada corpo no sistema.

$$
q=\left[q_{1}^{T} q_{2}^{T} \ldots q_{n b}^{T}\right]^{T}=\left[\begin{array}{llll}
q_{1} & q_{2} & \ldots & q_{n}
\end{array}\right]^{T}
$$

\subsubsection{Equações de movimento}

O movimento planar de um pêndulo simples fornece um paradigma excelente para explicar a formulação das equações no sistema multicorpos. e as técnicas de solução para análises dinâmicas e cinemáticas.

Durante uma simulação, as forças inerciais, as forças de restrição e ainda as forças externas sobre um mecanismo devem ser mantidas em equilíbrio (McCONVILLE; McGRATH, 1997). Esta afirmação dá fundamento `as 
equações de movimento de Lagrange, que é formulada em termos de expressões para energia cinética e potencial do sistema mecânico.

Para o movimento em um plano, isto é, em duas dimensões, a energia cinética do corpo rígido 'e igual a:

$$
T=\frac{1}{2}\left(m \dot{x}^{2}+m \dot{y}^{2}+\dot{I \theta}^{2}\right)
$$

onde $(x, y)$ é a localização do centro de massa em um sistema de coordenadas fixo e $\theta$ é a orientação do corpo no plano medido. Para um corpo de massa $m$ e inércia I em relação ao $\mathrm{CG}$, a energia potencial é dada por:

$$
V=m g y
$$

Onde g é a aceleração devido à gravidade.

A diferença entre a energia cinética e potencial, dada por $L$, é denotada Lagrangiano do sistema dinâmico. De acordo com as leis da dinâmica lagrangiana, o movimento do MBS é governado por:

$$
\left(\frac{d}{d t}\left(\frac{\partial L}{\partial \dot{q}}\right)-\frac{\partial L}{\partial q}+\Phi_{q}^{T} \lambda=Q\right.
$$

Onde $q$ é matriz coluna das coordenadas generalizadas segundo equação (4.3.3).

Para o caso de um pêndulo simples, a equação torna-se:

$$
q=\left[\begin{array}{l}
x \\
y \\
\theta
\end{array}\right]
$$

A matriz-coluna $Q$ representa as forças externais não potenciais aplicadas no sistema. Esta é balanceada contra os três termos no lado direito 
da equação, onde $\frac{d}{d t}\left(\frac{\partial L}{\partial \dot{q}}\right)$ é a aceleração dos componentes mecânicos, $\frac{d}{d t}\left(\frac{\partial L}{\partial q}\right)$ inclui as forças potenciais e finalmente $\Phi_{q}^{T} \lambda$, que contém as forças de restrição. O termo $\lambda$ é a matriz coluna de $\mathrm{m}<\mathrm{n}$, onde $\mathrm{n}$ é o número de multiplicadores de Lagrange e $T$ significa o vetor transposto.

A matriz jacobiana $\Phi_{q}=\left(\frac{\partial \Phi}{\partial q}\right)$ de equações restritivas é formada a partir de derivadas parciais de expressões para as restrições com respeito `as coordenadas generalizadas. Na mecânica lagrangiana, é a matriz $\Phi_{q}^{T}$ de n por m que acopla as condições de restrição nas equações de balanço de forças.

$$
p_{y}=\left(\frac{\partial L}{\partial \dot{x}}\right)=m \dot{y}
$$

As componentes do momento de translação de um corpo são:

Por analogia, o momento angular é definido como:

$$
p_{B_{x}}=\left(\left(\frac{\partial L}{\partial \ddot{\theta}}\right)\right) \equiv \ln \ddot{\theta} x
$$

Ainda, a fórmula do momento é:

$$
p_{q}=\left(\frac{\partial L}{\partial \dot{q}}\right)
$$

para qualquer coordenada generalizada $q$.

A derivada da equação (4.3.14) resulta em: 


$$
\frac{d}{d t}\left(\frac{\partial L}{\partial \dot{q}}\right)=p_{q}=m \ddot{q}
$$

Se $q$ é a coordenada rotacional, então:

$$
\frac{d}{d t}\left(\frac{\partial L}{\partial \dot{q}}\right)=\dot{p}_{q}=I \ddot{q}
$$

As equações (4.3.15) e (4.3.16)) representam a força inercial do corpo na direção $q$.

As três coordenadas generalizadas associadas com o pêndulo são $x, y e$ $\theta$. A única força externa aplicada neste exemplo é a força potencial resultante da aceleração da gravidade $g$ na direção vertical. Assim, o balanceamento das equações resulta:

$$
\left[\begin{array}{ccc}
m & 0 & 0 \\
0 & m & 0 \\
0 & 0 & I
\end{array}\right]\left[\begin{array}{l}
\ddot{x} \\
\ddot{y} \\
\ddot{\theta}
\end{array}\right]-\left[\begin{array}{c}
0 \\
m g \\
0
\end{array}\right]+\Phi_{q}^{T} \lambda=0
$$

Onde a força inercial devido à aceleração angular é balanceada pelo torque resultante em relação ao CG do pêndulo.

\subsubsection{Juntas no ADAMS}

De uma forma genérica, juntas no ADAMS são consideradas restrições que agem entre algumas coordenadas $q_{1}$ à $q_{n}$ da equação (4.3.7). Numa notação matemática, tal restrição pode ser escrita como: 


$$
\Phi(q)=0
$$

Por exemplo, uma junta de revolução agindo entre dois corpos induziria a um conjunto de 5 restrições do formato da equação (4.3.18), formando apenas um grau de liberdade entre os corpos.

A reunião de todas as restrições causadas pelas juntas presentes no modelo é denotada por $\Phi$ :

$$
\Phi(q)=\left[\begin{array}{llll}
\Phi_{1}^{T}(q) & \Phi_{2}^{T}(q) & \ldots & \Phi_{n j}^{T}(q)
\end{array}\right]^{T}=\left[\begin{array}{llll}
\Phi_{1}(q) & \Phi_{2}(q) & \ldots & \Phi_{m}(q)
\end{array}\right]^{T}
$$

Onde $n_{j}$ é o número de juntas no modelo e $m$, a soma do número de restrições induzidas por cada junta.

Note que $q \in R^{n}$, enquanto que $\Phi \in R^{m}$. Tipicamente, $m<n$, isto é, o número de coordenadas generalizadas é maior que o número de restrições que devem ser satisfeitas.

Derivando a expressão representativa das restrições de posição (4.3.19), obtem-se as equações de restrição cinemática de velocidade:

$$
\Phi_{q} \dot{q}=0
$$

Tomando-se a segunda derivada da equação (4.3.20), obtêm-se as equações de aceleração cinemáticas:

$$
\Phi_{q} \ddot{q}=-\left(\Phi_{q} \dot{q}\right)_{q} \dot{q} \equiv \tau
$$

De acordo com as deduções anteriores, conclui-se que as equações de (4.3.19) a (4.3.21) devem ser satisfeitas pelas coordenadas generalizadas $q$ e 
suas derivadas de primeira e segunda ordem no tempo.

Isto assegura que a evolução do sistema mecânico faça sentido, isto é, o mecanismo permaneça montado e as partes movam de tal forma que as restrições impostas pelas juntas sejam obedecidas para todo instante de tempo.

Para o caso do pêndulo, concluí-se que o sistema de (4.3.17) forma um problema de segunda ordem que ainda não está completamente determinado. As três equações contêm cinco incógnitas, as variáveis $x, y, \theta$ e ainda $\lambda x$ e $\lambda y$ das forças de restrição devido ao pivoteamento do pêndulo.

Equações adicionais são necessárias para resolver o equilíbrio do sistema. Elas são obtidas por restrições que, no exemplo em questão, são impostas pelo pino ou junta de revolução, que prende o pêndulo contra o ground.

Assim:

$$
\vec{R}+\vec{r}-\vec{A}=0
$$

Onde, $\vec{A}$ é o vetor constante que localiza a junta de revolução no sistema de coordenada do ground. $\vec{r}$ é o vetor do centro de massa do pêndulo em relação a junta. $\vec{R}$ localiza o centro de massa do pêndulo na referência do ground.

A equação (4.3.22) pode ser reescrita na forma vetorial como uma equação de restrição, satisfazendo a equação (4.3.18):

$$
\vec{\Phi}(x, y, \theta)=\left(x+r_{x}-A_{x}\right) \hat{i}+\left(y+r_{y}-A_{y}\right) \hat{j}=0
$$

Onde $\hat{i}$ e $\hat{j}$ são vetores unitários `as coordenadas cartesianas globais $\mathrm{x}$ e y. Ainda, a equação $\vec{R}=x \hat{i}+y \hat{j}$ mostra a relação entre as coordenadas 
cartesianas globais e o vetor $\vec{R}$

A equação (4.3.23) pode ser escrita na forma de equação matricial em termos das coordenadas independentes no tempo, x, y e $\theta$, resultando:

$$
\Phi(x, y, \theta)=\left[\begin{array}{l}
x-A_{x}-l \cos \theta \\
y-A_{y}-l \operatorname{sen} \theta
\end{array}\right]=0
$$

Onde l é o comprimento constante do vetor $\vec{r}$ que descreve o centro de massa do pêndulo em relação `a junta de revolução. Assim:

$$
\vec{r}=-l \cos \theta \hat{i}-l \operatorname{sen} \theta \hat{j}
$$

Onde $\vec{r}$ é dependente do tempo.

Em resumo, há cinco equações para se determinar cinco incógnitas: três equações de balanceamento de forças em (4.3.17) e duas equações de restrição em (4.3.24).

O sistema se faz assim determinado.

Vale ainda mencionar que a formulação empregada pelo software ADAMS utiliza o método padrão de se introduzir uma nova variável dependente para cada derivada de primeira ordem com a finalidade de reduzir o sistema para primeira ordem. Para o exemplo do pêndulo: 


$$
\begin{aligned}
& u=x \\
& v=y
\end{aligned}
$$

$$
\omega=\dot{\theta}
$$

$$
Y=\left(\begin{array}{l}
u \\
v \\
\omega \\
x \\
y \\
\theta \\
\lambda_{1} \\
\lambda_{2}
\end{array}\right)
$$

Onde $u, v$ e $\omega$ são as novas variáveis introduzidas.

\subsubsection{Resolução das equações}

Ser'á utilizado a descrição da solução do pêndulo como simplificação. $\mathrm{O}$ Adams simula o movimento do pêndulo resolvendo o sistema $x x x x$ de equações diferenciais e algébricas. Estas equações podem ser reescritas na forma compacta como:

$$
G(Y, \dot{Y}, t)=0
$$

Onde $G$ representa a matriz coluna das funções das variáveis desconhecidas e $\mathrm{Y}$ é a matriz coluna das variáveis:

As equações diferenciais do sistema descrito por (4.3.27) são de primeira ordem. O sistema como um todo é não linear. 
O sistema implícito de equações diferenciais algébricas em (4.3.23) não é prontamente transformado em um sistema explícito de equações diferenciais ordinárias no formato de (4.3.25), para o qual solvers padrões de integração como Runge-Kutta-Fehleberg ou Adams-Bashforth-Moulton podem ser aplicados.

Ainda, por conveniência, as equações diferenciais algébricas (4.3.27) são transformadas em um sistema de equações não-lineares, aproximando cada derivada na matriz coluna $\dot{Y}$ por uma fórmula de diferencial retrógrada (backward differenciation formula).

$$
\dot{Y}=f(Y, t)
$$

\subsubsection{O algorițo de Integração}

A matriz coluna $Y$ das variáveis na equação (4.3.25), é ainda conhecida como vetor de estados. A solução no ADAMS consiste na avaliação de $Y_{n}$ do vetor de estado $Y$ em tempos discretos:

$$
t_{1}<\ldots<t_{n-1}<t_{n}<\ldots t_{\text {final }}
$$

Distribuídos sobre um intervalo específico.

Após ter computado a solução de $G\left(Y_{j}, \dot{Y}_{j}, t_{j}\right)=0$ ter sido calculada para $j=0,1, \ldots, n-1$, o algoritmo de integração especifica um valor para:

$$
h=t_{n}-t_{n-1}
$$

e calcula a solução para: 


$$
G\left(Y_{n}, \dot{Y}_{n}, t_{n}\right)=0
$$

Dentro de um erro de tolerância $\in>0$.

Para cada uma das entradas em $Y$, um polinômio de predição de ordem $\mathrm{k}$ é formado através:

- das condições iniciais se a resolução do problema está no início ou

- da interpolação de valores calculados previamente.

Os polinômios são usados para estimar o valor da primeira derivada de cada variável no tempo $t_{n}$. Iniciando com os valores estimados para $Y_{n}$, um algoritmo de Newton-Raphson modificado corrige repetidamente a solução até que o critério de convergência seja satisfeito. Finalmente, os valores corrigidos são comparados com os valores estimados dos vetores de estado. A diferença deve estar menor que a tolerância do erro de integração especificado pelo usuário. A diferença entre o valor estimado e corrigido serve ainda para estimar o incremento de tempo otimizado e ainda a ordem do polinômio.

Se o erro de tolerância é satisfeito, o ADAMS prossegue para o próximo passo de integração com os valores otimizados de incremento e ordem. Do contrário, retorna aos valores originais de $h$ e $k$.

Para o caso específico do pêndulo, pode-se escrever os valores das variáveis e da primeira derivada: 


$$
Y=\left(\begin{array}{c}
u \\
v \\
\omega \\
x \\
y \\
\theta \\
\lambda_{1} \\
\lambda_{2}
\end{array}\right) \text { e } \dot{Y}=\left(\begin{array}{c}
\dot{u} \\
\dot{v} \\
\dot{\omega} \\
\dot{x} \\
y \\
\dot{\theta} \\
\lambda_{1} \\
\lambda_{2}
\end{array}\right)
$$

Se os valores respectivos das variáveis e derivadas de primeira ordem são conhecidos para tempo $t_{n}$, então os polinômios de primeira ordem estimados são:

$$
\left(\begin{array}{c}
u_{n}^{(0)}=u_{n-1}+\dot{u}_{n} h \\
v_{n}^{(0)}=v_{n-1}+\dot{v}_{n} h \\
\omega_{n}^{(0)}=\omega_{n-1}+\dot{\omega}_{n} h \\
x_{n}^{(0)}=x_{n-1}+\dot{x}_{n} h \\
y_{n}^{(0)}=y_{n-1}+\dot{y}_{n} h \\
\theta_{n}^{(0)}=\theta_{n-1}+\dot{\theta}_{n} h \\
\lambda_{1 n}^{(0)}=\lambda_{1 n-1}+\dot{\lambda}_{1 n} h \\
\lambda_{2 n}^{(0)}=\lambda_{2 n-1}+\dot{\lambda}_{2 n} h
\end{array}\right)\left(\begin{array}{l}
\dot{u}_{n}^{(0)}=\frac{u_{n}^{(0)}-u_{n-1}}{h} \\
\dot{v}_{n}^{(0)}=\frac{v_{n}^{(0)}-v_{n-1}}{h} \\
\dot{\omega}_{n}^{(0)}=\frac{u_{n}^{(0)}-u_{n-1}}{h} \\
\dot{x}_{n}^{(0)}=\frac{x_{n}^{(0)}-x_{n-1}}{h} \\
\dot{y}_{n}^{(0)}=\frac{y_{n}^{(0)}-y_{n-1}}{h} \\
\dot{\theta}_{n}^{(0)}=\frac{\theta_{n}^{(0)}-\theta_{n-1}}{h} \\
\dot{\lambda}_{1 n}^{(0)}=\frac{\lambda_{1 n}^{(0)}-\lambda_{1 n-1}}{h} \\
\dot{\lambda}_{2 n}^{(0)}=\frac{\lambda_{2 n}^{(0)}-\lambda_{2 n-1}}{h}
\end{array}\right)
$$

Onde o índice (0) indica a estimativa inicial da solução no tempo $t_{n}$.

Observa-se que a matriz-coluna dos valores estimados para a primeira derivada contém termos que estão em função das variáveis desconhecidas. Por exemplo, a fórmula da derivada retrógrada (backward differentiation 
formula) para $\dot{u}_{n+1}$ é dependente da variável $u_{n+1}$ e dos valores conhecidos de h e $u_{n}$. Esta peculiaridade auxilia na diferenciação entre métodos implícitos e explícitos.

As aproximações sucessivas de:

$$
G\left(Y_{n}^{(m)}, \frac{Y_{n}^{(m)}-Y_{n-1}}{h}, t_{n}\right)=0
$$

São determinadas fazendo-se:

$$
Y_{n+1}^{(m)}=Y_{n+1}^{(m-1)}+\Delta
$$

Para $m=1,2 \ldots$, até que

$$
\|\Delta\|<s \in
$$

Onde $\mathrm{s}$, o fator de escala, é $<<1$, e $\in$ é o erro de tolerância de integração.

Na notação matricial da equação (4.3.30), as variáveis desconhecidas são dadas como:

$$
Y_{n+1}=\left(\begin{array}{c}
u_{n+1} \\
v_{n+1} \\
\omega_{n+1} \\
x_{n+1} \\
y_{n+1} \\
\theta_{n+1} \\
\lambda_{x_{n+1}} \\
\lambda_{y n+1}
\end{array}\right)
$$

E $\Delta$ é a matriz-coluna das correções (ou deltas) para a solução.

O incremento $\Delta$ para cada iteração é dada pela solução do sistema 
linearizado:

$$
J \Delta=-G\left(Y_{n+1}^{(m-1)}, \frac{Y_{n+1}^{(m-1)}-Y_{n-1}}{h}, t_{n+1}\right)=0
$$

Onde $J$ é a matriz jacobiana para a matriz-coluna das funções de $G$. Nos algorítimos modificados de Newton-Raphson no ADAMS, a matriz jacobiana não é necessariamente reavaliada e refatorizada em cada iteração.

O algorítimo de Newton-Raphson para o sistema de equações não lineares requer a formação da matriz Jacobiana para o qual a entrada da iésima linha e a j-ésima coluna corresponde à derivada parcial da i-ésima equação com relação a j-ésima variável. Assim, para o pêndulo e seu sistema de equações não lineares, a matriz jacobiana é calculada como:

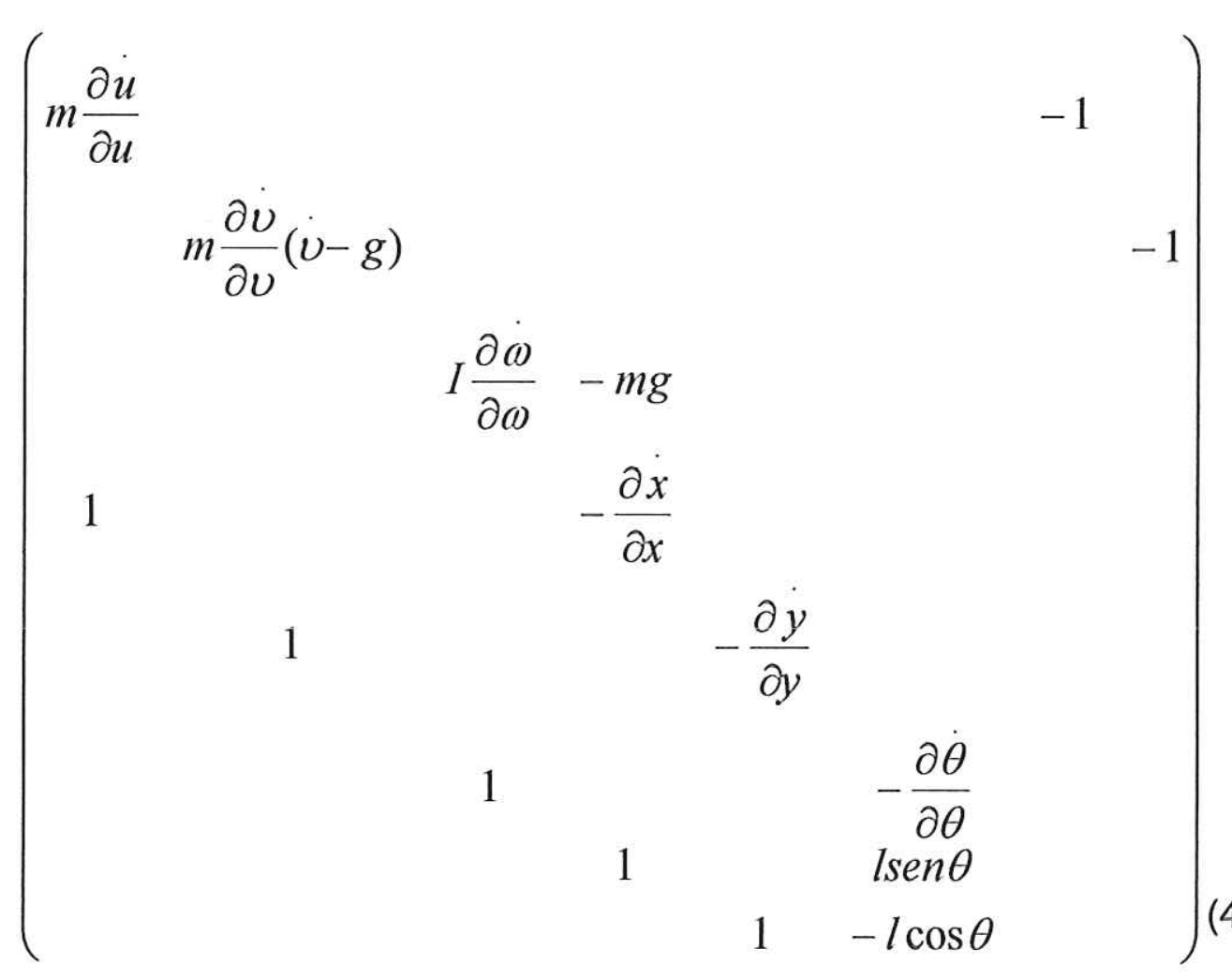

Onde os espaços em branco são identicamente zero. As fórmulas de diferenciação retrógrada (backward differentiation formula) na equação (4.3.29) definem a relação numérica entre a coordenada generalizada $q$ e sua primeira derivada $\dot{q}$. Da equação(4.3.29), para a fórmula de diferenciação retrograda 
(BDF),

$$
\frac{\partial q}{\partial q}=\frac{1}{h}
$$

Isto vale para cada variável $q$ no vetor de estado. Substituindo a equação (4.3.33) em (4.3.32), a matriz Jacobiana para primeira ordem torna-se:

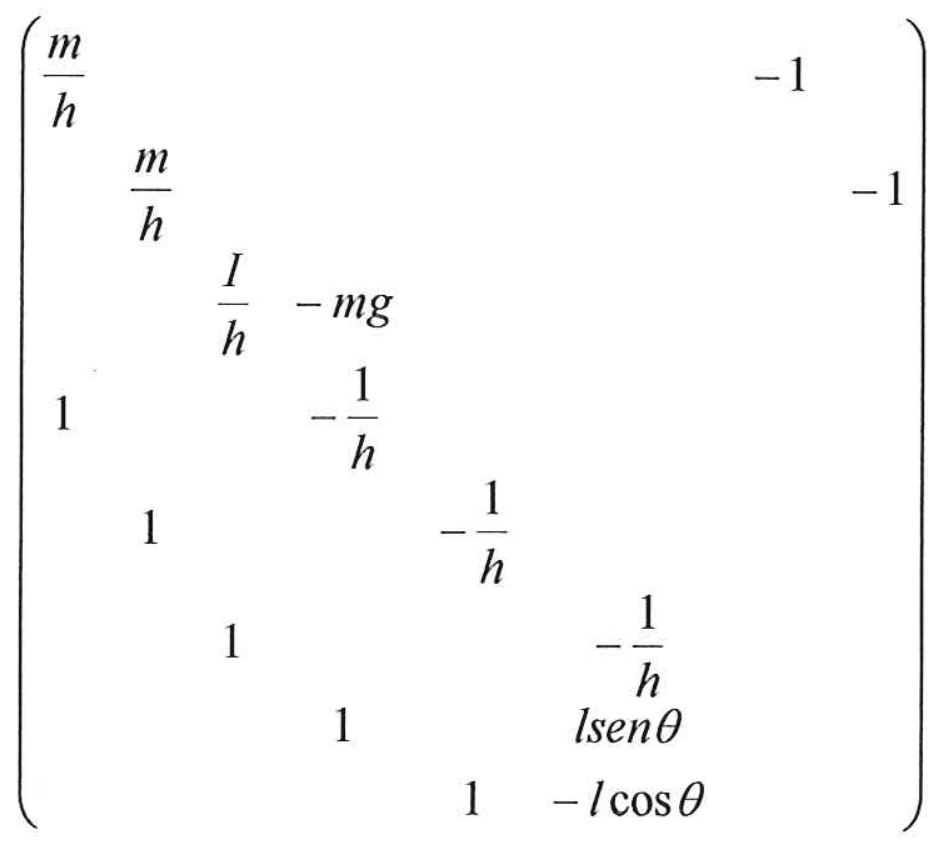

Para mais altas ordens, a equação (4.3.33) torna-se:

$\frac{\partial q}{\partial q}=\frac{1}{\beta h}$, onde $\beta$ depende da ordem da fórmula.

Se o processo interativo falhar, o tamanho do passo de integração é diminuído e outro passo é tentado. Usuários de ADAMS estão familiarizados com mensagens informando que o tamanho do passo foi reduzido em demasia, e mesmo assim nenhuma convergência foi atingida. Neste caso, o usuário provavelmente deve revisar o modelo e mudar alguns parâmetros de simulação, ou tentar um integrador diferente. 


\section{Construção de modelo Multicorpos e validação}

\subsection{Introdução}

Neste capítulo, será apresentado um modelo Multicorpos de uma lavadora comercial de eixo vertical BRASTEMP, com $10 \mathrm{~kg}$ de capacidade. $\mathrm{O}$ intuito do mesmo é auxiliar no estudo do comportamento dinâmico da lavadora, bem como compará-lo com resultados experimentais para sua validação. 0 modelo servirá ainda como base para estudos posteriores em componentes, através da obtenção de esforços sobre a área de interesse. Por fim, o modelo auxiliará os engenheiros da empresa no estudo e validação de eventuais modificações futuras, propostas ao produto.

A lavadora a ser estudada apresenta sua unidade de lavagem suspensa por quatro conjuntos de suspensão presos ao gabinete. Esta configuração de suspensão se enquadra na classificação hang suspension, muito usada no mercado sul americano e asiático.

Este modelo utiliza um sistema de balanceamento por anel hidrodinâmico, cujo princípio de funcionamento foi abordado no Capitulo 3.

\subsection{Construção do Modelo}

O modelo Multicorpos da lavadora foi criado no software ADAMS/View. A abordagem de estudo utilizada neste trabalho pode ser resumida nas seguintes etapas, representadas pelo diagrama da Figura 5.1. 


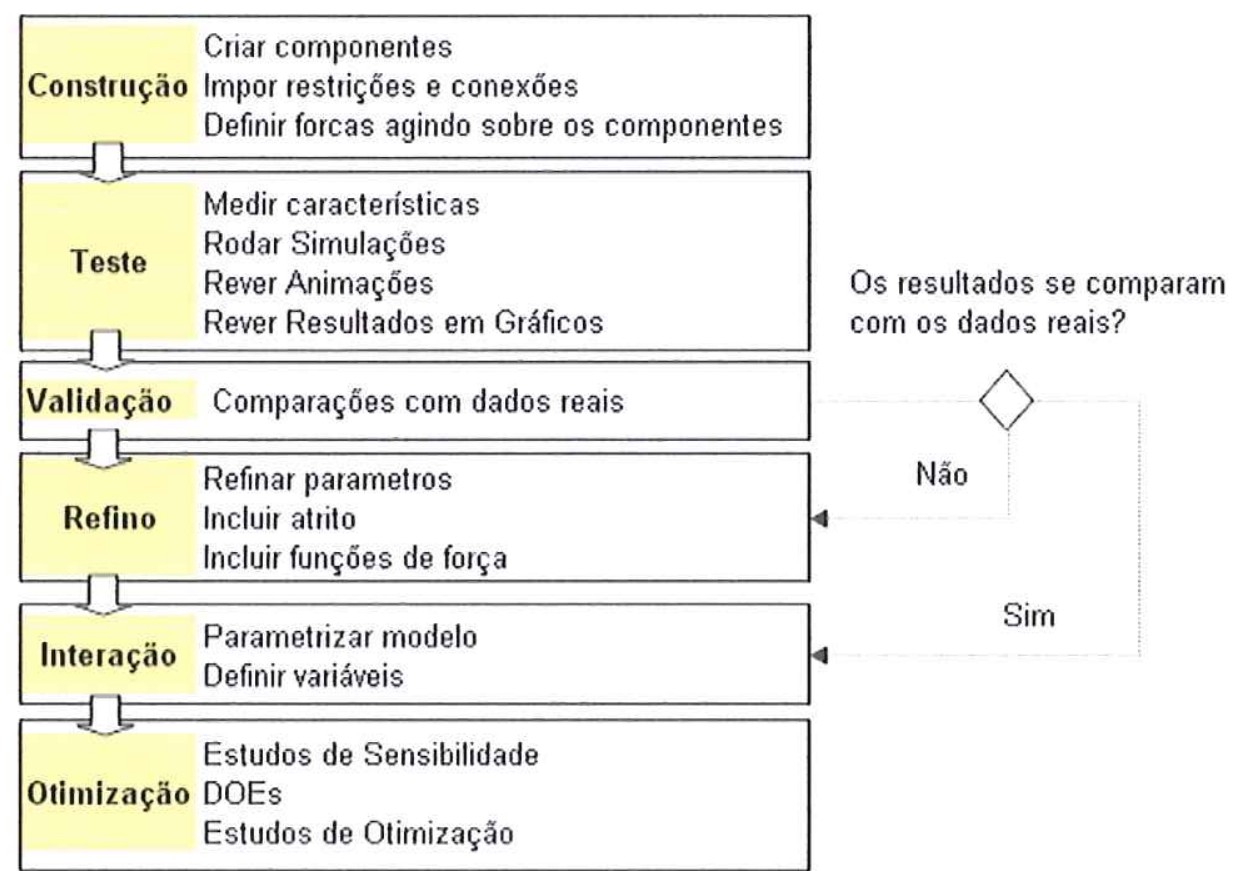

Figura 5.1 - Etapa de Construção do Modelo MBS-Fonte Adams reference manual (1992)

A construção do modelo consistiu na união dos principais componentes da máquina, assumidos como rígidos, através de conexões e juntas disponíveis no ADAMS. Naturalmente, a escolha das conexões deve ser feita de forma criteriosa por parte do engenheiro. Isto exige grande conhecimento e compreensão dos conceitos físicos que sustentam o modelo, de forma a representar de forma eficiente o comportamento da máquina como um todo.

As geometrias dos componentes foram previamente desenvolvidas em ambiente CAD com auxílio do software PRO/ENGINEER. Uma vez desenvolvido o modelo em CAD, sua geometria foi importada para o ADAMS com formato de estereolitografia (stl). As massas e matrizes de inércia dos componentes envolvidos, bem como a posição do CG, foram calculados no software PRO/ENGINEER, através da inserção da densidade de seus respectivos materiais. Algumas partes tiveram suas propriedades confrontadas com medições em balança, para se atestar a acuracidade das informações disponibilizadas pelo software. Tais propriedades foram então inseridas no ambiente ADAMS/Niew. A Figura 5.2 exemplifica este processo de entrada de parâmetros de um componente específico. Neste caso, o software ADAMS foi 
alimentado com as propriedades de massa e inércia do componente, bem como a posição do CG do componente segundo um sistema de coordenadas global.

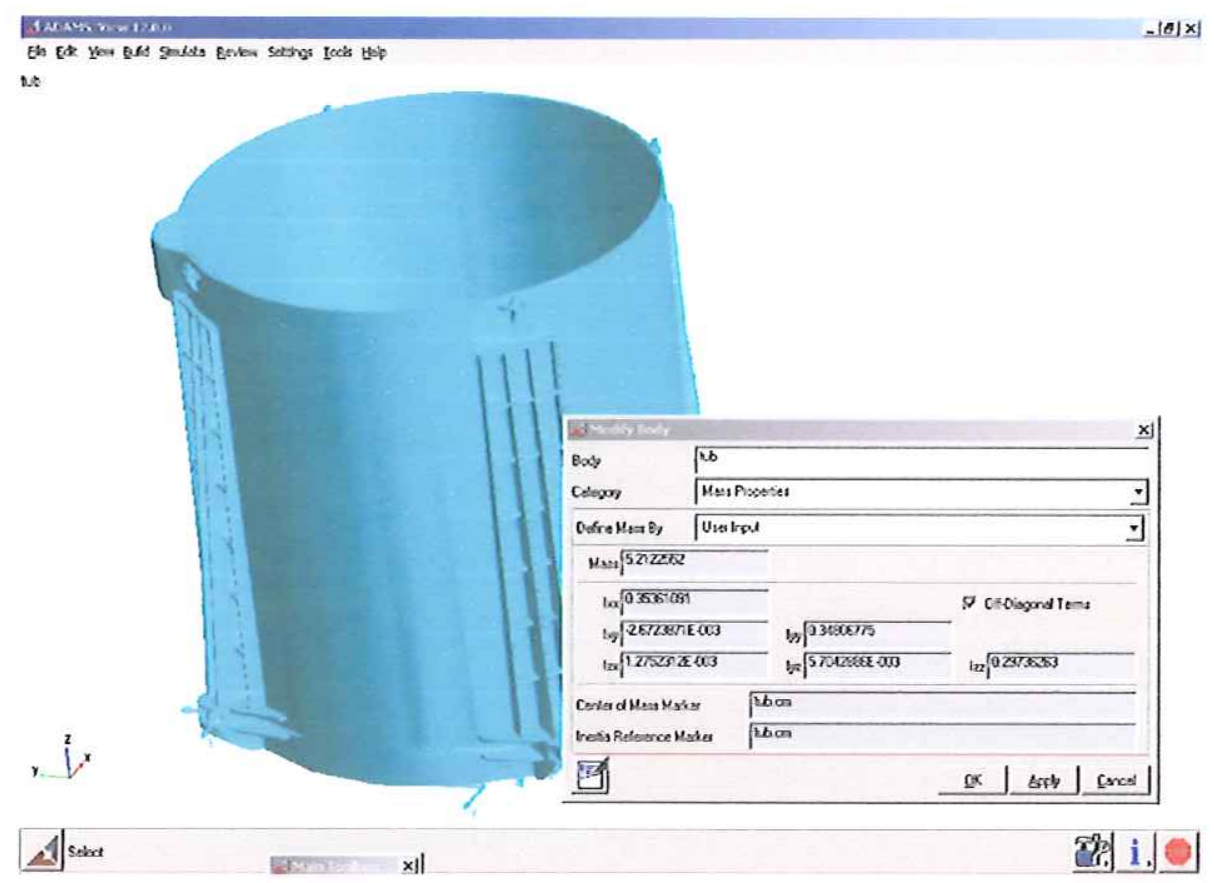

Figura 5.2 - Exemplo de componente e seu tensor de massa e inércia

O processo de construção do modelo em ambiente virtual segue os mesmos passos que seriam usados na construção de um protótipo físico. Uma técnica bastante usual consiste em se montar e testar pequenos elementos ou subsistemas de seu modelo completo, antes de construí-lo e testá-lo por inteiro, numa só fase.

Isto permite que o engenheiro caminhe passo-a-passo e assegure que cada subsistema funcione adequadamente antes de formar todo o conjunto.

A topologia completa do modelo apresenta 20 corpos rígidos e 26 juntas, como descrito na Tabela 5.1. Por motivos de confidencialidade, a descrição completa e detalhada do modelo será omitida. Basicamente, o modelamento envolve a criação de componentes-chave da máquina e a remoção de certos graus de liberdade, de acordo com as inter-relações entre as partes. A remoção de graus de liberdade é feita através da introdução de juntas ou restrições. Restrições removem um ou mais graus de liberdade do sistema, dependendo de seu tipo. A restrição pode remover graus de liberdade (GDL) 
de rotação ou translação, dependendo de sua natureza.

O software fornece um número estimado de GDL usando a regra de Gruebler, descrita abaixo:

GDL.do.sistema $=($ número.de.partes.móveis * 6GDL/ parte $)-$ $\sum n_{o}$ de.restrições * $n_{o} G D L($ restrição)

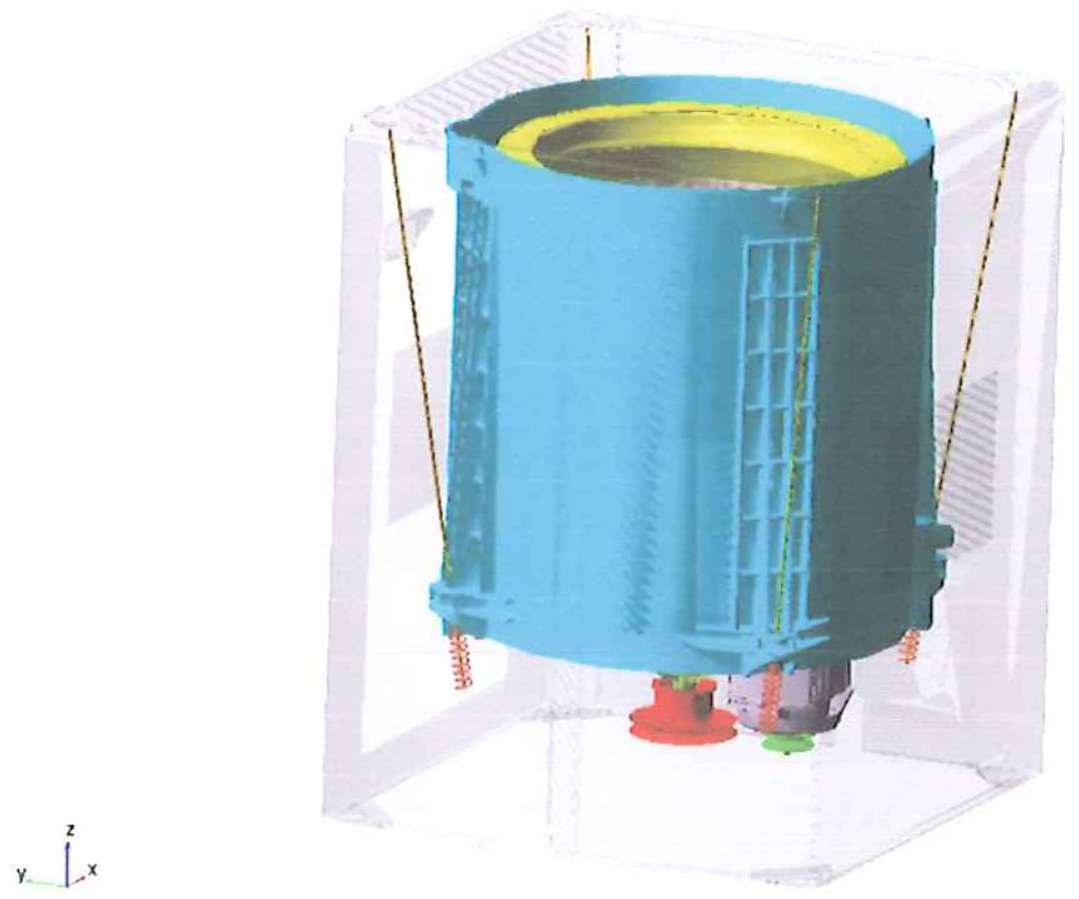

Figura 5.3 - Modelo Multicorpos da Lavadora BRASTEMP 24“ em ADAMS

A Figura 5.3 representa o modelo gerado neste trabalho. Tal modelo apresenta 16 Graus de Liberdade e 20 partes móveis. A Tabela 5.1 representa a descrição do modelo dada pelo ADAMS. 


\section{VERIFY MODEL: .mod24}

16 Gruebler Count (approximate degrees of freedom)

20 Moving Parts (not including ground)

2 Revolute Joints

9 Spherical Joints

4 Translational Joints

7 Fixed Joints

1 Inline Primitive_Joints

1 Perpendicular Primitive_Joints

1 Motions

1 Couplers

16 Degrees of Freedom for .mod24

Tabela 5.1 Verificação do Modelo ADAMS

O sistema de suspensão é composto por quadro varetas dispostas nos quatro cantos do gabinete, suportadas por cantoneiras e vinculadas à mesma através de apoios plásticos de formato esférico. A outra extremidade é fixada ao tanque através do copo de amortecimento, cujo formato também se assemelha a um contato esférico.

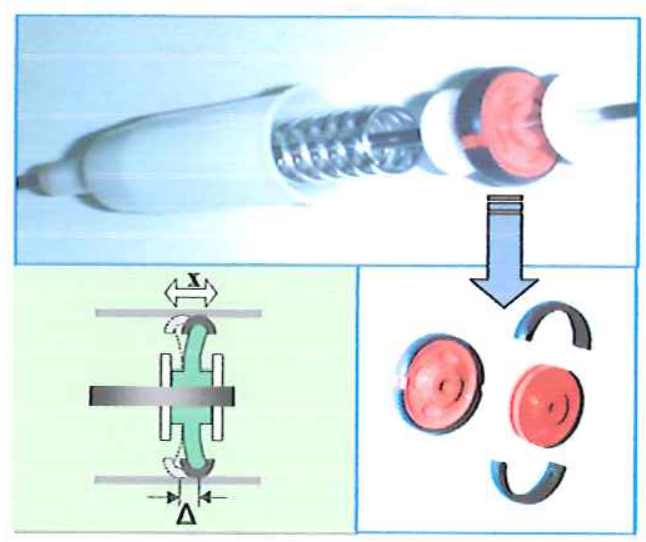


O amortecimento é basicamente caracterizado por atrito seco e seus parâmetros foram levantados experimentalmente por uma empresa especializada. A constante de elasticidade da mola usada está na faixa de $2000 \mathrm{~N} / \mathrm{mm}$ e seu comprimento livre é de $94 \mathrm{~mm}$.

O comportamento do anel hidrodinâmico é simulado através de uma subrotina em FORTRAN desenvolvida pela Whirlpool Corporation, cujos esforços são aplicados pontualmente através de um vetor de forças generalizadas, disponível no ADAMS (General Force Vector). O anel-hidro utilizado no modelo de lavadora em questão tem da ordem de 1,6 L de água doce. Basicamente, os parâmetros de entrada para simulação do anel-hidro são:

- Ri: Raio interno do anel

- Ro: Raio externo

- $\rho:$ densidade do fluido

- n: numero de câmaras do anel

- h: altura

- $\quad \mathrm{t}$ : espessura da parede do anel-hidro.

Através destes parâmetros e das equações (3.3.8), (3.3.9) e (3.3.10), são calculadas as forças de restituição e momentos produzidos pelo deslocamento de água no anel. A subrotina descreve o comportamento do líquido no anel baseado na excentricidade instantânea e é atualizada a cada passo de integração do software.

Portanto, os efeitos transientes dinâmicos do fluido bem como a iteração do mesmo com aletas internas no anel são negligenciadas. Como será discutida posteriormente, esta simplificação é responsável pela adição de erro no modelo dinâmico da lavadora, especialmente no transiente.

O sistema de transmissão é equipado com motor de $1 / 3 \mathrm{HP}$ e a transmissão é feita com correia poli V. A máquina tem uma rampa de aceleração da ordem de 23 segundos na centrifugação para a carga em estudo, cuja rotação final está na faixa de 760 rpm. Assim, aplicou-se ao eixo movido uma rampa que correspondesse a estes valores, como mostrado na Figura 5.5 . 


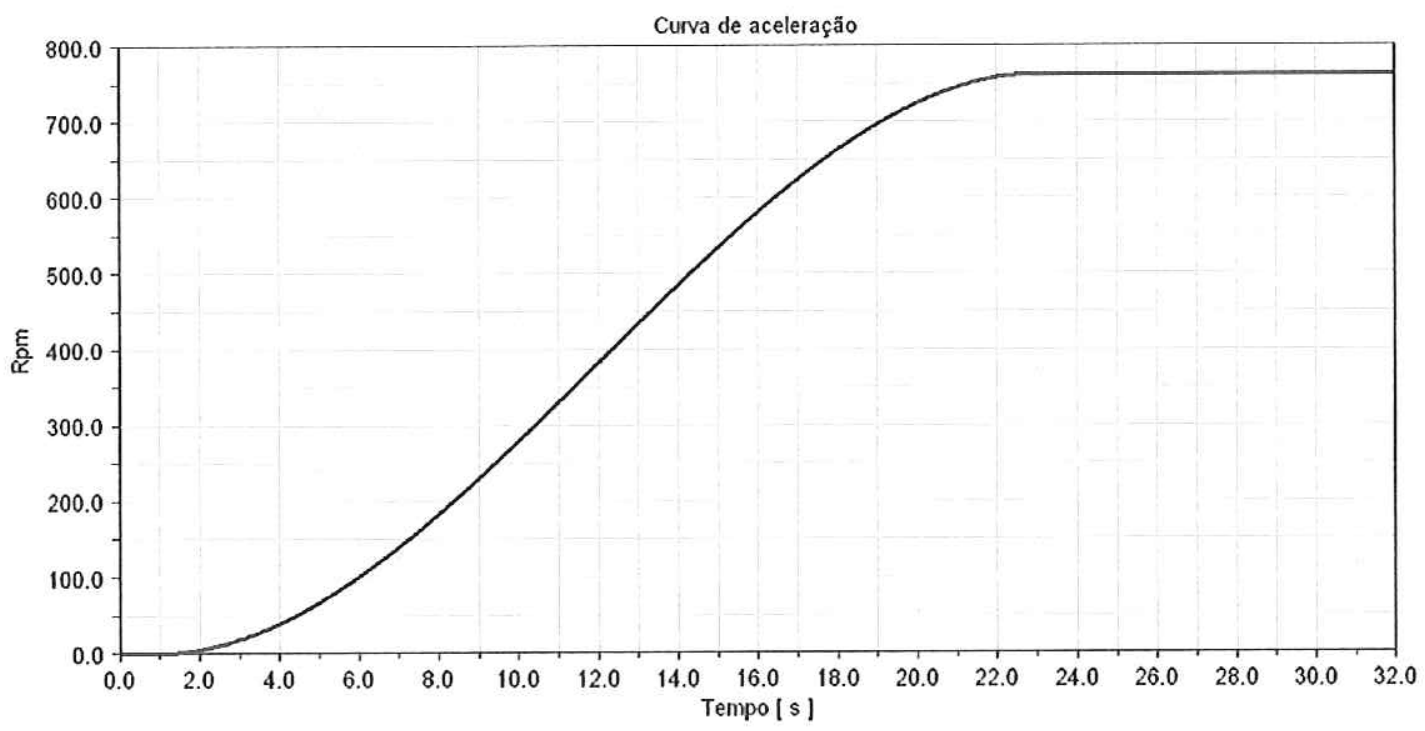

Figura 5.5 -Rampa de aceleração

Os pés e cantoneiras de fixação, onde a máquina é apoiada, estão modelados através de elementos do tipo BUSHING, cuja rigidez linear e torsional foram determinadas através da analise de elementos finitos (EF).

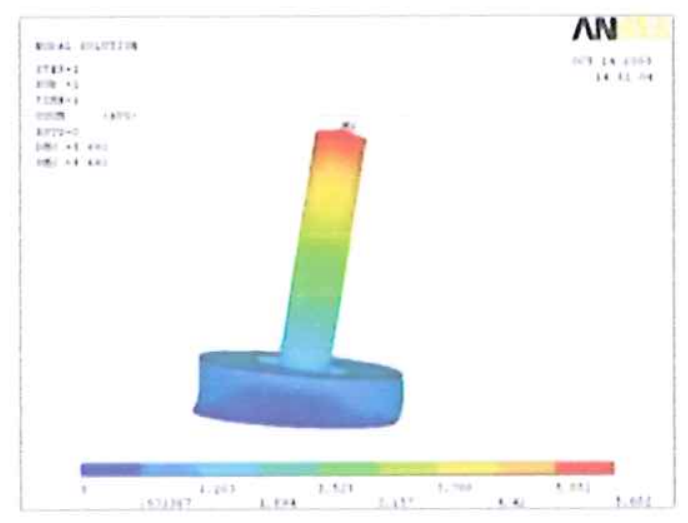

Figura 5.6 - Modelo em EF do pé de uma lavadora para caracterização de rigidez

A seguir, o procedimento de medição da lavadora real será descrito para comparação futura e validação.

\subsection{Análise experimental e validação do Modelo}

\subsubsection{Equipamentos e forma de medição}

Um das mais importantes variáveis-resposta de uma lavadora de roupas é o deslocamento do tanque no plano de rotação. Através destes 
deslocamentos, é possível construir a órbita do tanque durante centrifugação.

Tal parâmetro é de vital importância para se prever a colisão do tanque contra o gabinete, durante a fase de remoção de água das roupas, na etapa de centrifugação. Além disso, a minimização da amplitude do movimento pode significar uma redução de ruído da lavadora. A Figura 5.7, extraída de Türkay (1992), mostra um exemplo de deslocamento obtido em uma lavadora de eixo vertical, via simulação numérica.
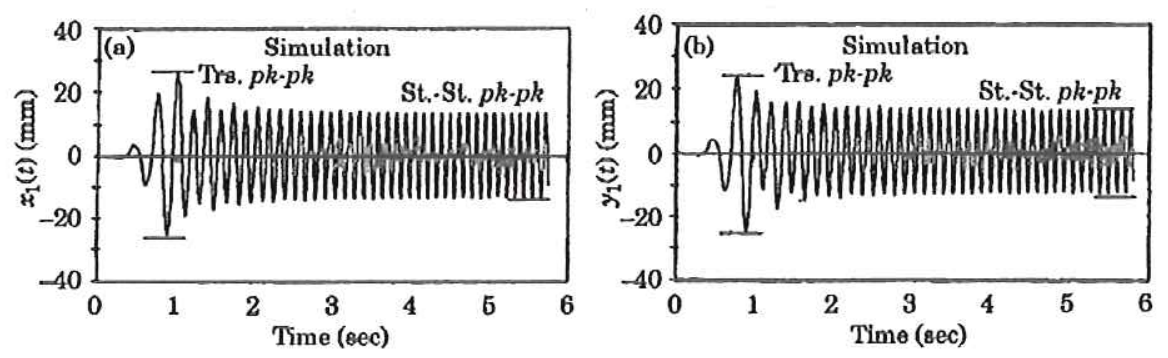

Figura 5.7-Deslocamento do tanque de uma lavadora de eixo horizontal em centrifugação. Fonte: Türkay (1992)

Através do uso de acelerômetros localizados no topo e na base do tanque, mediu-se os deslocamentos superiores e inferiores, pela integração dupla da aceleração medida. Foi possível então comparar tais valores com o protótipo virtual em ADAMS e ajustar o modelo de forma satisfatória. 


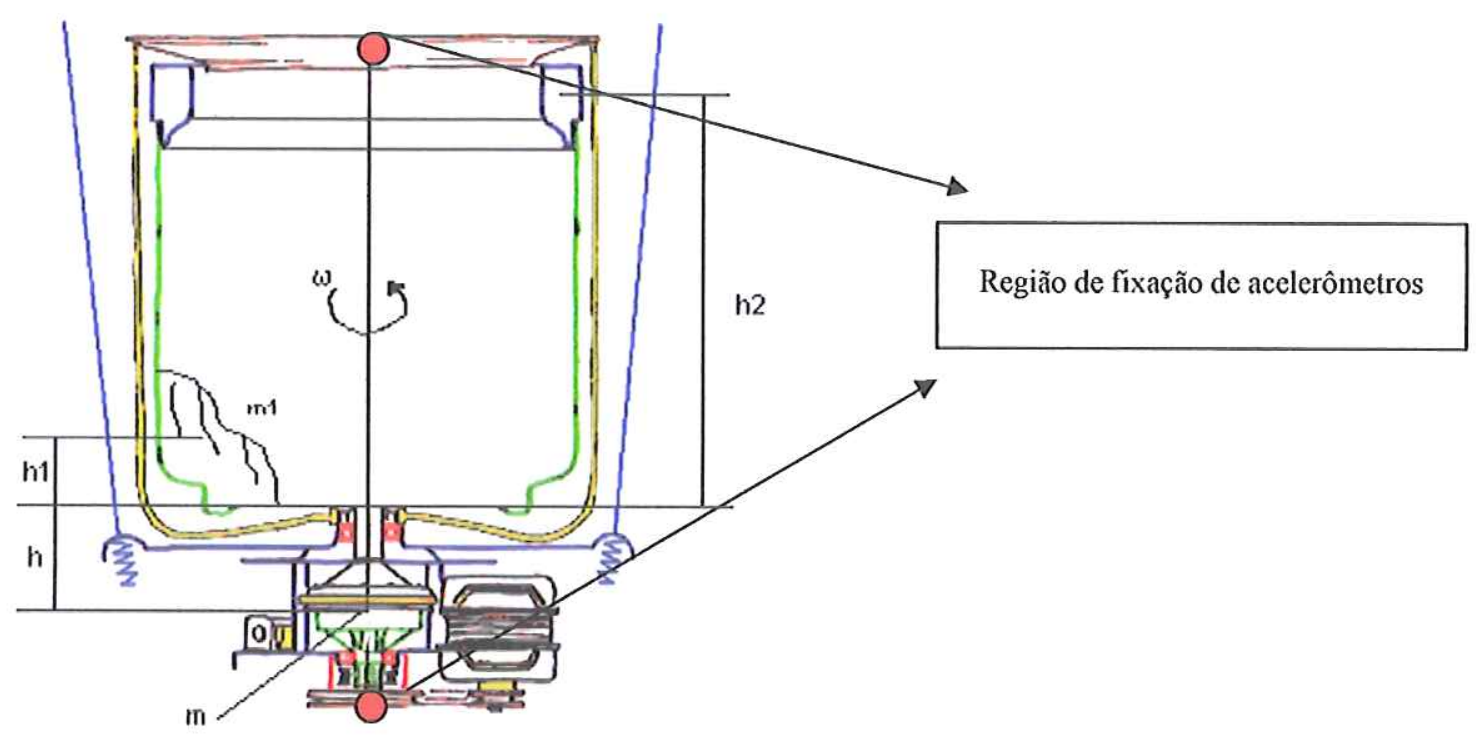

Foram utilizados dois acelerômetros triaxiais do fabricante Bruel \& Kajaer, modelo 4506B. As figuras abaixo ilustram o design do acelerômetro, bem como sua carta de calibração.
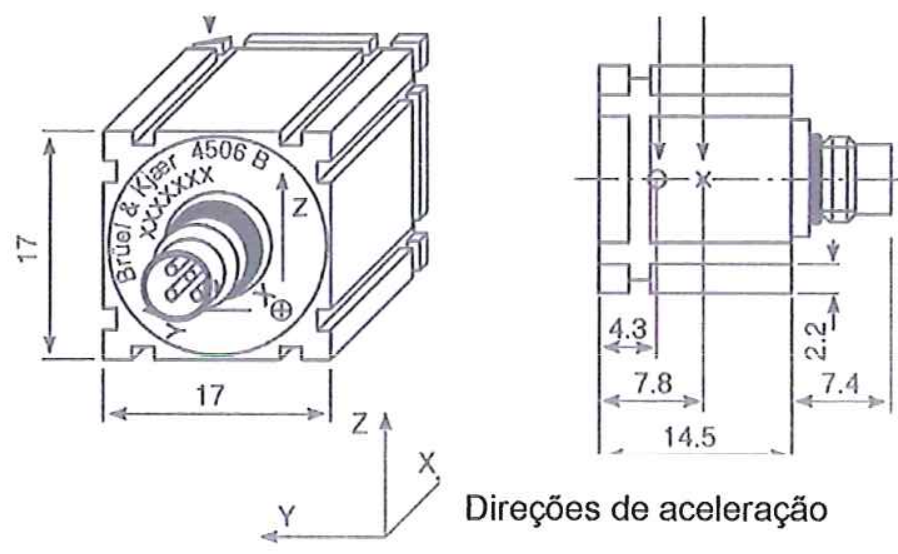

Direçöes de aceleração

Dimensões em mm

Figura 5.8 -Design mostrando acelerômetro utilizado 


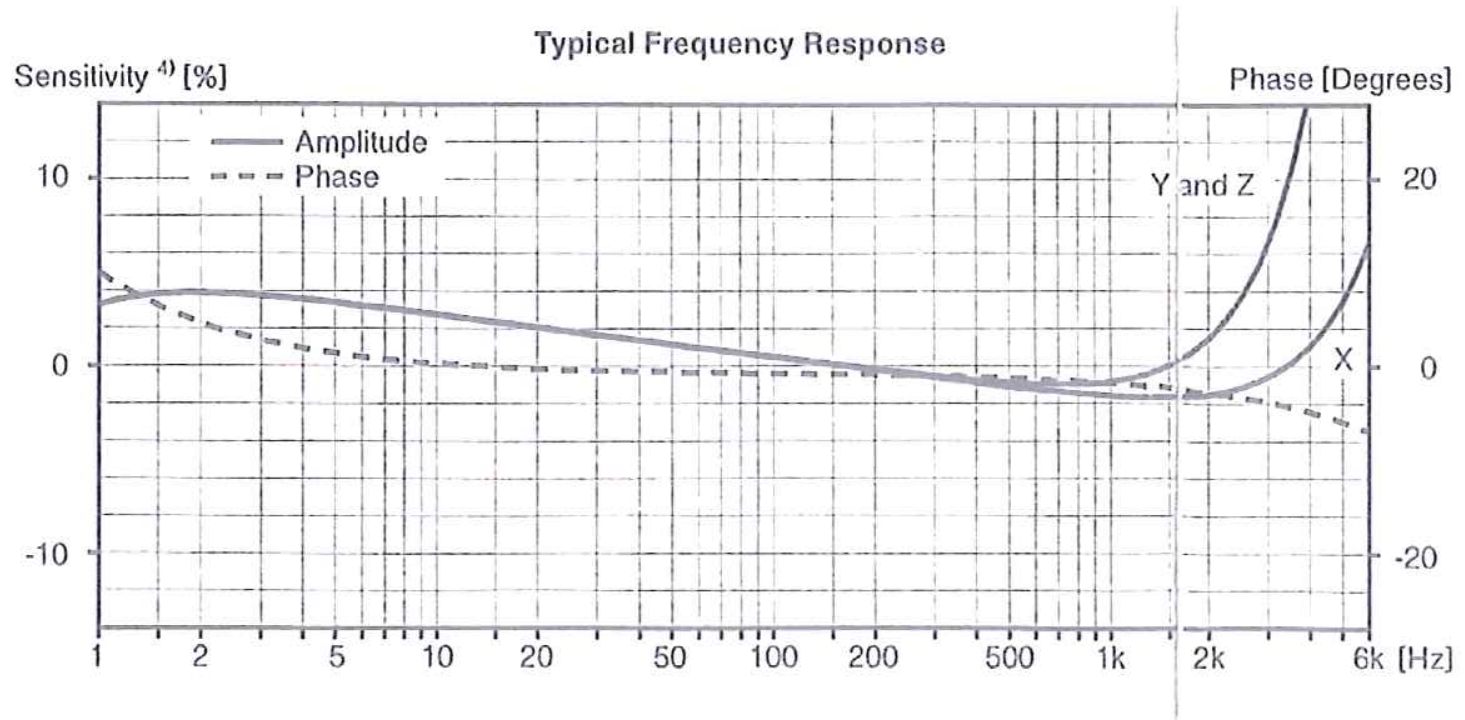

Figura 5.9-Resposta em freqüência do acelerômetro B\&K 4506B

\section{Calibration Chart for \\ Triaxial DeltaTron ${ }^{\circledR}$ Accelerometer Type 4506 B}

Serial No.: ...2337393.

Reference Sensitivity " at $159.2 \mathrm{~Hz}$

$\left(\omega=1000 \mathrm{~s}^{-1}\right), 20 \mathrm{~ms}^{-2} \mathrm{RMS}$,

$4 \mathrm{~mA}$ supply current and ...24.... ${ }^{\circ} \mathrm{C}$ :

Frequency Range: Amplitude $( \pm 10 \%)$ :

Phase $\left( \pm 5^{\circ}\right)$ :

Mounted Resonance Frequency:

Transverse Sensitivity re Ref. Sensitivity:

Maximum (at $30 \mathrm{~Hz}, 100 \mathrm{~ms}^{-2}$ ):

Calculated values for TEDS ${ }^{3)}$ :

Resonance frequency:

Quality factor @ fres:

Amplitude slope:

High pass cut-off frequency:

Low pass cut-ofl frequency:

Measuring Range:

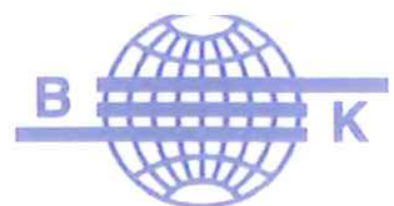

Brüell \& Kjæer

$X-\quad Y-\quad Z-\quad$ axis

$10.11 \quad$. $9.86 \quad 9.98 \mathrm{mV}^{-2} \mathrm{~ms}^{-2}$ .99.1. …7.7. .97.9. $\mathrm{mV} / \mathrm{g}$

1- $6 \mathrm{k} \quad 1-3.5 \mathrm{k} \quad 1-3.5 \mathrm{k} \quad \mathrm{Hz}$

$3-3 k \quad 3-3 k \quad 3-3 k \quad H z$

$\begin{array}{llll}19 & 10 & 10 & \mathrm{kHz}\end{array}$

$<5<5 \quad<5 \quad \%$

$\begin{array}{llll}16,1 . & 10,0 & 9.9 \ldots \ldots & \mathrm{kHz}\end{array}$ $.7 \ldots \ldots . .360 \ldots . .364 \ldots$ $\begin{array}{ccc}-1.8 & -2.6 & -2.4 \%\end{array}$ $\begin{array}{llll}0.09 & 0.32 & 0.29 & \mathrm{~Hz}\end{array}$ $.750 \ldots .499 .143 \ldots . \quad \mathrm{kHz}$ $\pm 700 \mathrm{~ms}^{-2}$ peak ( $\pm 70 \mathrm{~g}$ peak)

Figura 5.10 - Carta de calibração do acelerômetro B\&K 4506B

Deseja-se medir o deslocamento lateral do tanque durante o processo de centrifugação, cuja freqüência de excitação varia de 0 a 12,6 Hz (rotação final da máquina). Foi utilizado o software do equipamento Pulse para dupla 
integração do sinal de aceleração, a fim de obter-se o sinal de deslocamento.

O software introduz um filtro passa alta cuja freqüência de corte é de 0.7 $\mathrm{Hz}$. Este é o filtro com mais baixa freqüência oferecida pelo sistema de aquisição.

Vale lembrar que o acelerômetro não oferece boa sensibilidade abaixo de $1 \mathrm{~Hz}$ como mostra a carta de calibração. Esta limitação no sistema faz com que não sejamos capazes de captar alguma freqüência abaixo de $1 \mathrm{~Hz} c o m$ precisão, que possa estar presente no sistema, como por exemplo alguns módulos pendulares de baixa freqüência, como será mostrado posteriormente.

Equipamento a laser para medição direta de deslocamento ou ainda LVDT seriam os equipamentos mais indicados para este tipo de medição, devido à capacidade dos mesmos em se medir o deslocamento em baixas freqüências.

O laser apresenta um custo relativamente alto, enquanto que o LVDT apresenta problemas de desgaste, especialmente pelo tipo de medição proposto.

\subsection{Resultados de Deslocamento Medidos}

\subsubsection{Análise experimental no domínio do tempo}

A análise a seguir foi feita utilizando-se cargas de chumbo colocadas no interior do cesto, simulando uma carga distribuída de $12 \mathrm{~kg}$ juntamente com 1,5 $\mathrm{kg}$ desbalanceados. 
Os gráficos abaixo mostram o deslocamento superior e inferior do tanque, nas direções $X$ e $Y$ como ilustrado (Figura 5.11):

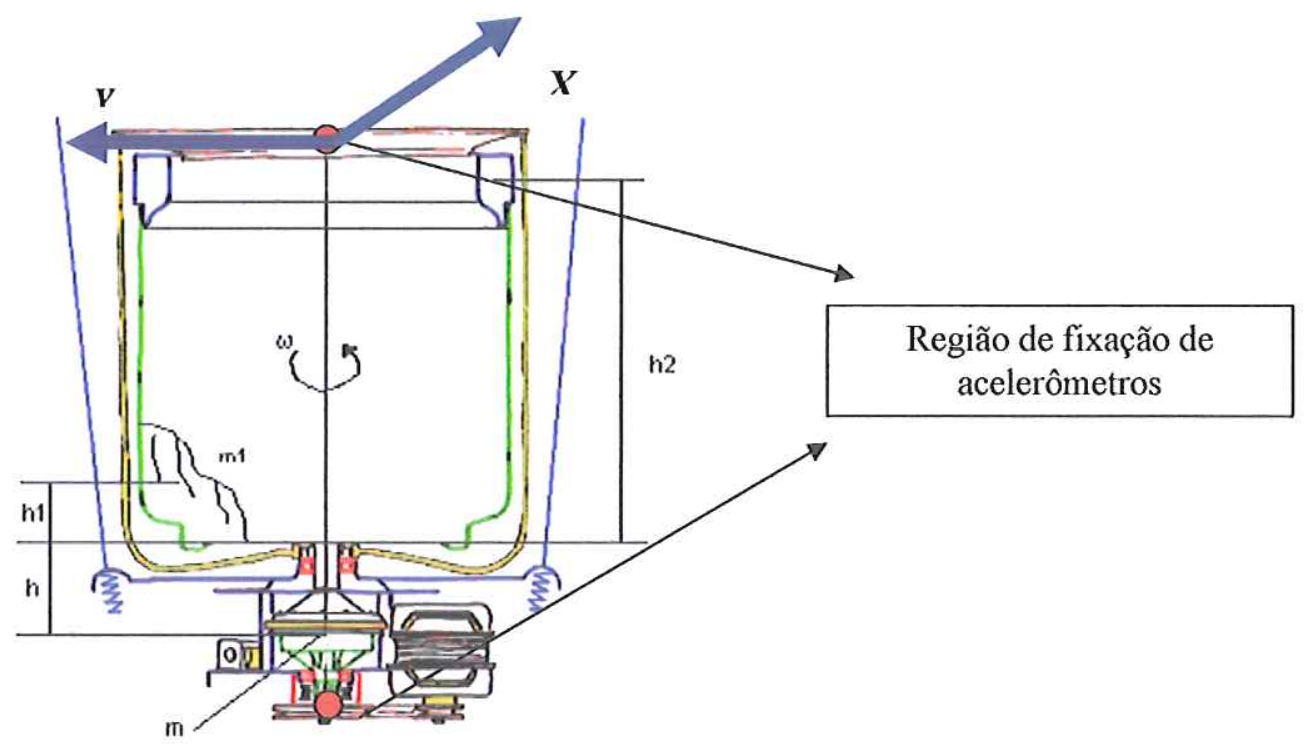

Figura 5.11 - Ilustração do sistema de coordenadas utilizado

Os gráficos abaixo ilustram os deslocamentos superiores experimentais do tanque em milímetros.

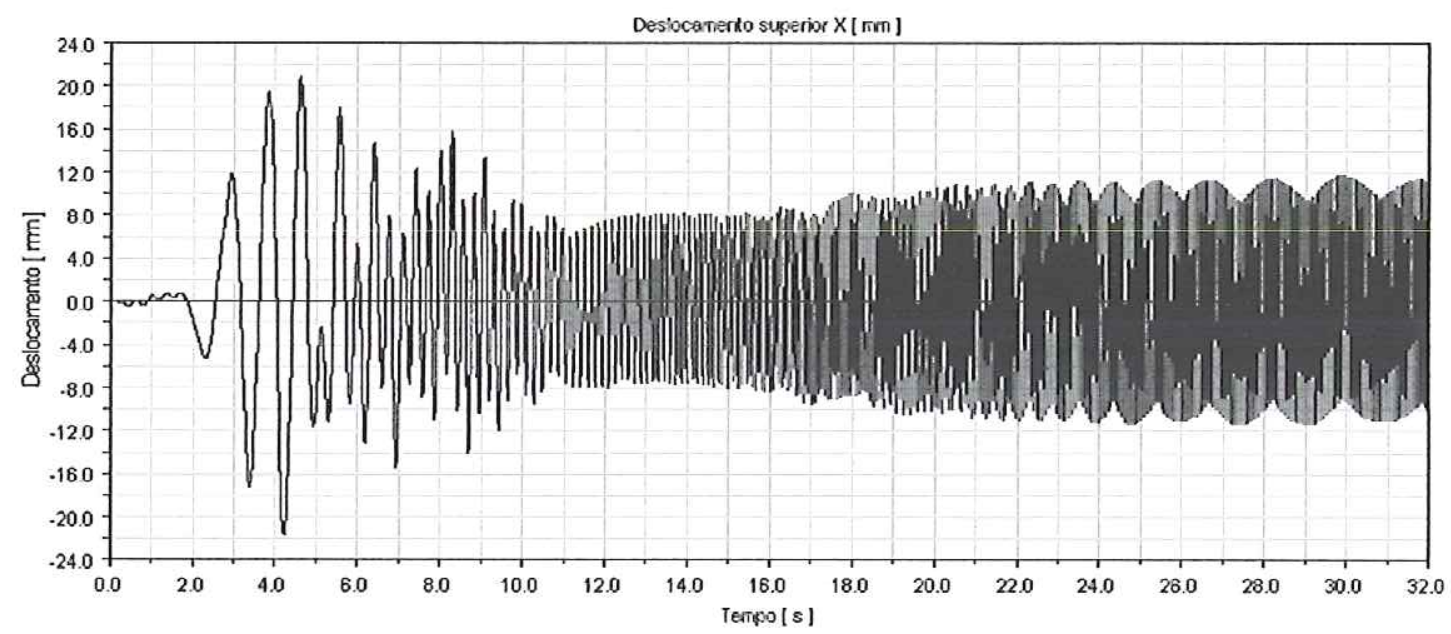

Figura 5.12 - Deslocamento superior do tanque na direção $X$ 


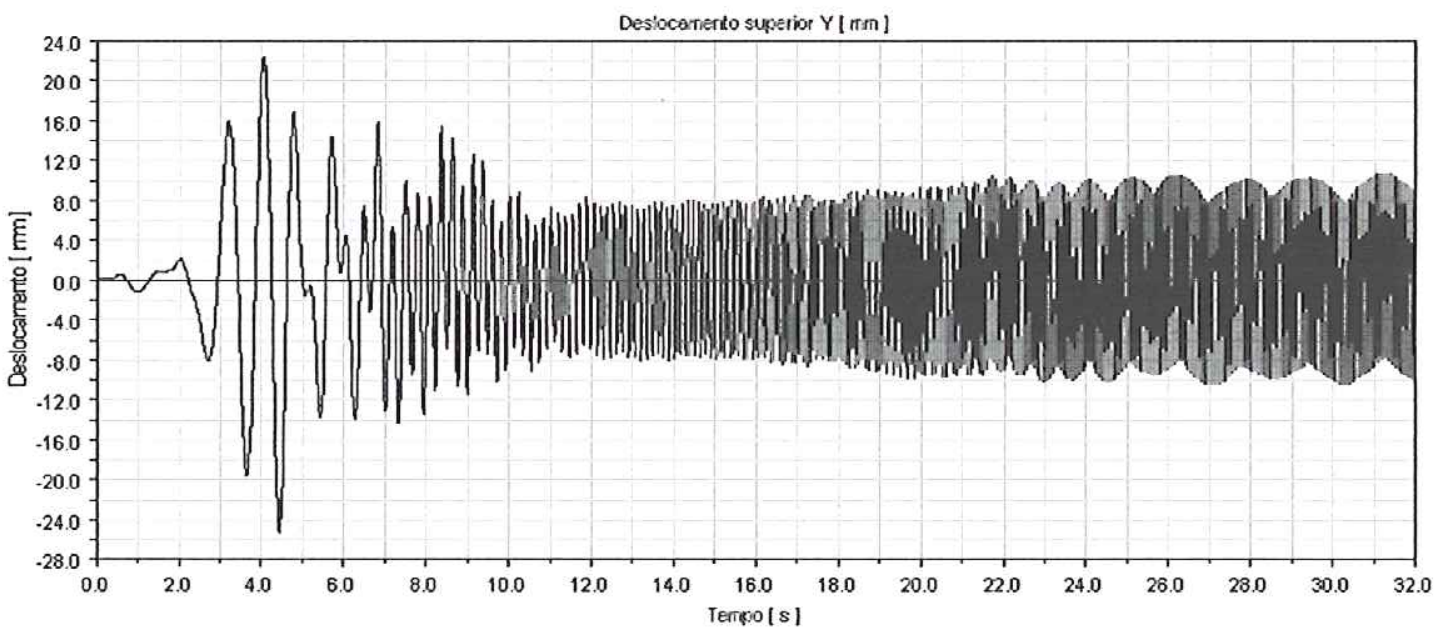

Figura 5.13 - Deslocamento superior do tanque na direção $Y$

Plotando o deslocamento superior $Y$ contra $X$, obtém-se o gráfico da órbita superior, como ilustrado abaixo:

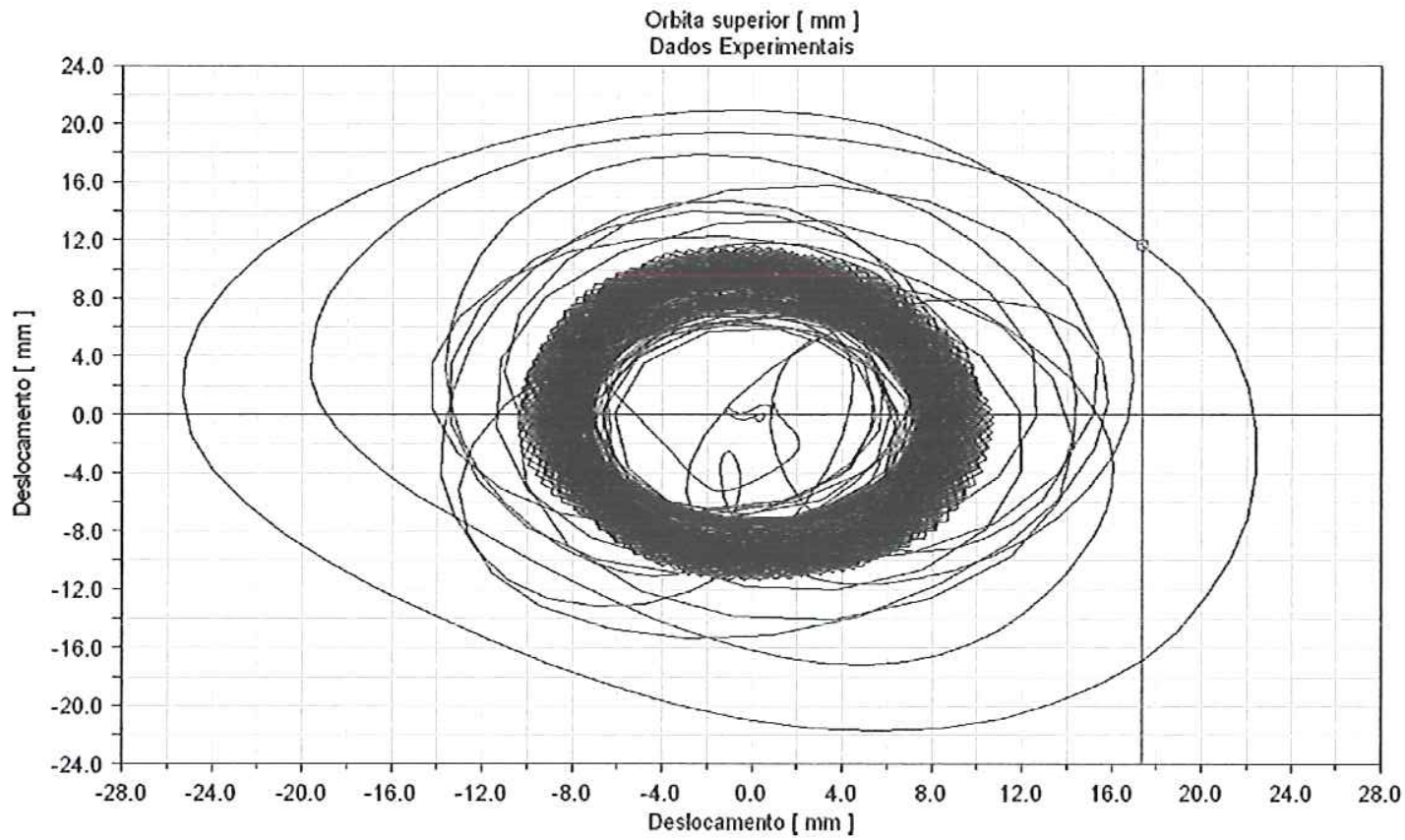

Figura 5.14 - Órbita superior do tanque experimental

Pode-se ainda calcular o raio da órbita da lavadora através da composição dos valores de $\mathrm{X}$ e $\mathrm{Y}$. O resultado é mostrado abaixo: 


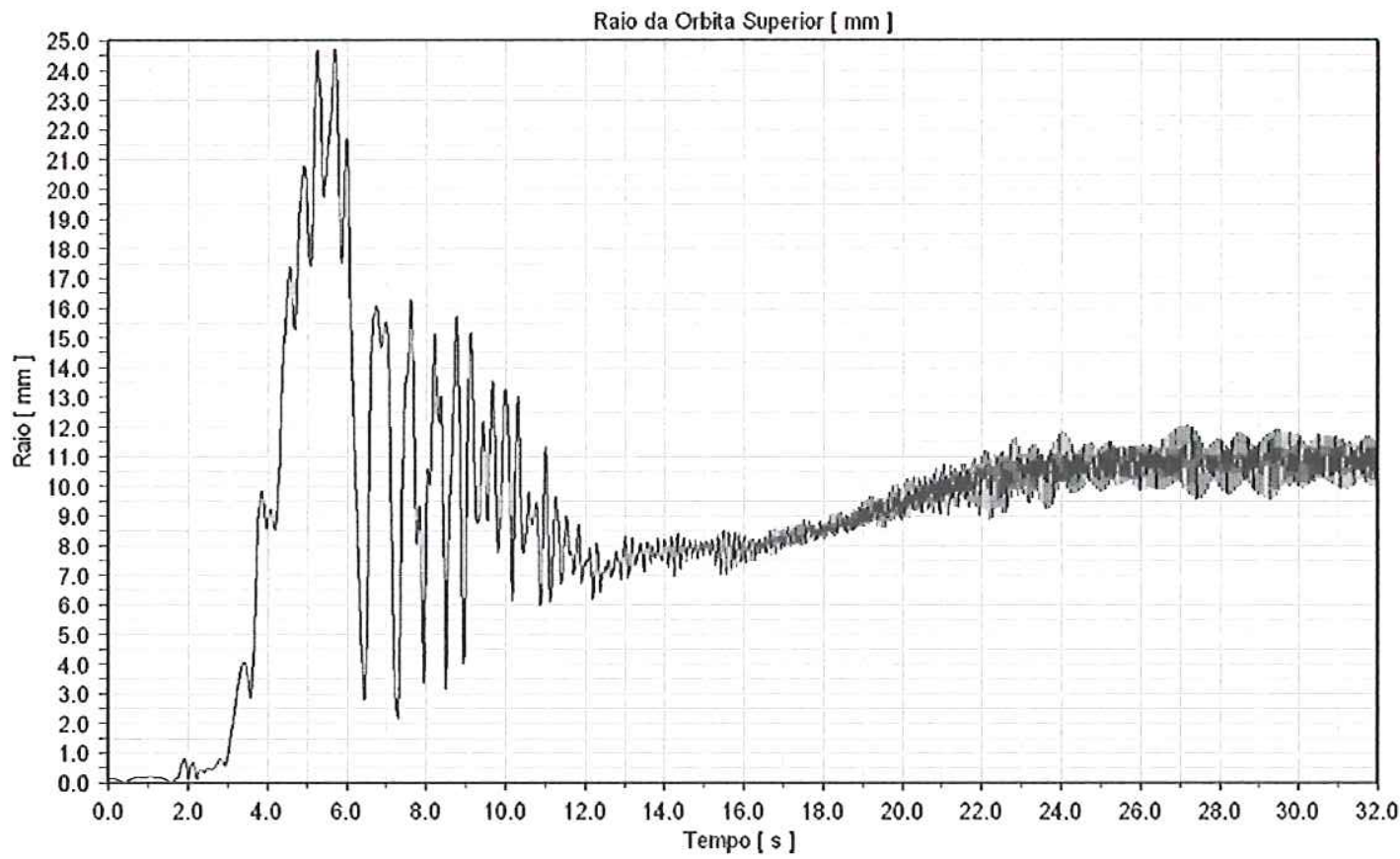

Figura 5.15 - Raio da órbita superior experimental

Similarmente, foram feitas as medições para os deslocamentos inferiores, obtendo-se os resultados abaixo:

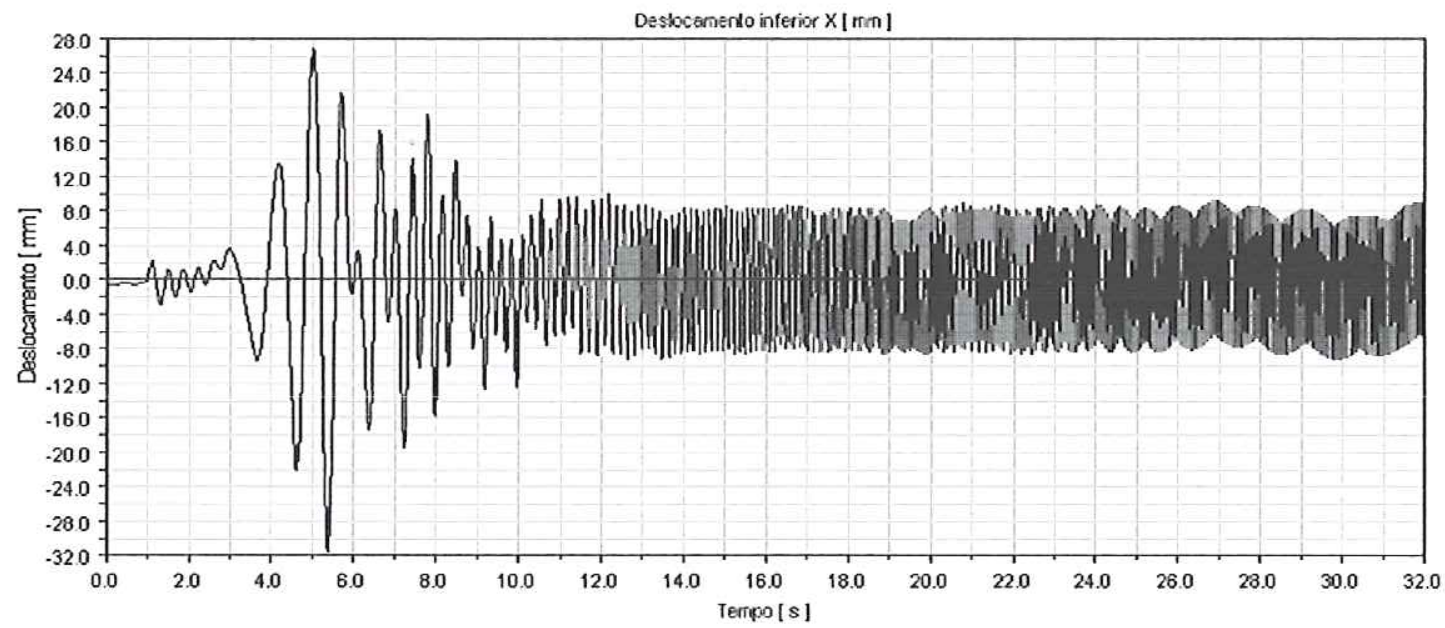

Figura 5.16 - Deslocamento inferior experimental do mecanismo na direção $X$ 


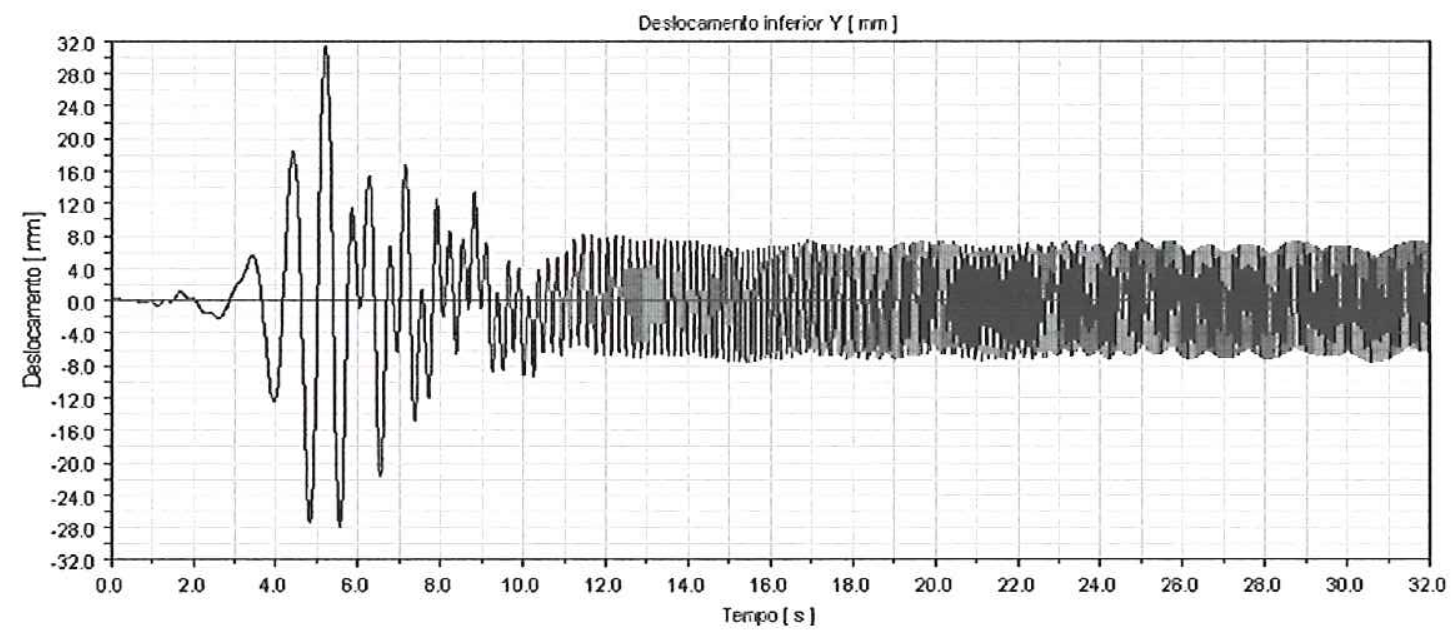

Figura 5.17 - Deslocamento inferior experimental do mecanismo na direçäo $Y$

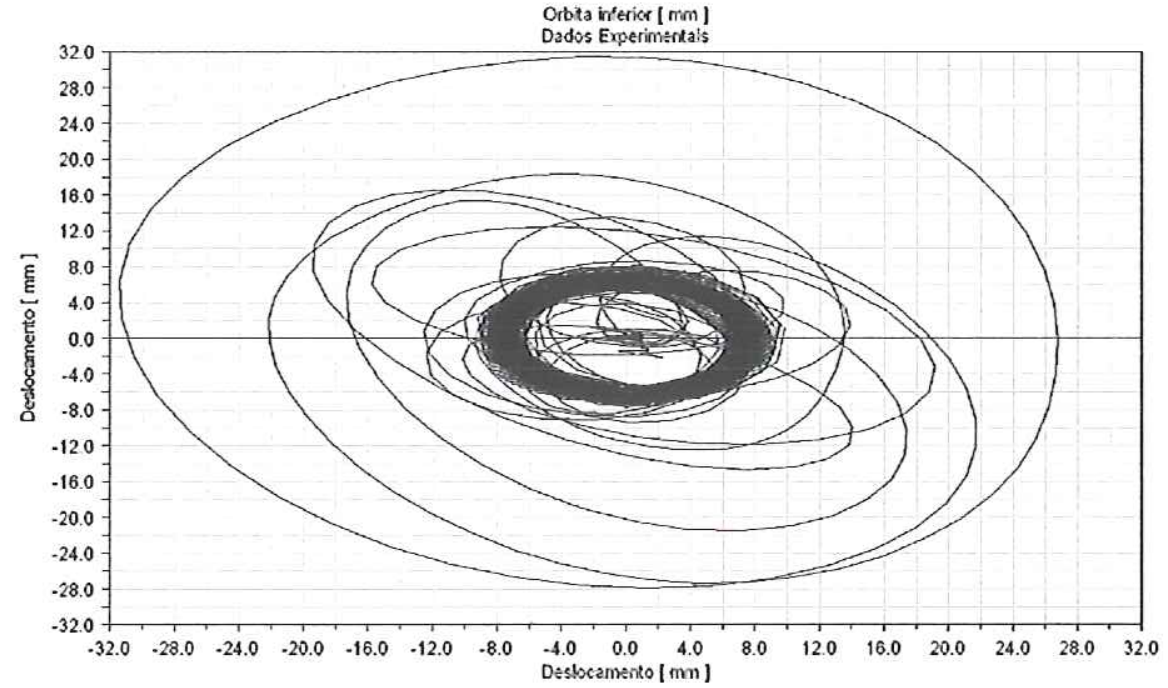

Figura 5.18 - Órbita inferior experimental do mecanismo 


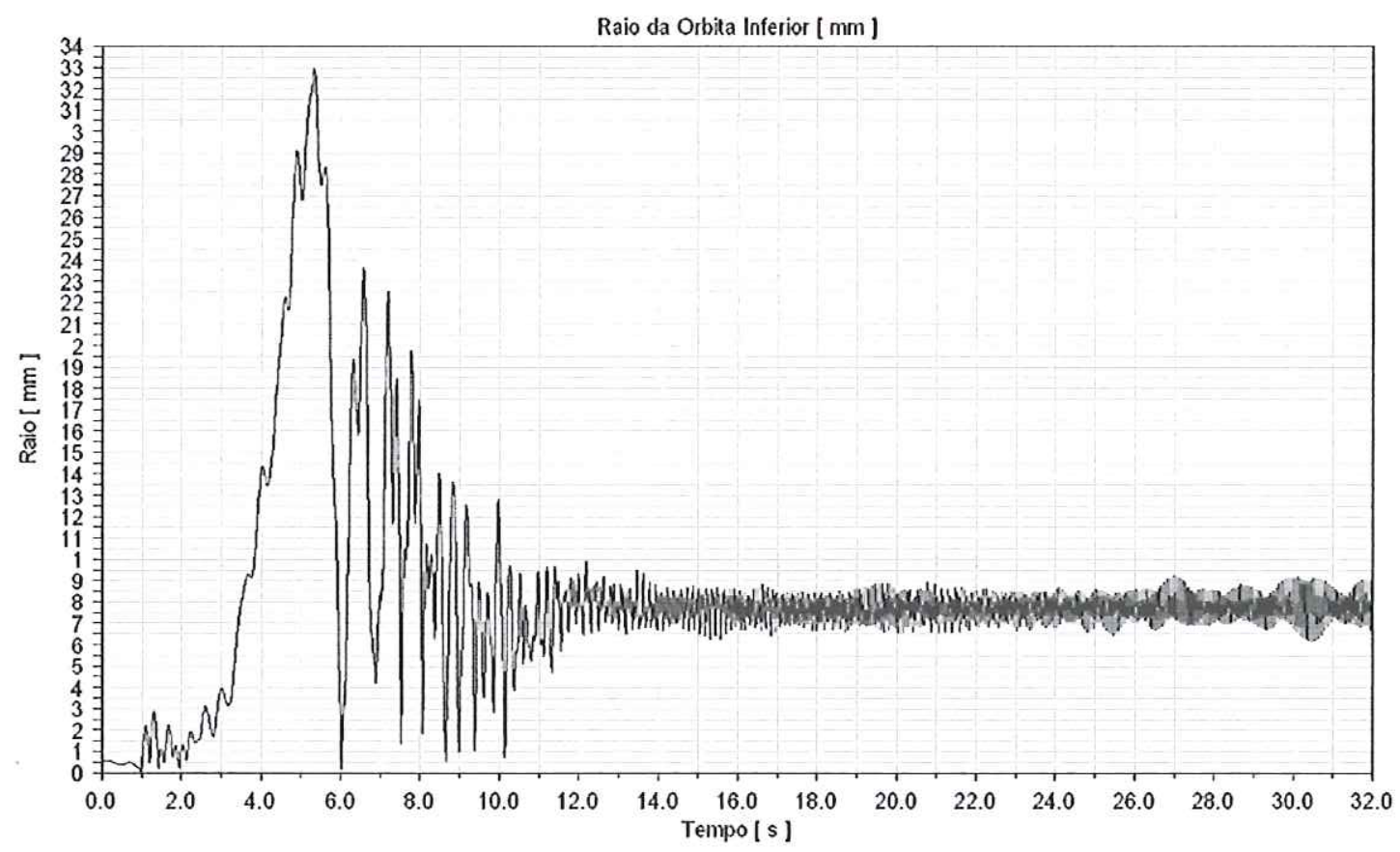

Figura 5.19 - Raio da órbita inferior experimental

A tabela abaixo sumariza o raio da órbita obtida nas medições experimentais com acelerômetro:

Resultados Experimentais

\begin{tabular}{lcc}
\hline & Transiente & Regime Estacionário \\
\hline $\begin{array}{l}\text { Deslocamento } \\
\text { Superior [ mm ] }\end{array}$ & 24,6 & 12,0 \\
$\begin{array}{l}\text { Deslocamento } \\
\text { Inferior [ mm ] }\end{array}$ & 33,0 & 9,5
\end{tabular}

Tabela 5.2 - Raio de deslocamento superior e inferior da lavadora. Dados experimentais

\subsubsection{Análise Experimental no Domínio da Freqüência}

Desde quando Baron J. B. Fourier, o matemático francês, mostrou ser possivel representar qualquer formato de onda por uma série de senos e cosenos de freqüências e amplitudes variadas, engenheiros vêm utilizando estes conceitos como forma de simplificar o trabalho. Pode-se através destes conceitos procurar pelas freqüências do sinal. Em máquinas, o objetivo é relacionar as diversas freqüências vistas no espectro (gráfico da amplitude versus freqüência) aos diversos fenômenos físicos ocorrendo na máquina. (Goldman, 1999).

Em 1965, Cooley e Tukey desenvolveram um algorítimo para cálculo da 
transformada rápida de Fourier (FFT) que facilitou enormemente o processamento de sinais.

O sinal que se pretende analisar não é um sinal periódico, o que nos leva a utilizar o diagrama em cascata para análise. Este diagrama é construído através da aplicação de diversas transformadas de Fourier em curtos períodos de tempo. Foi utilizado para isso a função FFT-3d disponível no software ADAMS.

Ao sinal é aplicado um janelamento Hanning a fim de se evitar vazamento do sinal e uma taxa de overlap de $95 \%$.

De posse dos sinais no tempo, traçou-se o diagrama cascata para o deslocamento superior $X$. Devido à natureza da excitação e à simetria dos componentes da lavadora, espera-se o mesmo comportamento em freqüência para as diferentes respostas superiores e inferiores e nas duas direções medidas ( $\mathrm{X}$ e $\mathrm{Y})$.

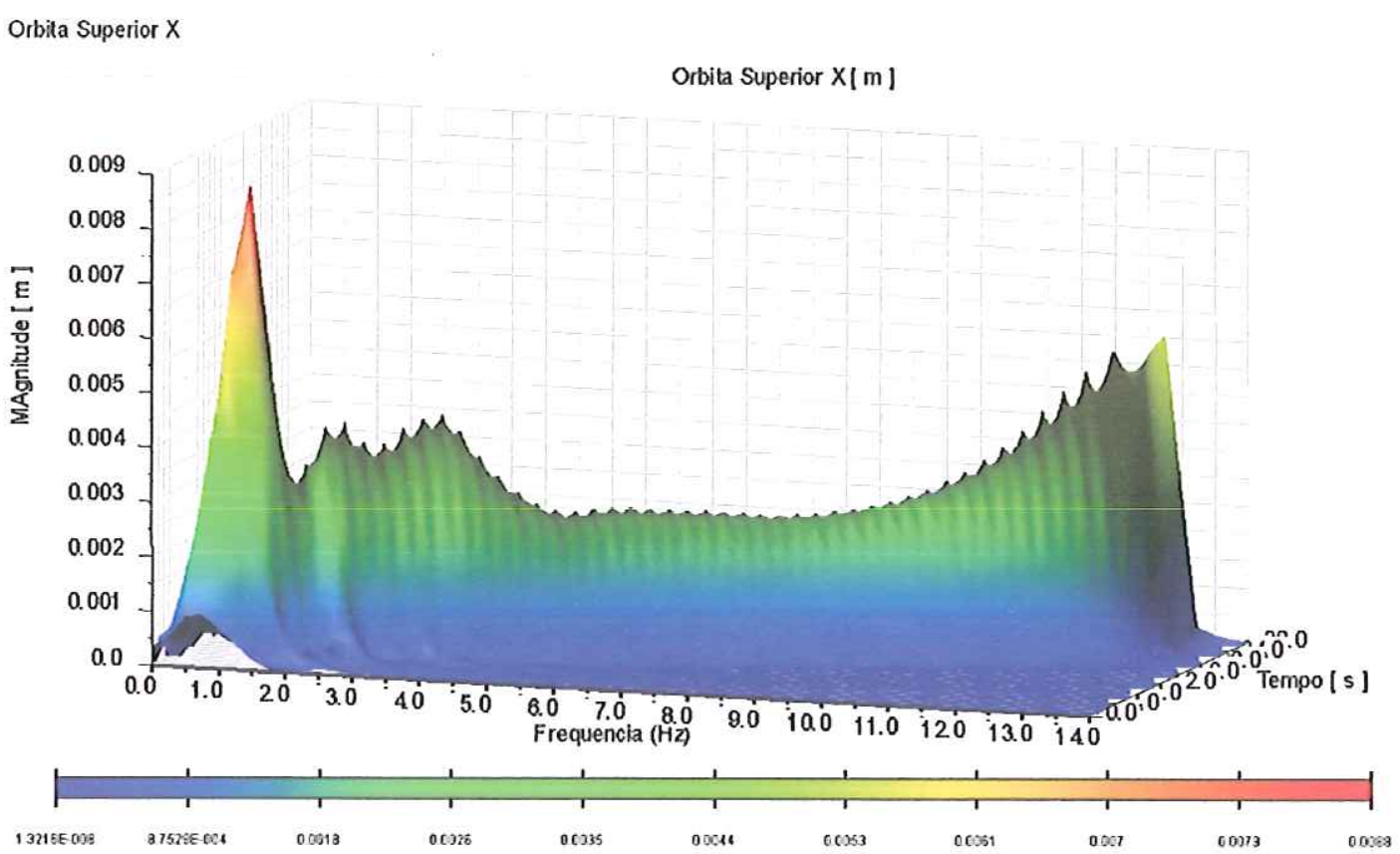

Figura 5.20 - Diagrama em cascata para deslocamento superior X. Experimental - Vista ISO 
Orbita Superior $\mathrm{X}$

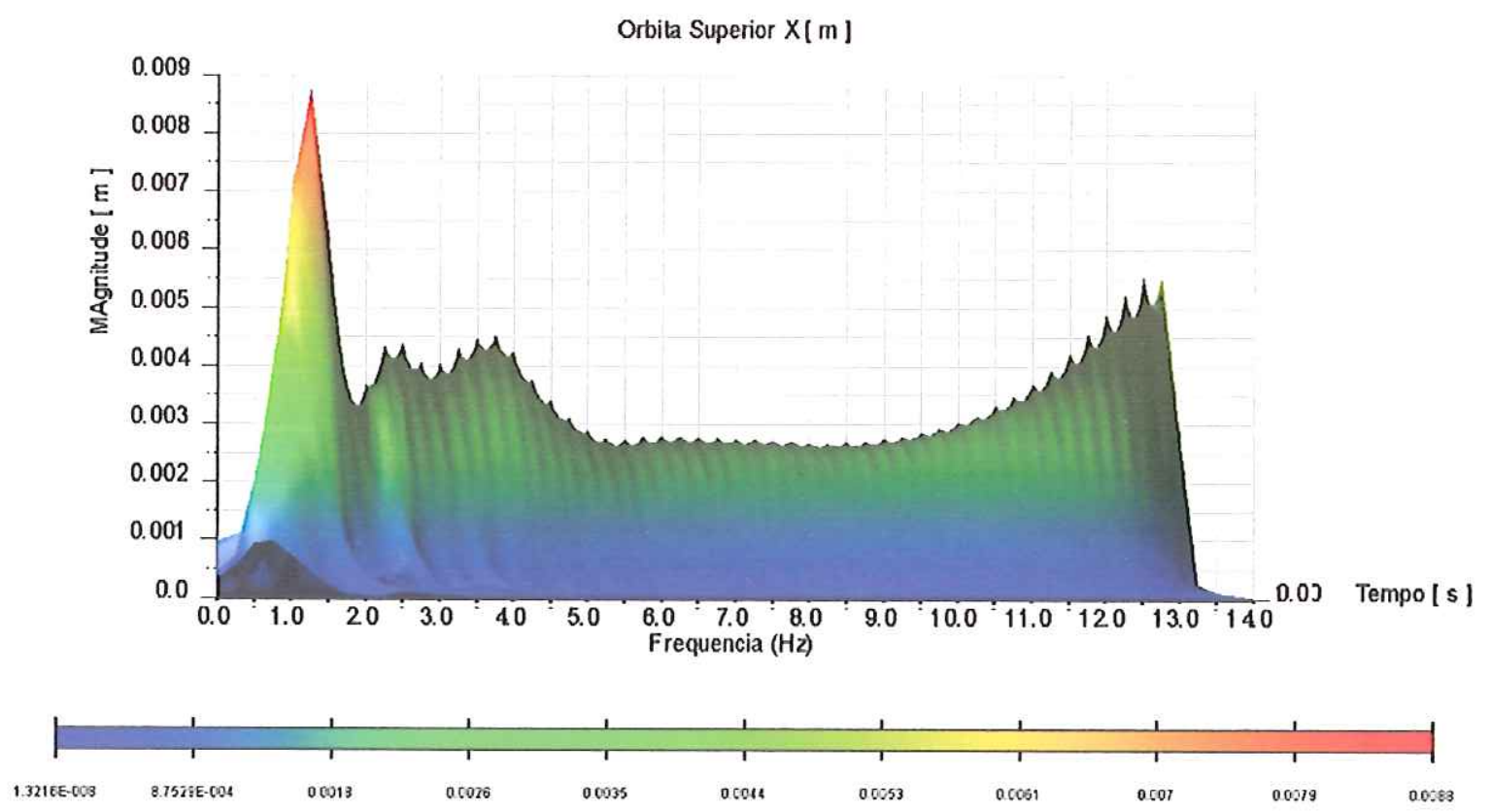

Figura 5.21- Diagrama em cascata para o deslocamento superior $X$. Experimental -Vista frontal

Orbita Superior $\mathrm{X}$

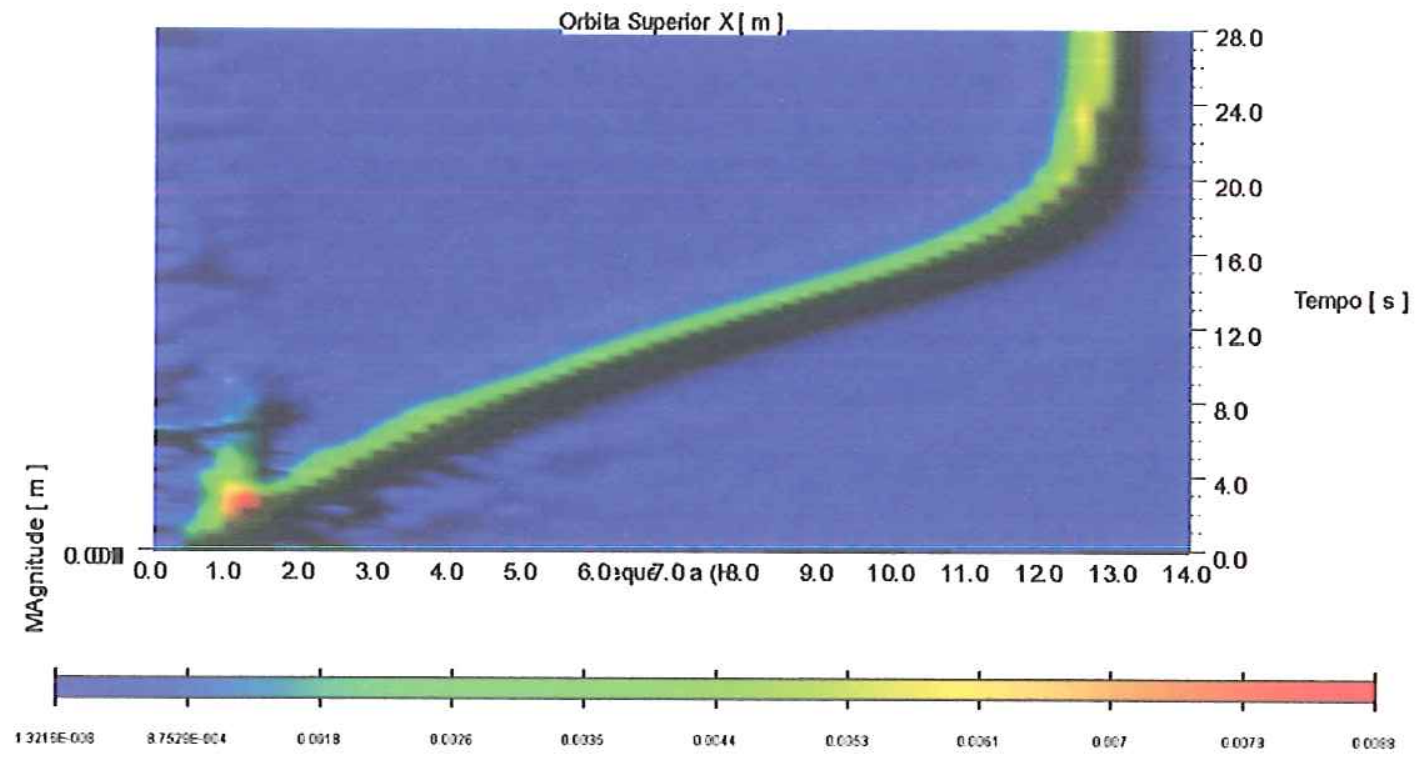

Figura 5.22 - Diagrama em cascata para o deslocamento superior X.-Experimental -Vista superior

Pode-se notar a contribuição (Figura 5.21) das baixas freqüências para a amplitude do sinal. Nota-se um pico ao redor de $1,3 \mathrm{~Hz}$, indicando a existência de uma possível freqüência crítica do sistema. Esta freqüência pode ser relacionada com o ponto de ativação do anel-hidro, onde o mesmo passará a balancear o sistema acima desta freqüência. Observa-se ainda uma grande contribuição das freqüências entre 2 e $4,5 \mathrm{~Hz}$, indicando a possível excitação 
de outros modos naturais. Finalmente, observa-se uma grande contribuição em $12,5 \mathrm{~Hz}$, referente à freqüência de regime da lavadora.

\subsection{Resultados teóricos}

\subsection{Análise teórica no domínio do tempo}

Analisou-se no ADAMS a dinâmica da lavadora sob a carga de $12 \mathrm{~kg}$ distribuída e $1,5 \mathrm{~kg}$ desbalanceada, forma também utilizada na parte experimental do trabalho. A curva de aceleração foi aplicada baseada no resultado experimental, cuja aceleração se deu em aproximadamente $23 \mathrm{~s}$.

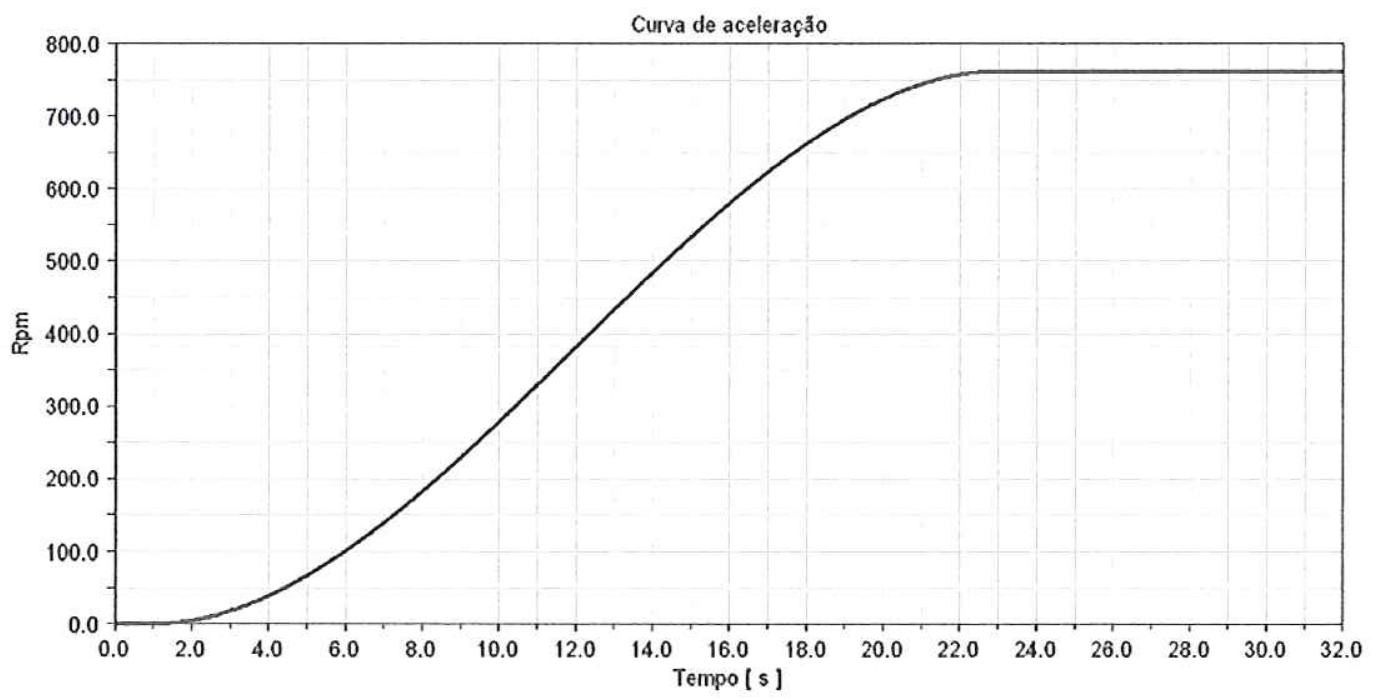

Figura 5.23 - Rampa de aceleração utilizada no ADAMS

No modelo teórico no ADAMS, criaram-se medições correspondentes às realizadas na máquina real, com a intenção de comparar e validar o modelo.

Os gráficos abaixo ilustram a evolução temporal do deslocamento superior do tanque da lavadora nas direções $X$ (Figura 5.24) e Y(Figura 5.25). 


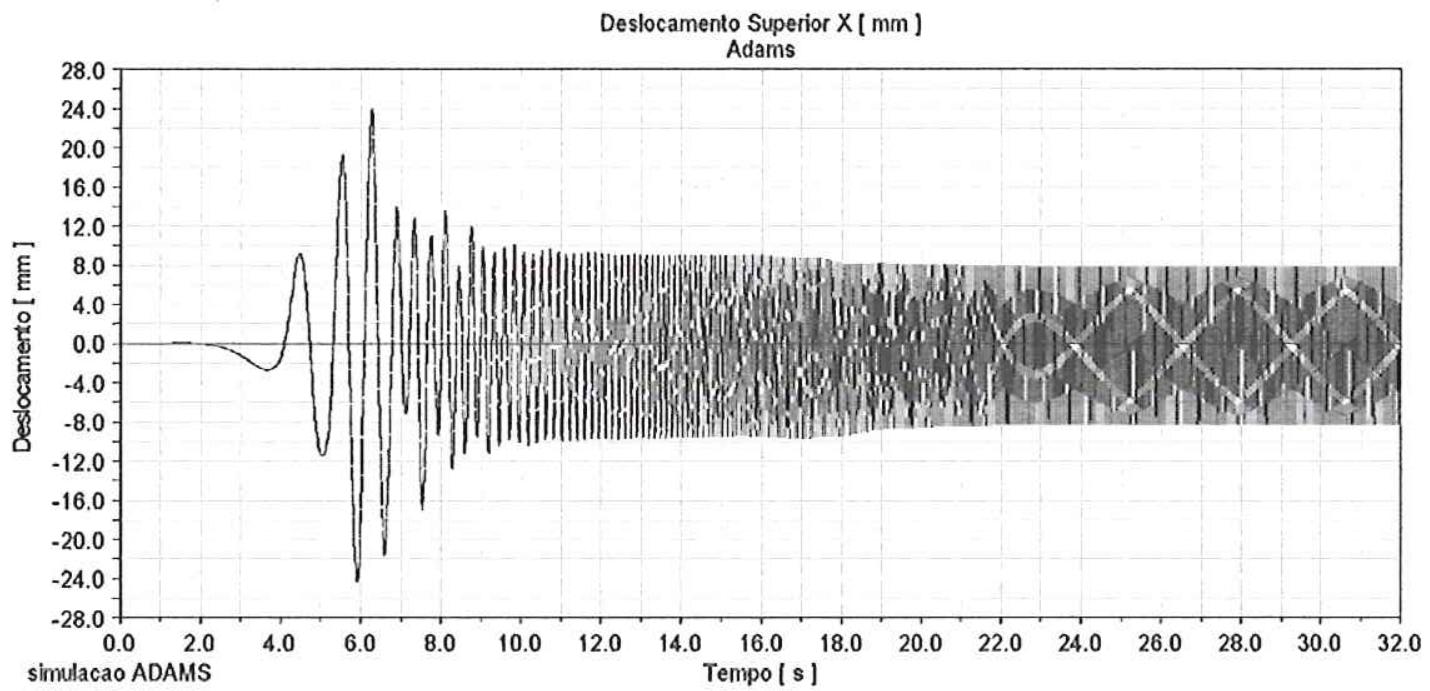

Figura 5.24 - Deslocamento teórico superior do tanque na direção $X$

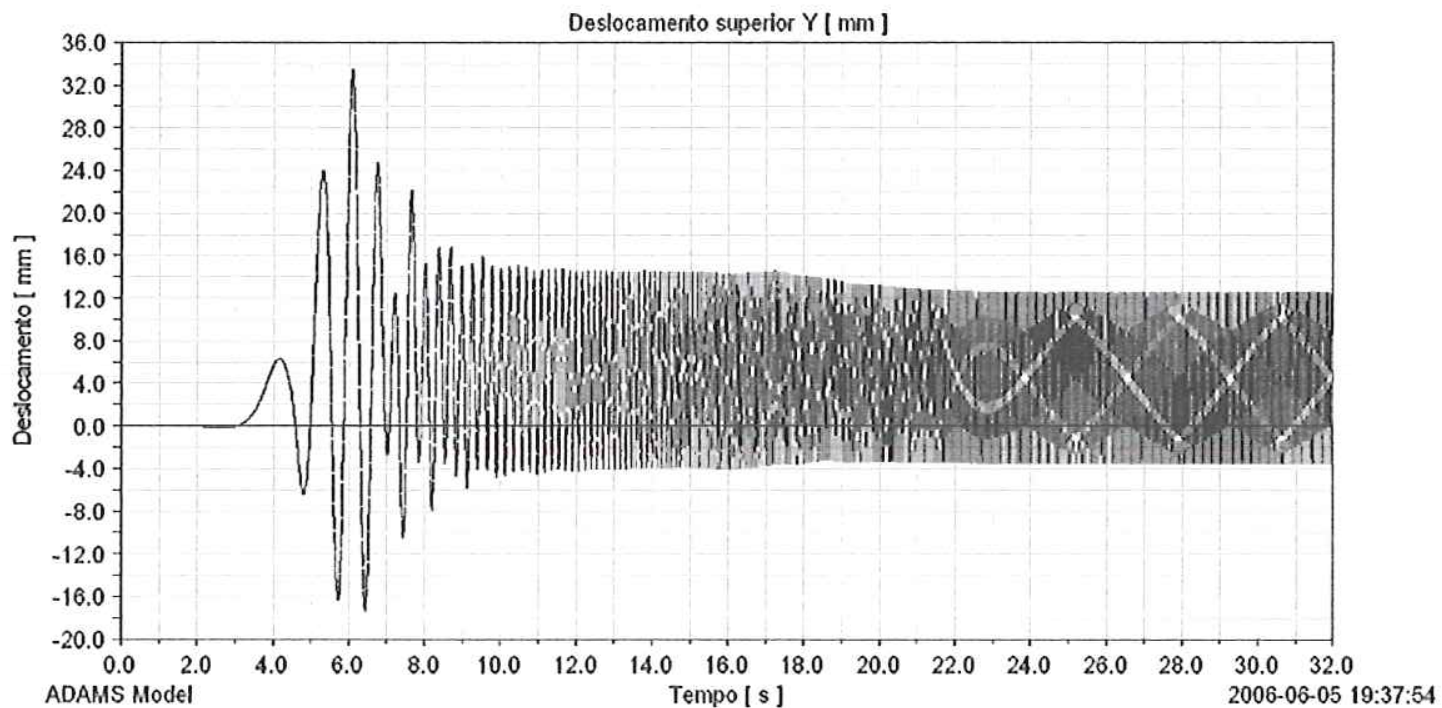

Figura 5.25 - Deslocamento teórico superior do tanque na direção Y

Combinando os sinais de $X$ e $Y$, a órbita superior do cesto (Figura 5.26), bem como o raio da órbita (Figura 5.27) são obtidos. 


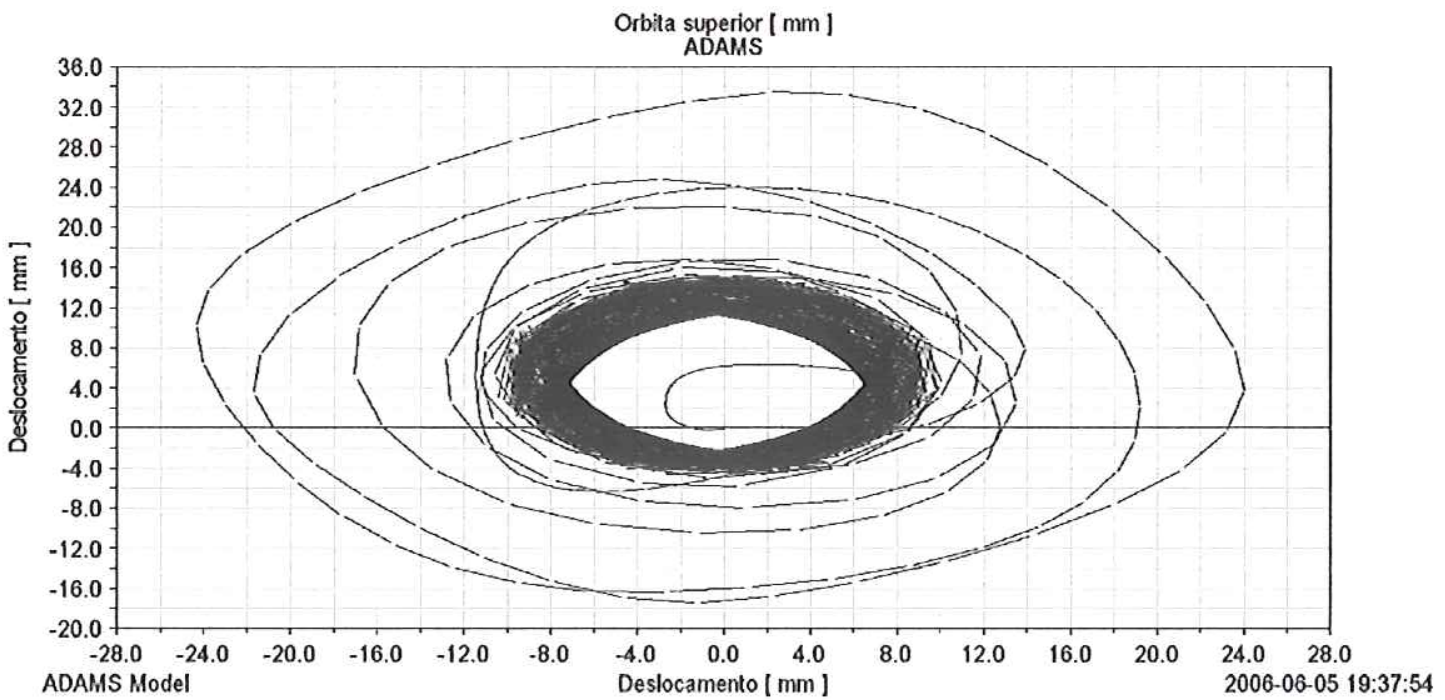

Figura 5.26 - Órbita superior teórica do tanque

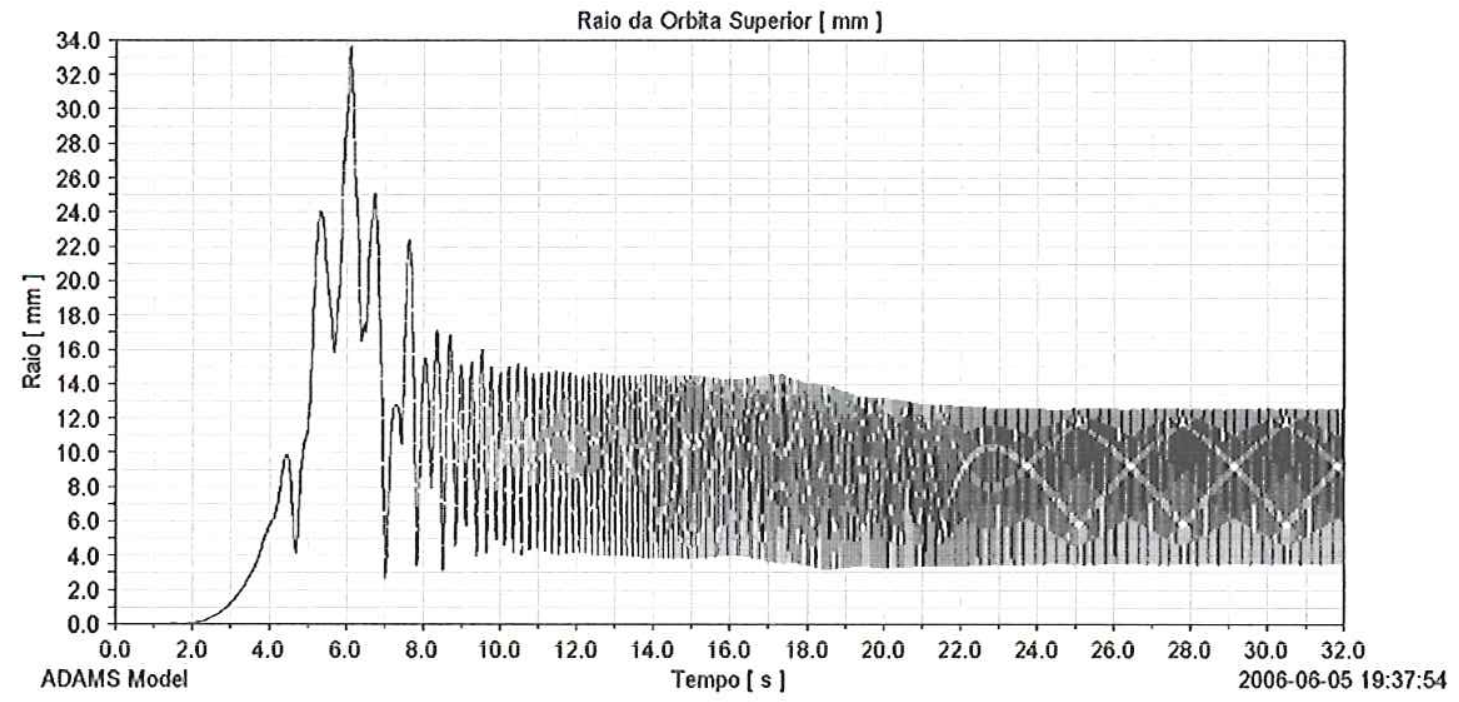

Figura 5.27 - Raio da órbita teórica superior do tanque

De forma análoga, são obtidos os resultados da órbita inferior como segue. 


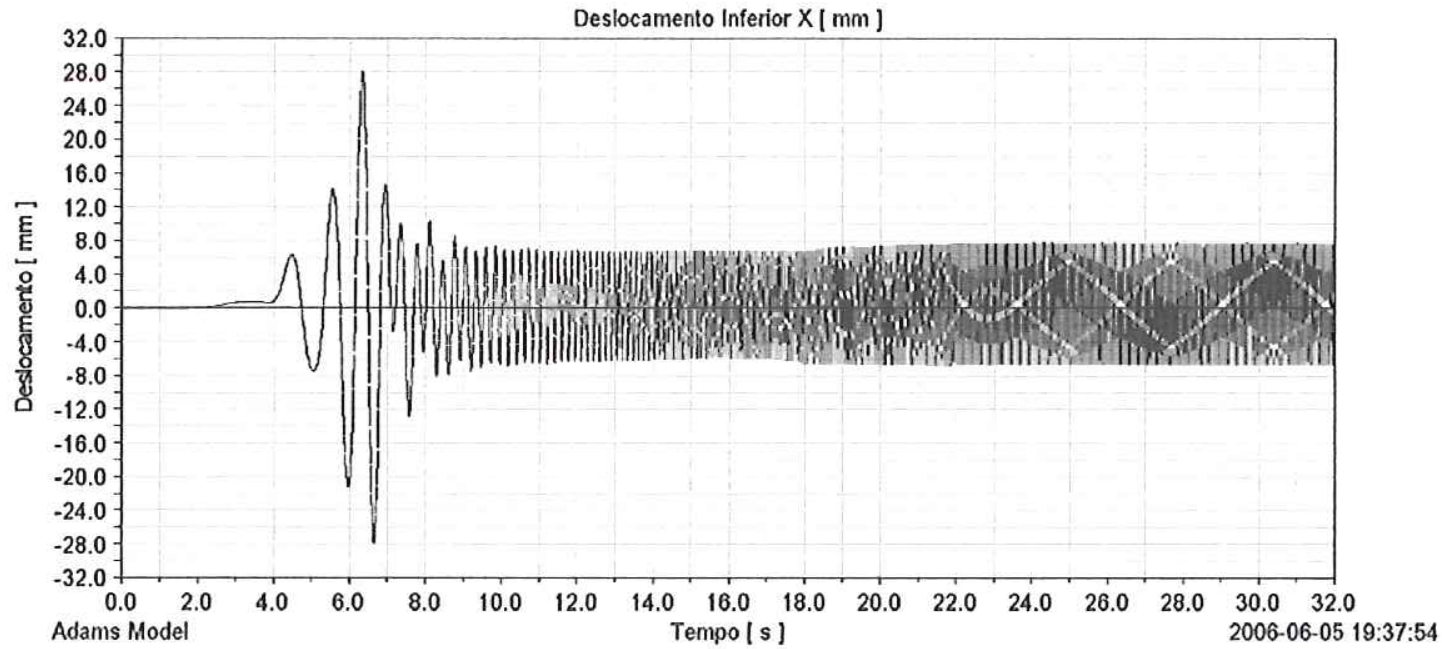

Figura 5.28 Deslocamento teórico inferior do mecanismo $\mathrm{X}$

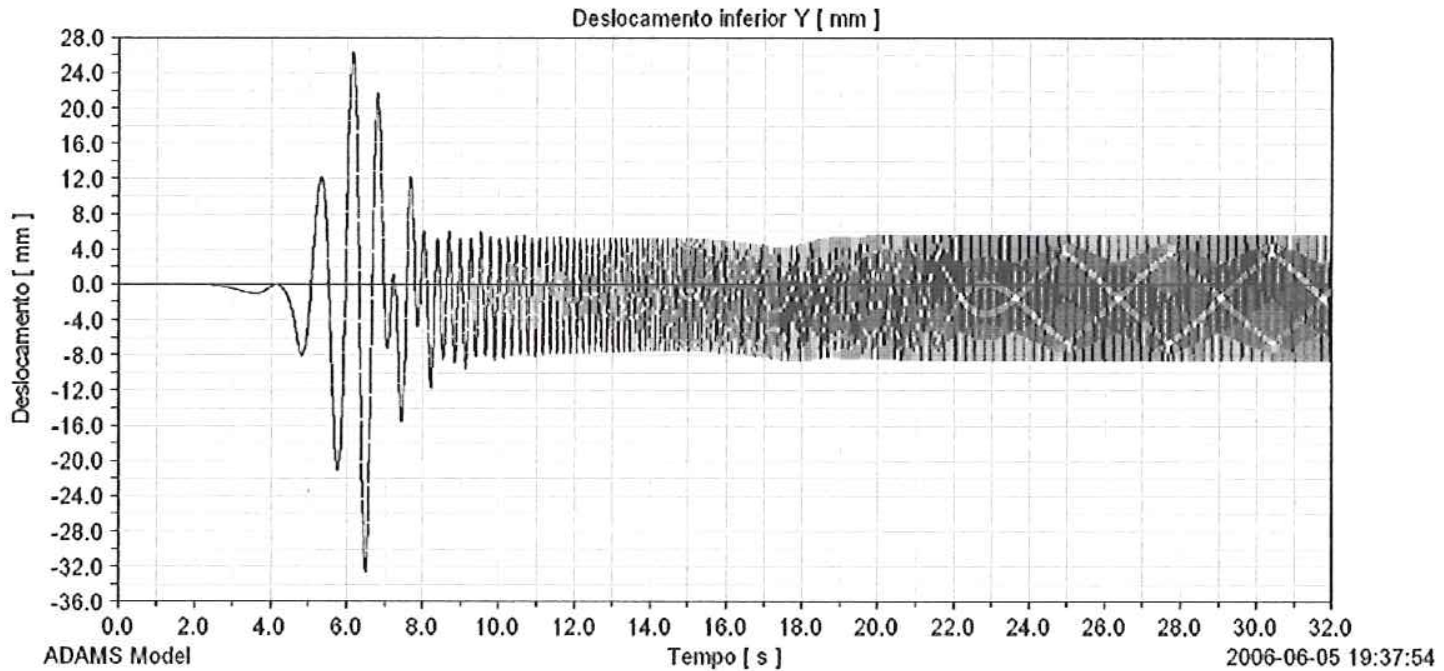

Figura 5.29-Deslocamento teórico inferior do mecanismo $Y$

Combinando os movimentos $\mathrm{X}$ e $\mathrm{Y}$, é obtida a órbita (Figura 5.30) bem como o raio inferior do mecanismo (Figura 5.31). 


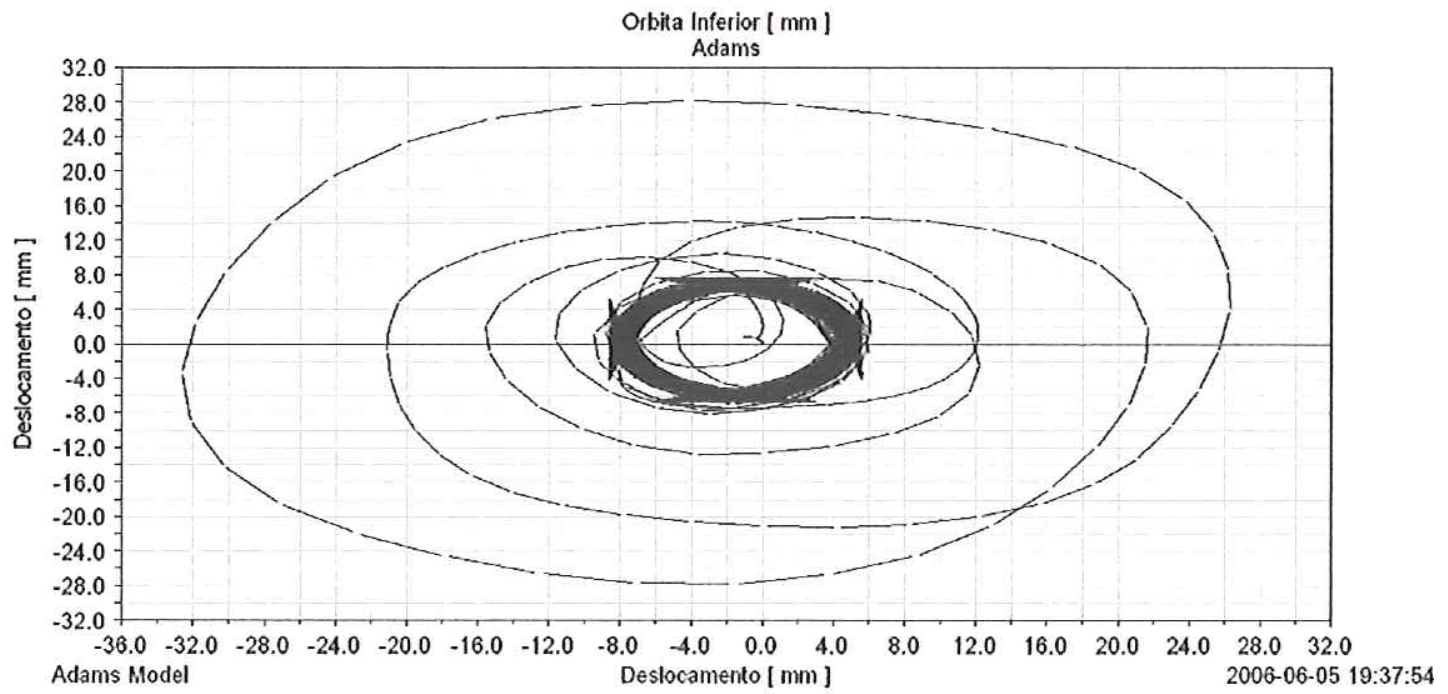

Figura 5.30 - Órbita inferior teórica do mecanismo

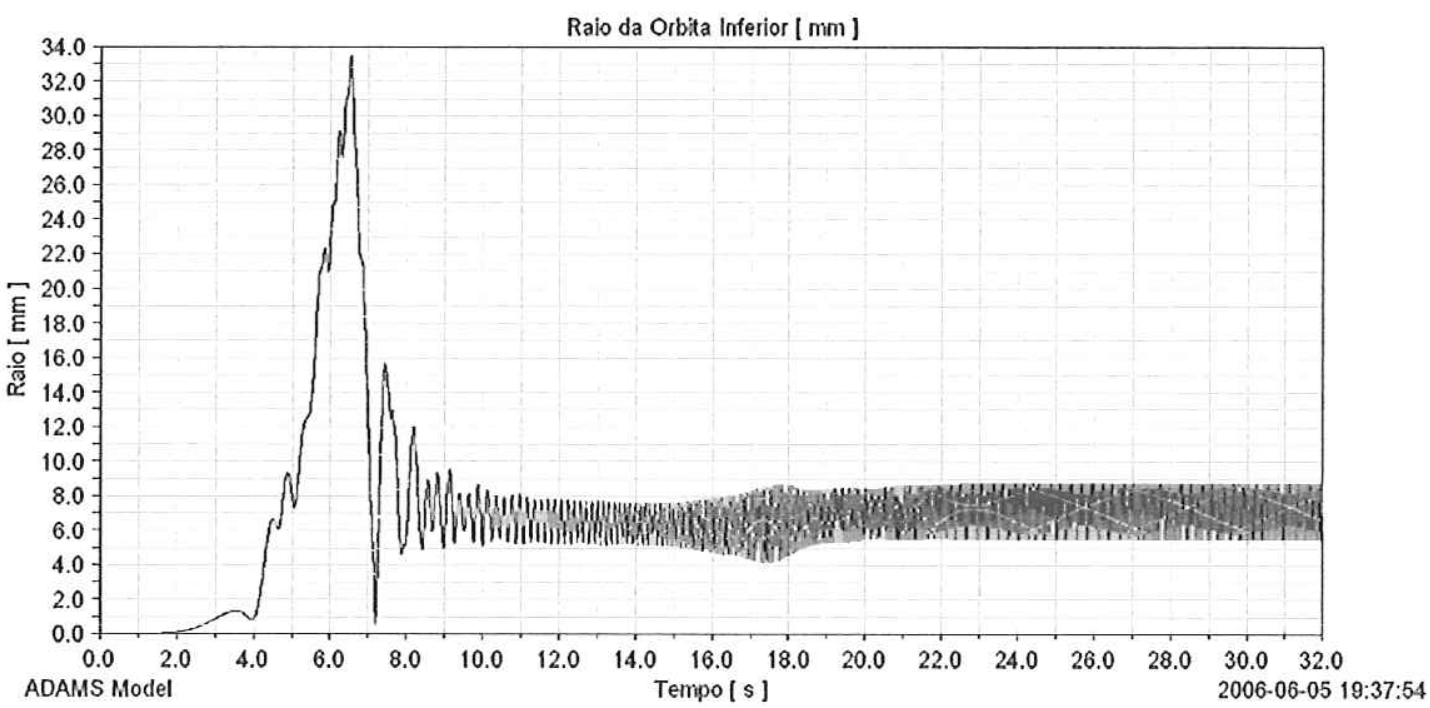

Figura 5.31 - Raio teórico da órbita inferior do mecanismo

A Tabela 5.3 sumariza os raios das órbitas superiores e inferiores obtidas no ADAMS:

Resultados Teóricos - ADAMS

\begin{tabular}{lcc}
\hline & Transiente & Regime Estacionário \\
\hline $\begin{array}{l}\text { Deslocamento } \\
\text { Superior [ mm ] }\end{array}$ & 33,5 & 12,5 \\
$\begin{array}{l}\text { Deslocamento } \\
\text { Inferior [ mm ] }\end{array}$ & 33,5 & 9,0
\end{tabular}




\subsection{Análise teórica no domínio da freqüência}

Analogamente aos dados experimentais, utilizou-se a função FFT-3D no ADAMS para obtenção do diagrama em cascata oriundo dos sinais no tempo.

Aplicou-se ainda um janelamento da forma Hanning no sinal teórico, seguindo os passos realizados na análise experimental, bem como uma taxa de overlap de $95 \%$.

Os resultados das órbitas superiores estão mostrados abaixo (Figura 5.32 e Figura 5.33).
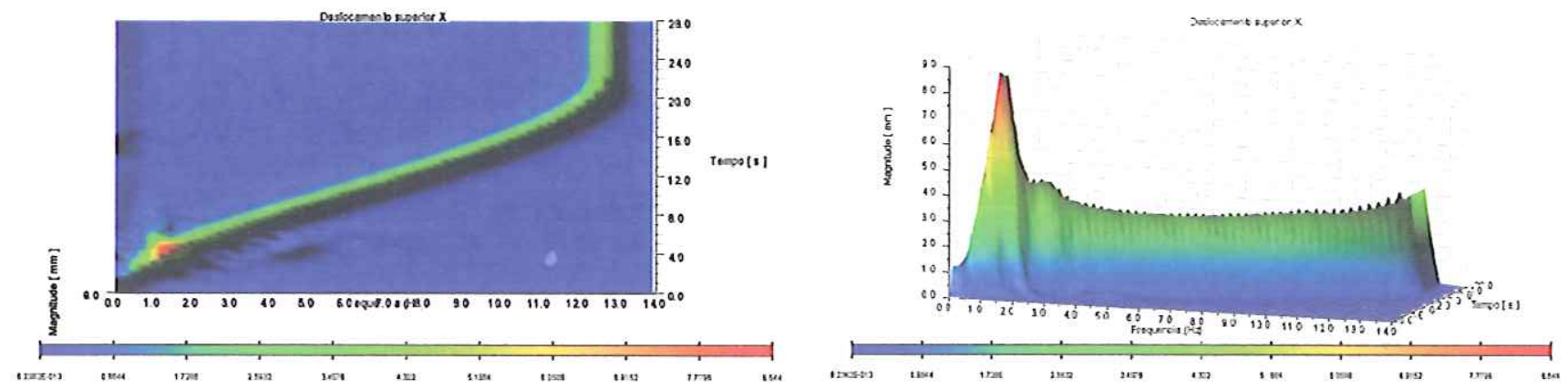

Figura 5.32 - Diagrama em cascata para o deslocamento superior em X - Teórico
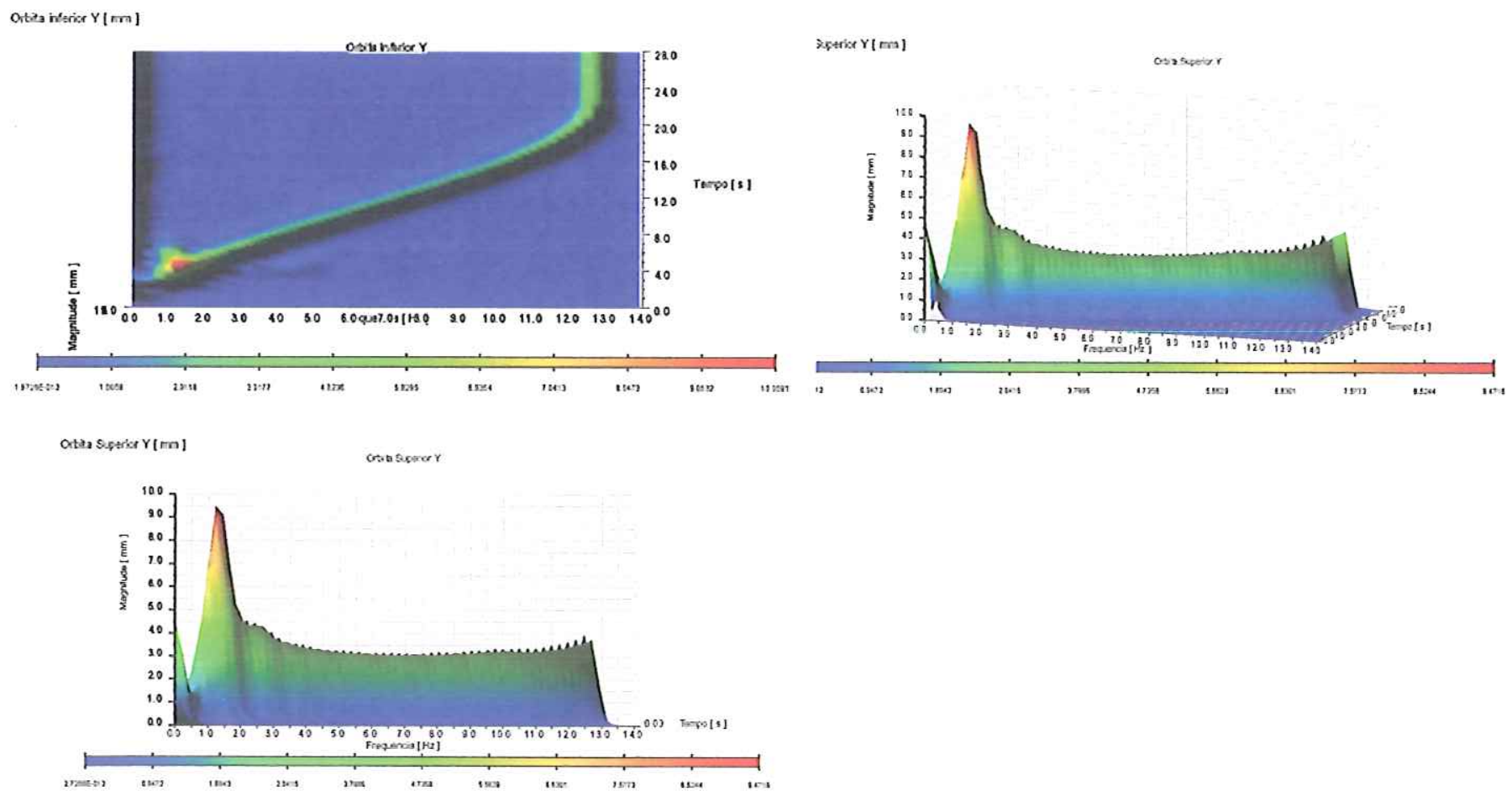

Figura 5.33 - Diagrama em cascata para o deslocamento superior em Y - Teórico

Da mesma forma, criou-se o diagrama para a órbita inferior (Figura 5.34). 


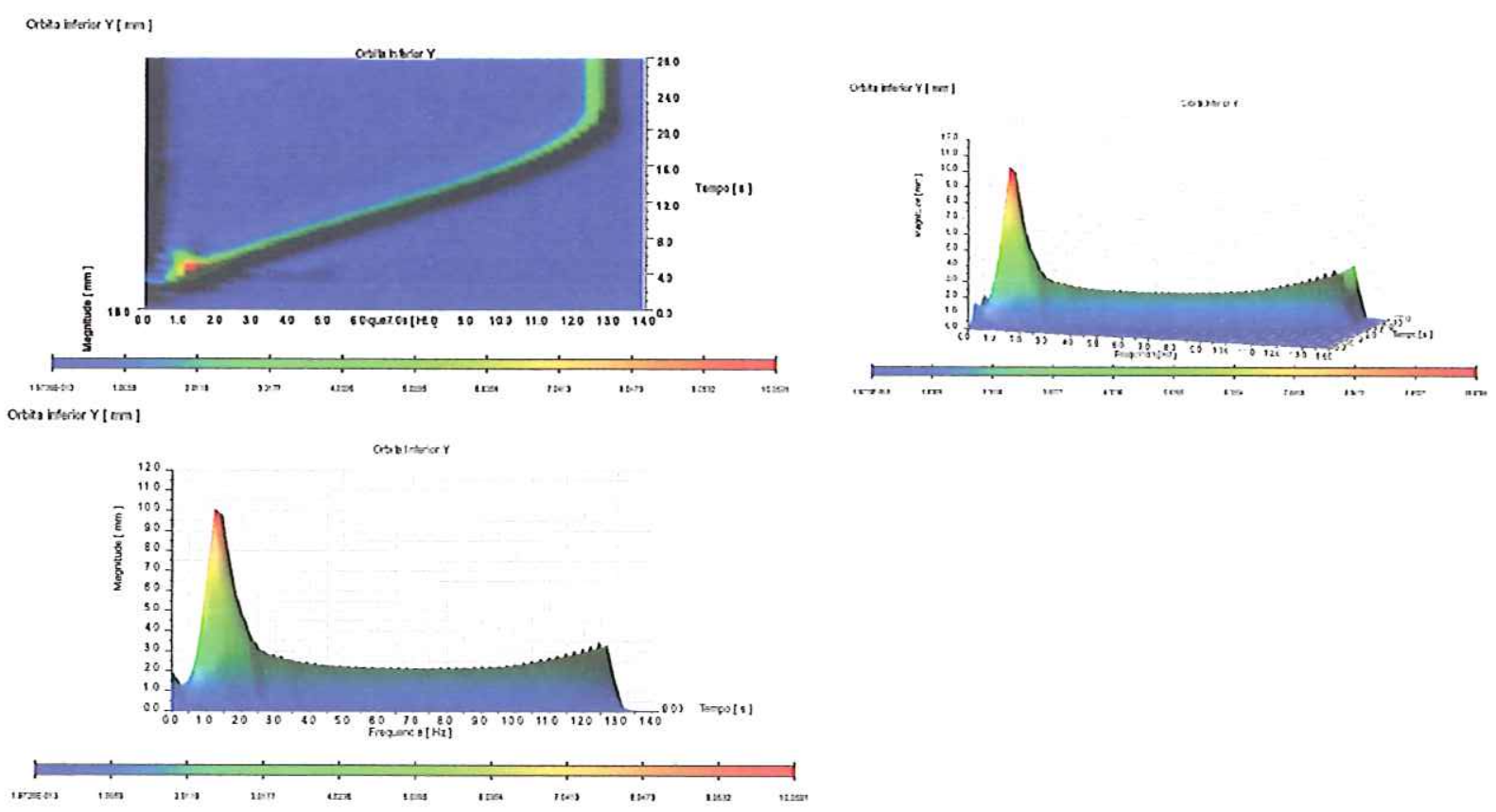

Figura 5.34 - Diagrama em cascata para o deslocamento inferior em Y - Teórico

\subsection{Discussão e validação do modelo teórico}

Os resultados teóricos de performance, comparados com dados experimentais e sumarizados abaixo (Tabela 5.4), mostram correlação satisfatória, principalmente no regime. Isto nos leva a confirmar a validade do modelo teórico. Este modelo, portanto, pode ser utilizado futuramente para estudos de mudança de design em parâmetros que influenciariam a performance dinâmica da lavadora. O modelo foi ajustado aos dados experimentais apenas pela mudança dos coeficientes de atrito presentes nas juntas esféricas das suspensões. Outro parâmetro importante, como o amortecimento da suspensão, havia sido caracterizado separadamente. O anel de balanceamento por sua vez pode ser facilmente validado pelas dimensões geométricas do mesmo, definindo a condição de volume ótimo com descrito no capítulo 3. 
Resultado Comparativo - Experimental versus Teórico

\begin{tabular}{lcccc}
\hline & \multicolumn{2}{c}{ Transiente } & \multicolumn{2}{c}{ Regime Estacionário } \\
\hline & $\begin{array}{c}\text { Deslocamento } \\
\text { Inferior }\end{array}$ & $\begin{array}{c}\text { Deslocamento } \\
\text { Superior }\end{array}$ & $\begin{array}{c}\text { Deslocamento } \\
\text { Inferior }\end{array}$ & $\begin{array}{c}\text { Deslocamento } \\
\text { Superior }\end{array}$ \\
Resultados Experimentais [ mm ] & 33,0 & 24,6 & 9,5 & 12,0 \\
Resultados Teóricos ADAMS [ mm ] & 33,5 & 33,5 & 9,0 & 12,5 \\
\hline \hline Erro \% & $1,5 \%$ & $36,2 \%$ & $-5,3 \%$ & $4,2 \%$
\end{tabular}

Tabela 5.4 Resultados comparativos - Teórico versus Experimental

Os resultados mostram uma diferença nominal de 1,5\% no deslocamento inferior e de $36,2 \%$ no deslocamento superior durante transiente. Durante regime, os erros projetados são de $5,3 \%$ e $4,2 \%$ respectivamente. Com exceção da resposta do deslocamento superior durante transiente, a comparação das respostas teórica e experimental apresentam diferenças menores que a precisão de medição do acelerômetro, da ordem de $+/-10 \%$ de variação no sinal medido na faixa de 1 a $6 \mathrm{KHz}$.

A diferença de $36,2 \%$ presente no deslocamento superior transiente pode ser explicada pela modelagem do comportamento do anel de balanceamento. Como comentado anteriormente, a sub-rotina utilizada para simular o anel assume uma resposta imediata do líquido, segundo as equações descritas no capítulo 3 .

O líquido, antes da primeira freqüência crítica, tende a estar concentrado no mesmo lado da carga desbalanceada como comentado. Conseqüentemente, há um grande aumento de órbita em transiente decorrente deste fenômeno.

Entretanto, existem detalhes construtivos de anéis de balanceamento que tendem a minimizar este efeito no transiente. Isto é possível através da disposição de aletas internas no anel-hidro e canais que dificultam a movimentação da água antes da freqüência crítica. Assim, o efeito da concentração de volume de líquido do mesmo lado da carga desbalanceada é minimizado, uma vez que o líquido sofre apenas a ação de forças internas de cisalhamento devido ao atrito.

Neste caso, a água não sofre arraste das aletas, abaixo da freqüência crítica, o que torna o anel inativo. Este artifício é utilizado na máquina real estudada, cujo efeito não é contabilizado pela sub-rotina do anel de balanceamento. 

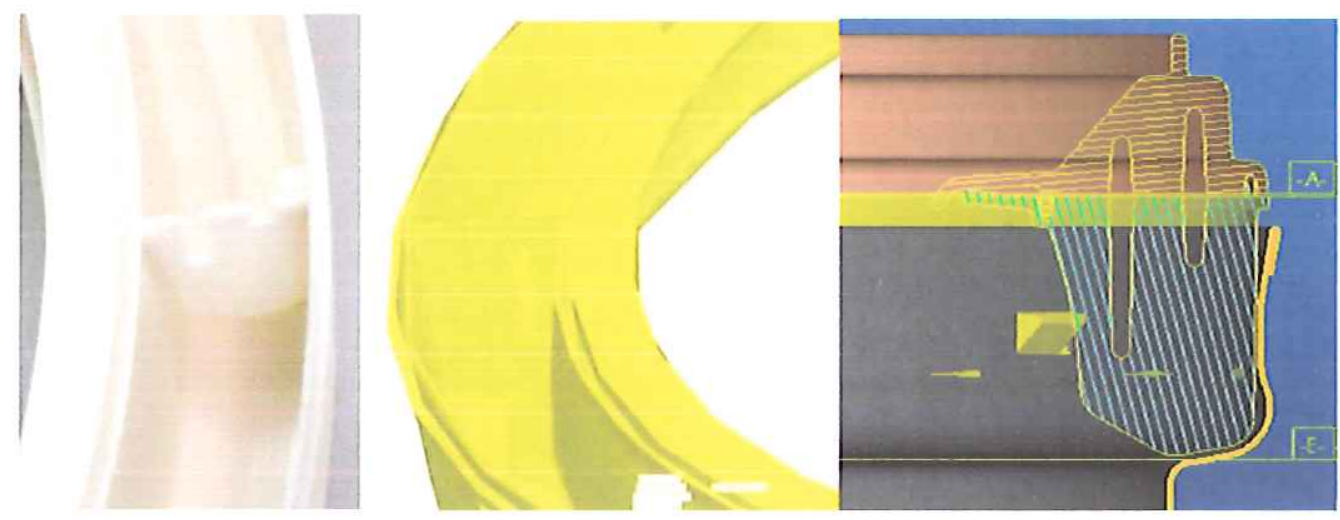

Figura 5.35 - Detalhe construtivo de anel-hidro, mostrando sua estrutura interna de aletas

Ainda com relação aos efeitos da sub-rotina, pode ser observada no regime uma variação muito maior de amplitude no raio da órbita, se comparado com o dado experimental. Isto pode ser observado nos diagramas teóricos (Figura 5.27, Figura 5.31) comparados aos experimentais ( Figura 5.15, Figura 5.19).

Esta diferença pode ser endereçada ao comportamento da sub-rotina no modelo teórico, que reage instantaneamente 'a excentricidade produzida no sistema. No modelo real, o anel é incapaz de reagir instantaneamente devido a efeitos inerciais.

Os gráficos abaixo mostram a superposição dos sinais teóricos e experimentais da órbita inferior e superior, aplicando-se um filtro passa alta de $0.7 \mathrm{~Hz}$, conforme dados experimentais coletados. 


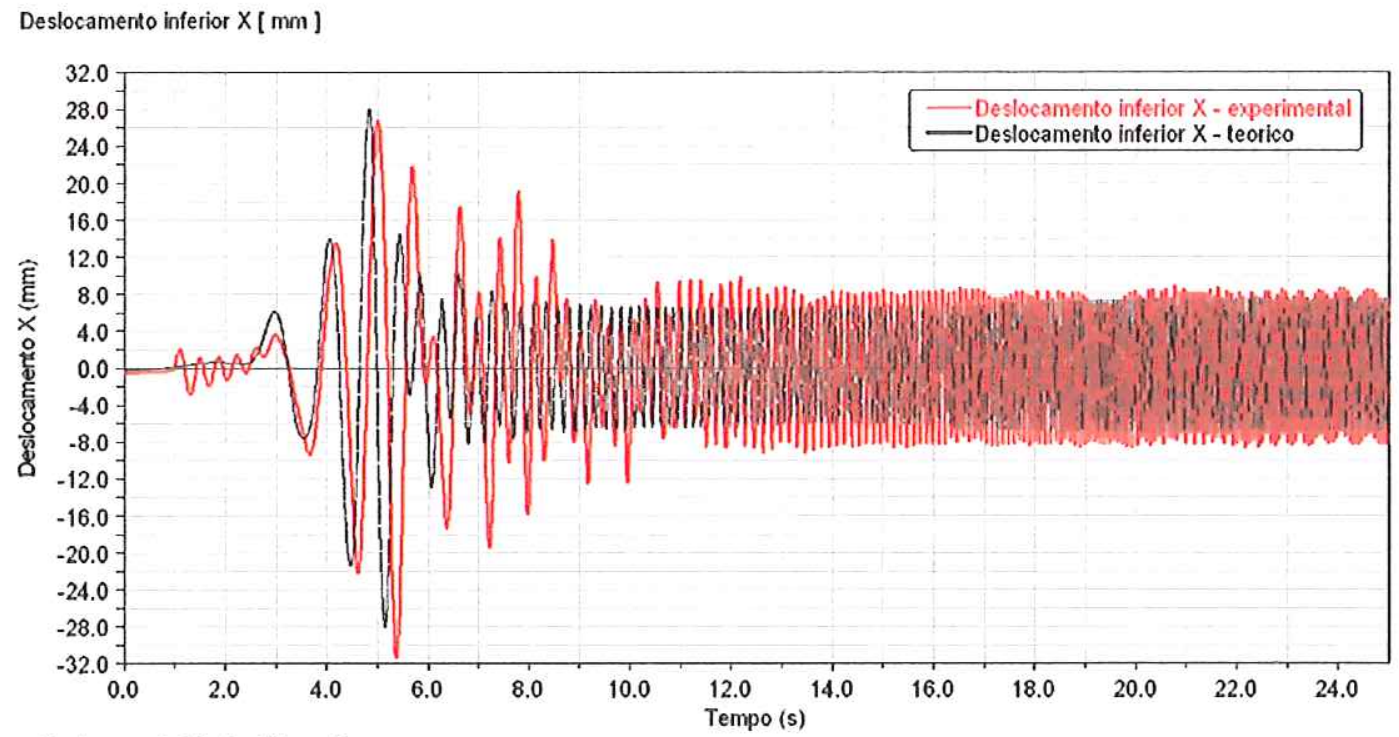

Deslocamento inferior $Y$ [ $\mathrm{mm}]$

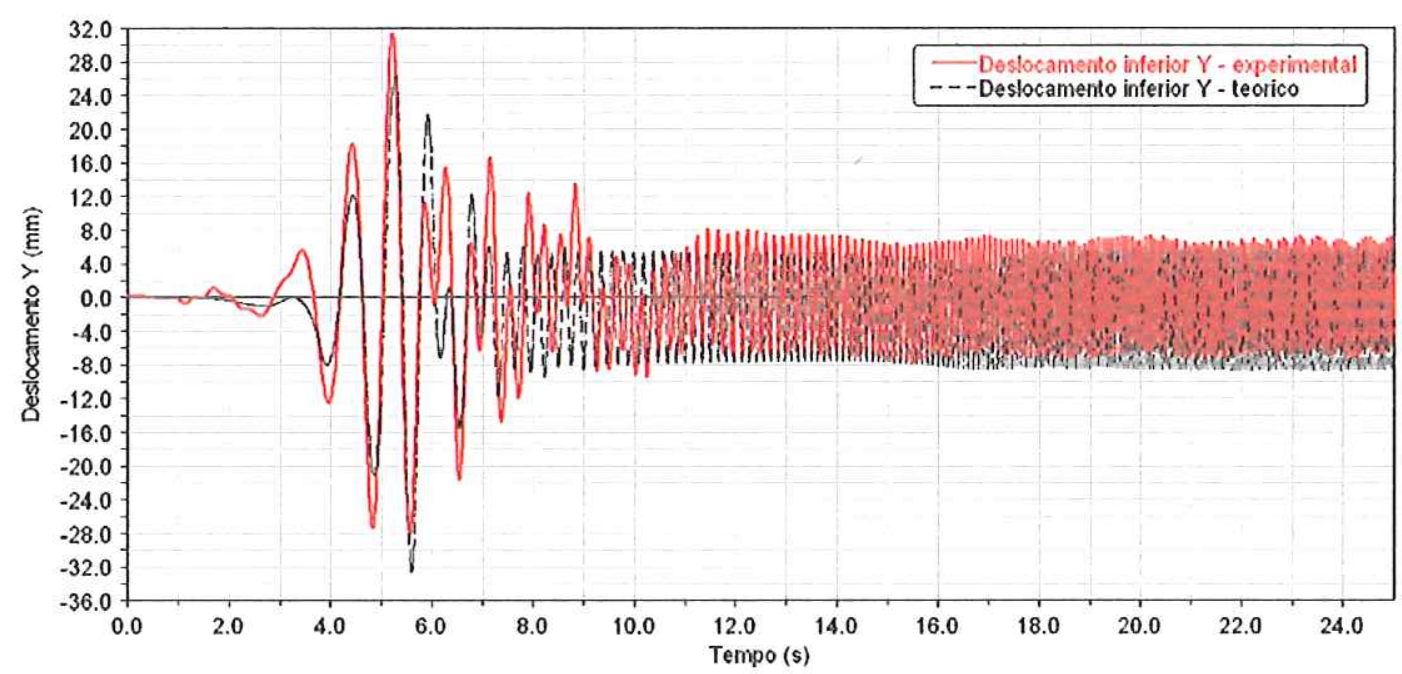

FIGURA 5.36 órbita inferior do conjunto na direção $\mathrm{X}$ e $\mathrm{Y}$ respectivamente - resultados teóricos vs.

experimentais 


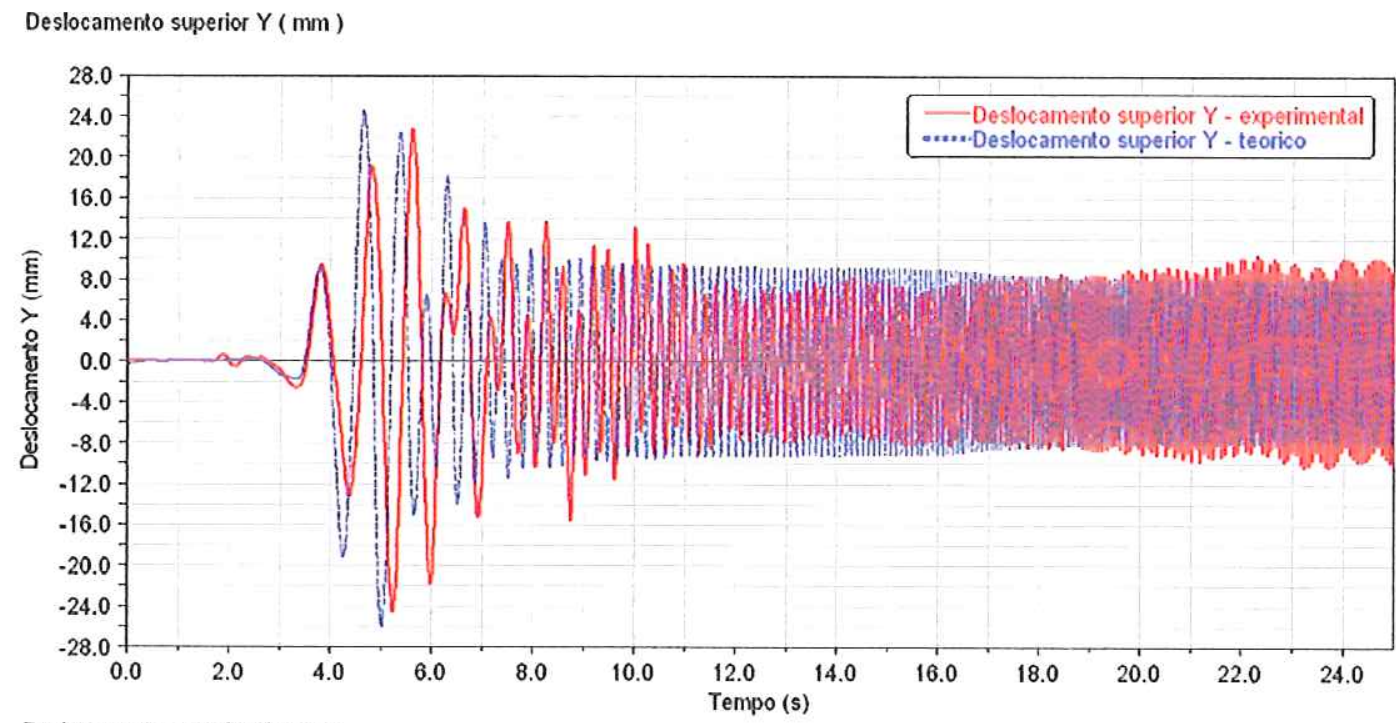

Deslocamento superior $X(\mathrm{~mm})$

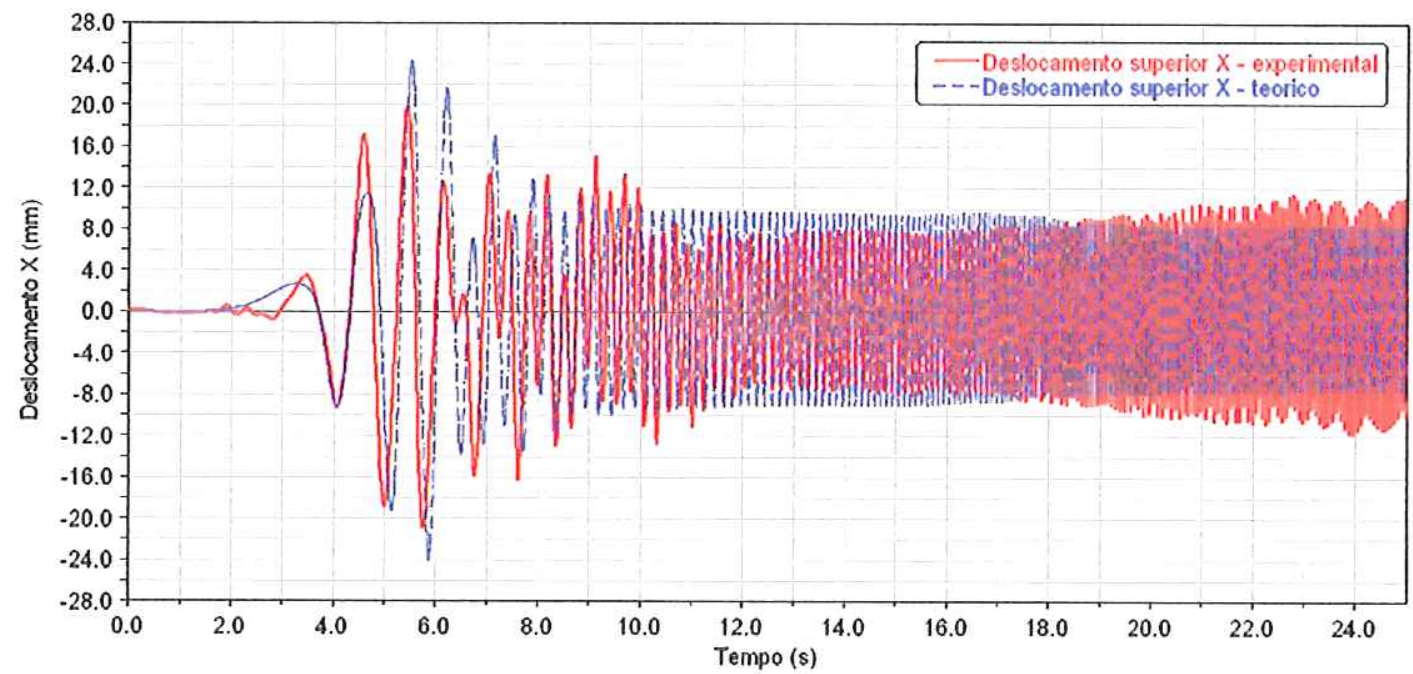

FIGURA 5.37 órbita superior do conjunto na direção $X$ e $Y$ respectivamente - resultados teóricos vs. experimentais

Os diagramas abaixo ilustram a resposta em freqüência do sinal do deslocamento superior $X$. 


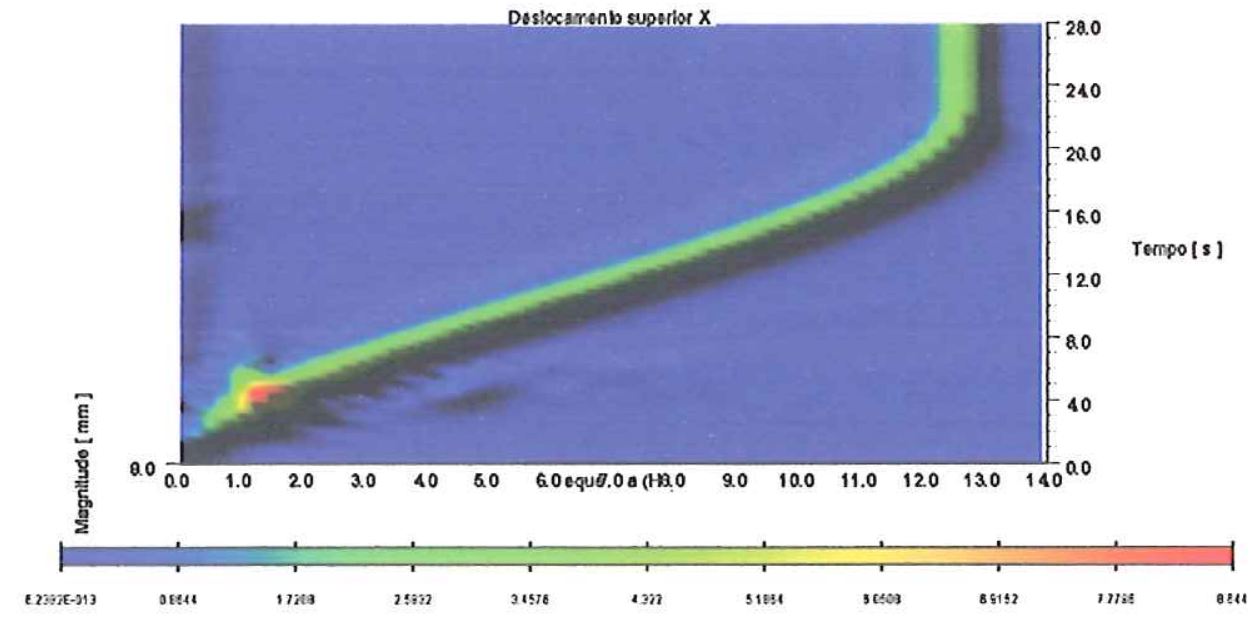

Figura 5.38 - Diagrama em cascata para deslocamento superior em X - Experimental

Orbta Superior $x$

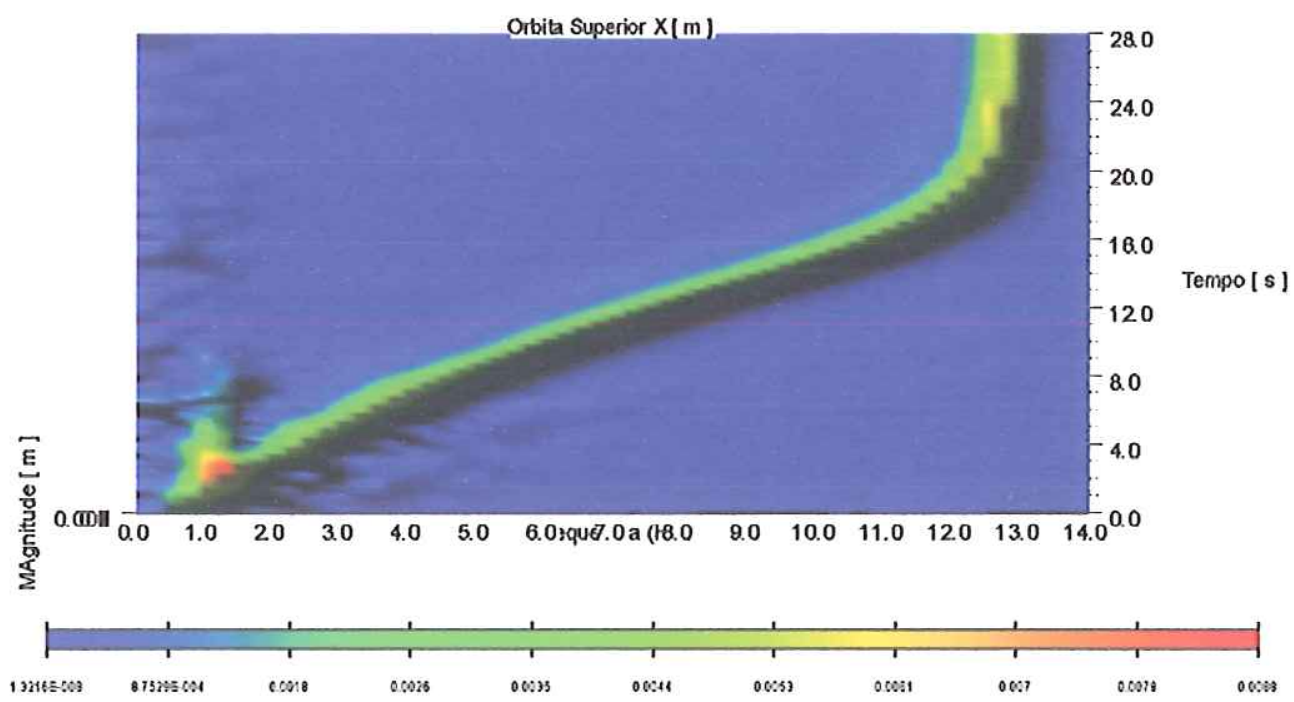

Figura 5.39 - Diagrama em cascata para deslocamento superior em X -Teórico

Observando os diagramas experimental (Figura 5.38) e teórico (Figura 5.39), observa-se uma boa correlação no domínio da freqüência, mostrando a validade do modelo. 


\section{Comportamento teórico dinâmico via Multicorpos}

\subsection{Introdução}

Neste capítulo, pretende-se utilizar as vantagens em se ter um modelo teórico validado para estudo do comportamento do sistema.

Pretende-se analisar a resposta em freqüência da lavadora através de análises modais e diagramas de Campbell, muito utilizados em corpos rotativos. Finalmente, propõe-se a utilização de um absorvedor de vibração colocado no gabinete, mostrando sua eficácia na redução de vibrações e ruídos indesejáveis.

\subsection{Análise modal}

Através do pacote Adams/Linear, foram extraídos os modos de vibração da lavadora a ser estudada.

A análise modal caracteriza-se pelas freqüências naturais bem como seus modos de vibração. Foi realizada uma análise para obtenção dos modos de vibração não amortecidos.

Os resultados são mostrados nas figuras abaixo: 


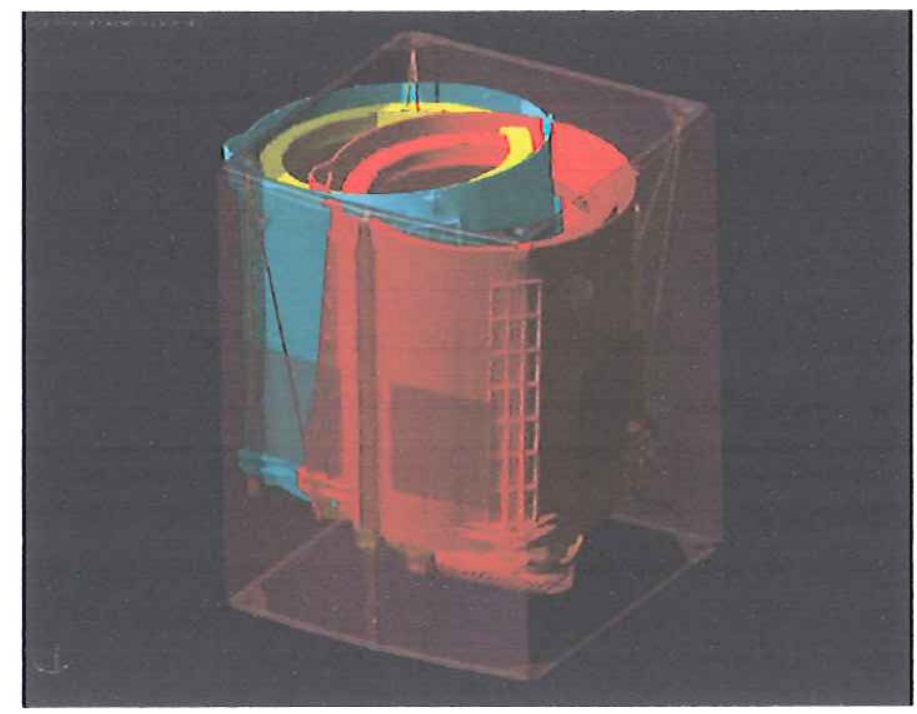

Figura 6.1 - Modo Pendular $1-0.58 \mathrm{~Hz}$

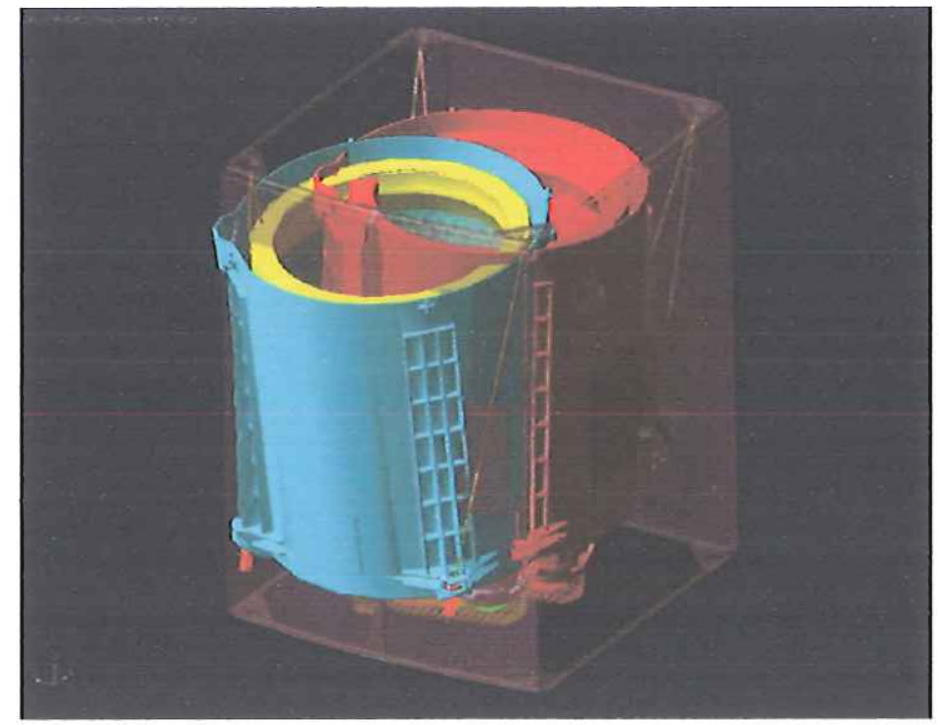

Figura 6.2 - Modo Pendular $2-0.58 \mathrm{~Hz}$

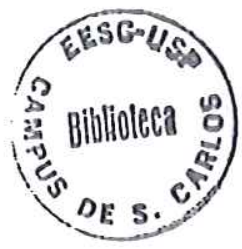




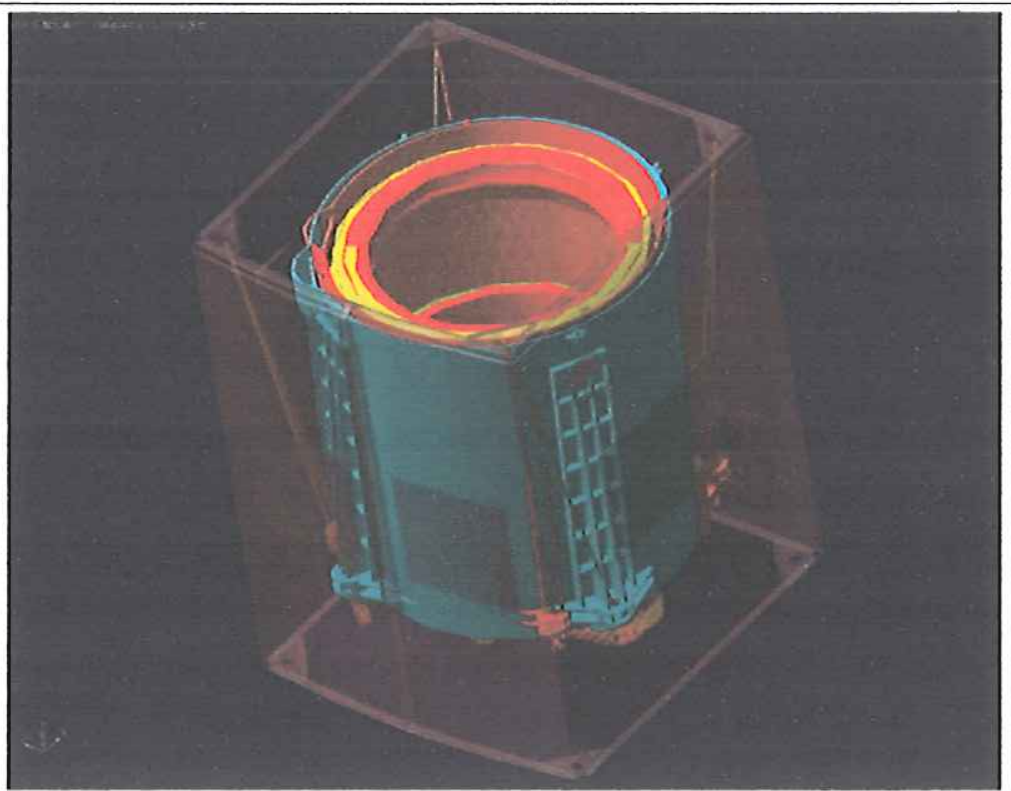

Figura 6.3 - Modo Torsional $-1.06 \mathrm{~Hz}$

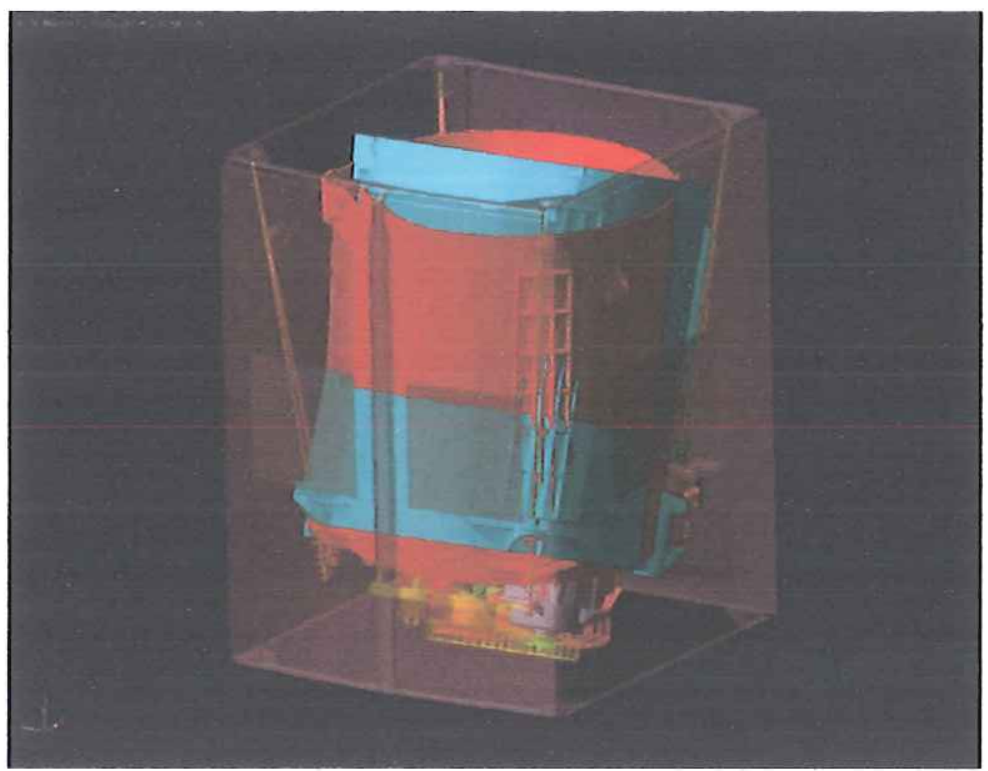

Figura 6.4 - Modo Vertical de solicitação das molas traseiras $-2.4 \mathrm{~Hz}$ 


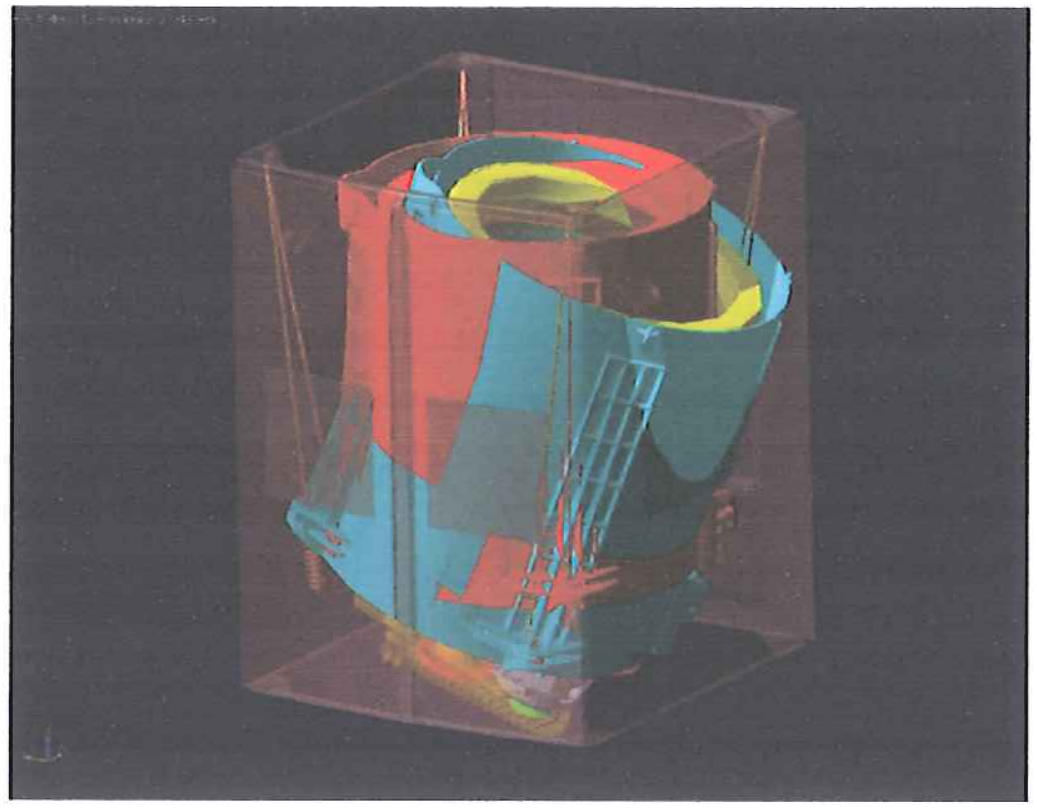

Figura 6.5 -Modo Vertical de solicitação das molas laterais $2.19 \mathrm{~Hz}$

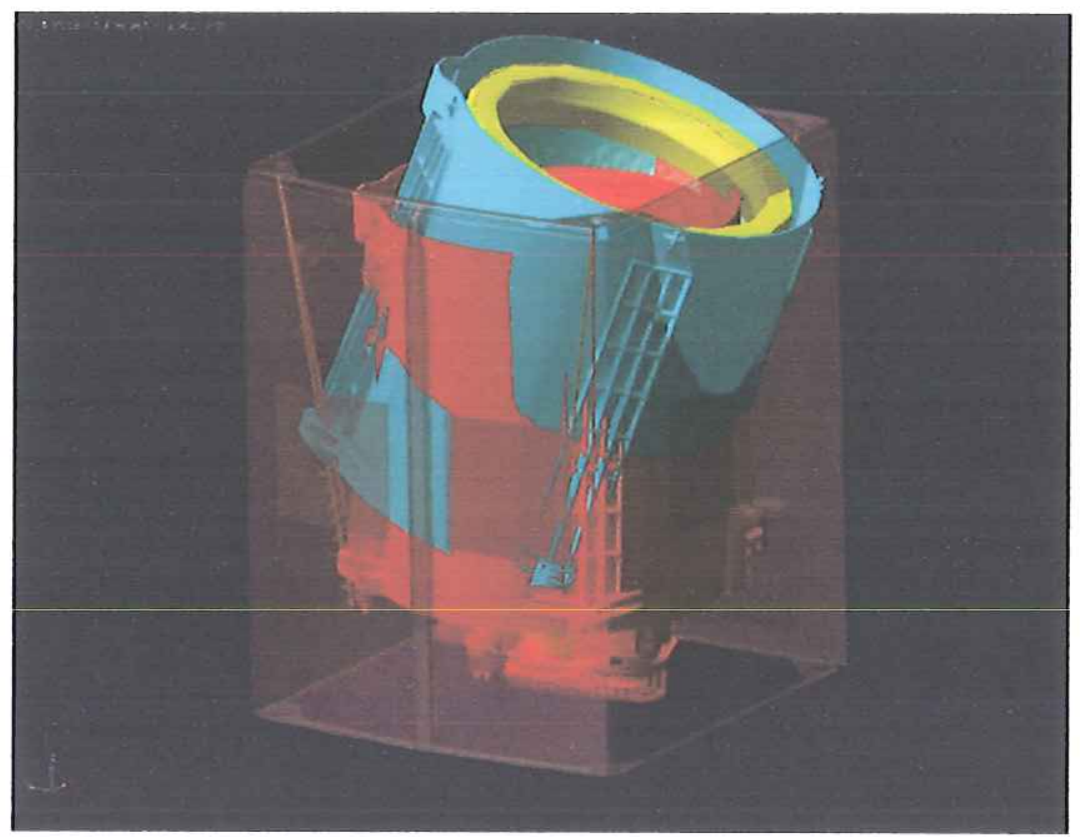

Figura 6.6 - Modo vertical $2.56 \mathrm{~Hz}$

Os primeiros modos (Figura 6.1 e Figura 6.2) ilustram os modos pendulares de muita baixa freqüência. Tais modos são simétricos entre si e seus efeitos não seriam capturados na análise experimental, uma vez que o equipamento utilizado apresentava uma freqüência passa-alta de 0,7 Hz.

Entretanto, seus efeitos são minimizados pela rápida aceleração de rotação e ainda pelo alto amortecimento das juntas da suspensão. Além disso, 
a utilização de tirantes na suspensão prendendo as varetas ao gabinete acabam por limitar os movimentos pendulares. O uso de espumas colados ao gabinete, solução bastante utilizada no mercado por competidores, acaba também por amortecer tais modos pendulares.

O modo seguinte (Figura 6.3) corresponde a um modo torsional das varetas de suspensão. Por fim, os últimos três modos (Figura 6.4, Figura 6.5 e Figura 6.6) apresentam relações diretas com a rigidez das molas de suspensão.

\subsubsection{Diagrama de Campbell}

Como descrito por Genta (2005), as freqüências naturais de vibração de uma máquina contendo um rotor podem variar com a rotação. Quando isso ocorre, o comportamento livre do sistema é geralmente sumarizado por um gráfico de freqüências naturais em função da rotação. Devido às forças de excitação também dependerem da velocidade, costuma-se plotar um gráfico contendo a rotação e as freqüências naturais do sistema. Tal gráfico é também conhecido como Diagrama de Campbell. (PEREIRA, 2003) analisa a dinâmica de rotores e a construção de diagramas para sistemas simples.

Conceitualmente, o diagrama de Campbell pode ser plotado somente no caso de sistemas lineares, porque somente neste caso o conceito de freqüências naturais se aplica. Entretanto, no caso de sistemas não lineares, o diagrama de Campbell do sistema linearizado pode fornecer informações importantes sobre o comportamento do sistema em estudo.

O diagrama abaixo foi traçado utilizando-se o modelo virtual da lavadora e variando-se a rotação. Os autovalores correspondentes `as freqüências naturais de vibração foram extraídos com auxílio do ADAMS/Linear. 


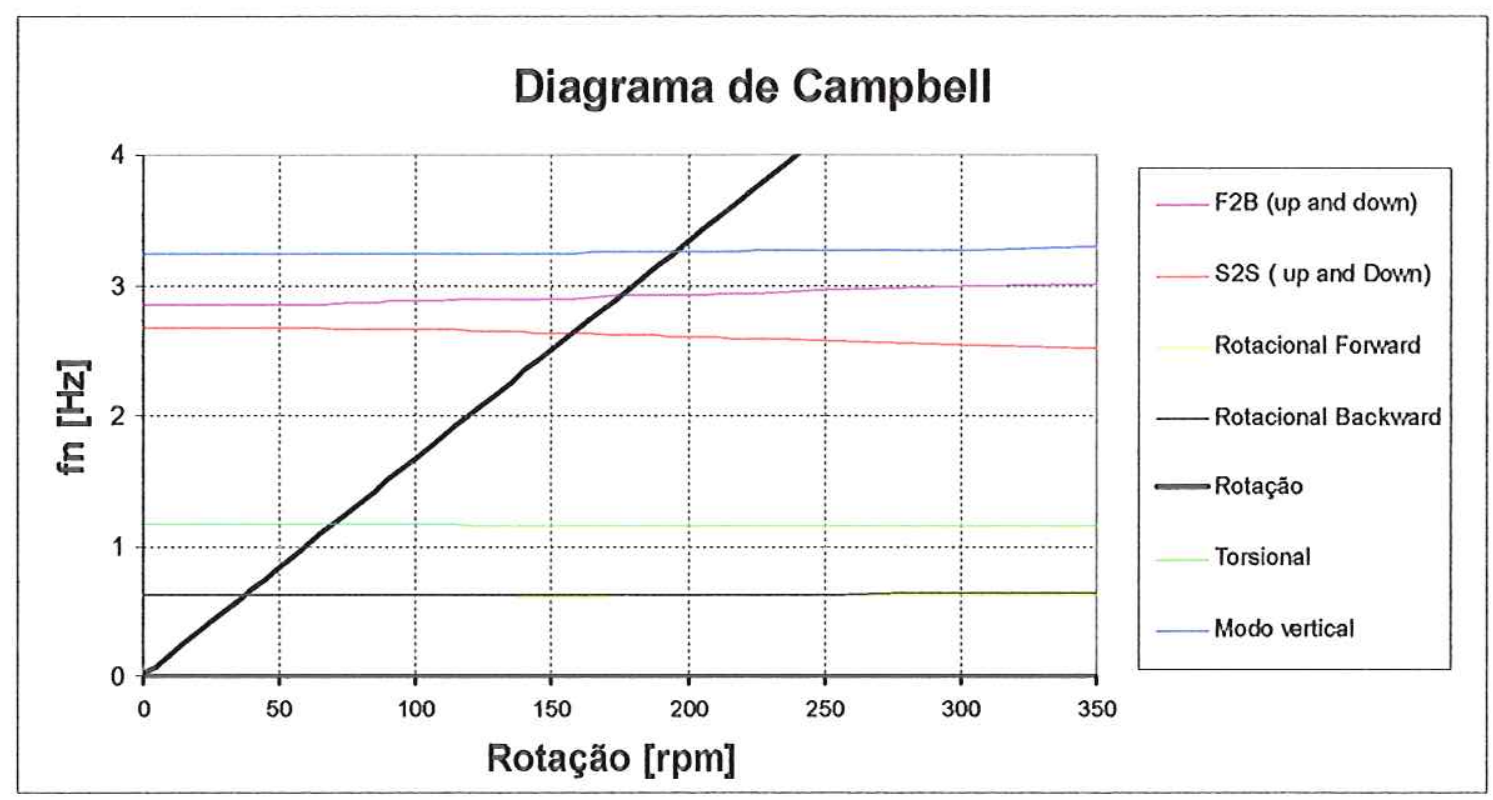

Figura 6.7 - Diagrama de Campbell do modelo teórico da lavadora

São mostrados os sete primeiros modos de vibração. Observa-se, para alguns modos, a dependência da freqüência de excitação na resposta. Os modos laterais são transformados em modos rotacionais backward e forward.

As freqüências naturais correspondentes aos modos laterais (side to side e front to back) são também dependentes da freqüência de excitação.

Este gráfico permite fazer considerações importantes em termos do desempenho do sistema. A curva de rotação da máquina mostrada acima auxilia na identificação das freqüências críticas do sistema. Ao cruzar as linhas de freqüências naturais, o sistema automaticamente tem uma freqüência excitada.

Nas considerações de projeto, é interessante amortecer estas freqüências de forma a reduzir as vibrações causadas pela excitação.

É ainda desejável que o rotor passe rapidamente pelas freqüências críticas mostradas acima. Isto pode ser realizado através do uso de motores potentes, proporcionando uma rampa de aceleração agressiva.

\subsection{Performance da lavadora contra deslocamento}

Muitos autores equacionaram o desempenho da lavadora frente ao 
problema do deslocamento relativo ao solo, também conhecido como fenômeno do deslocamento ou walking. (CONRAD, 1994, 1995; TÜRKAY ET AL, 1992, 1993A, 1993B, PAPADOPOULOS; PAPADIMITRIOU 2001; BARCHA 2004).

Com o intuito de avaliar o desempenho da lavadora neste quesito, equacionou-se as forças nos pés segundo a equação já relatada anteriormente:

$$
T A=\mu^{*} \sum F_{\text {vertical }}-\sum F_{\text {horizontal }}
$$

A análise da equação nos faz concluir que, a tendência ao deslocamento, acontece quando TD < 0 . Os parâmetros de atrito variam significativamente em função do tipo de piso. $\mathrm{Na}$ análise realizada utilizou-se um coeficiente de atrito de 0.4 entre os pés e o solo. A força residual dada pela equação acima é mostrada no gráfico abaixo (Fligura 6.8).

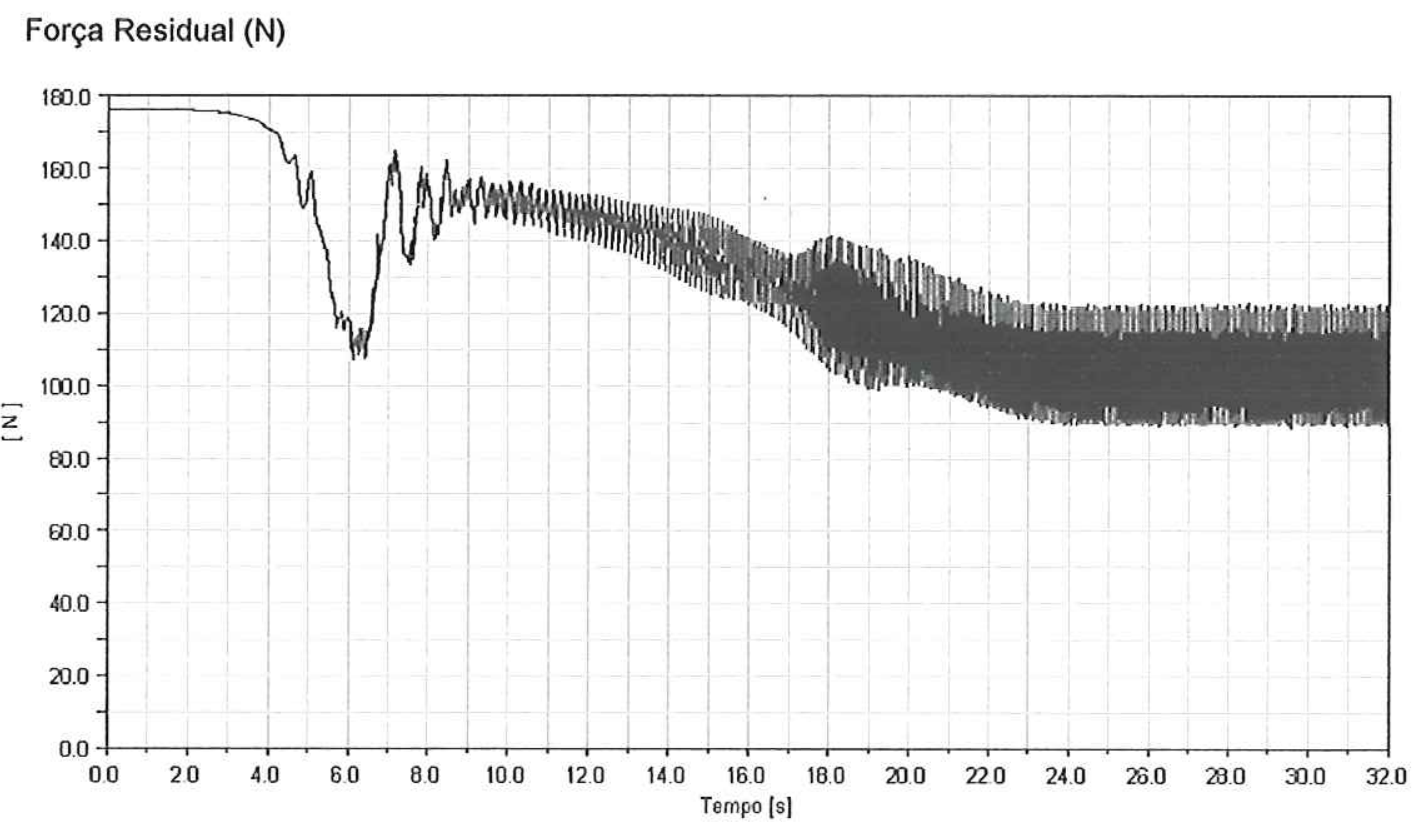

Fligura 6.8 - Força residual nos pés e tendência de andar.

De acordo com o gráfico acima, observa-se que a lavadora apresenta uma margem de segurança antes de se deslocar no piso. 


\subsection{Absorvedor de vibração}

Absorvedores de vibração podem ser utilizados em lavadoras com a finalidade de reduzir vibrações em determinadas freqüências. Seu equacionamento, já discutido no Capítulo 3 , ilustra o efeito causado pelo absorvedor de vibração em um sistema mecânico.

Alguns fabricantes de lavadoras já utilizam comercialmente este tipo de aplicação (HARR, 1999).

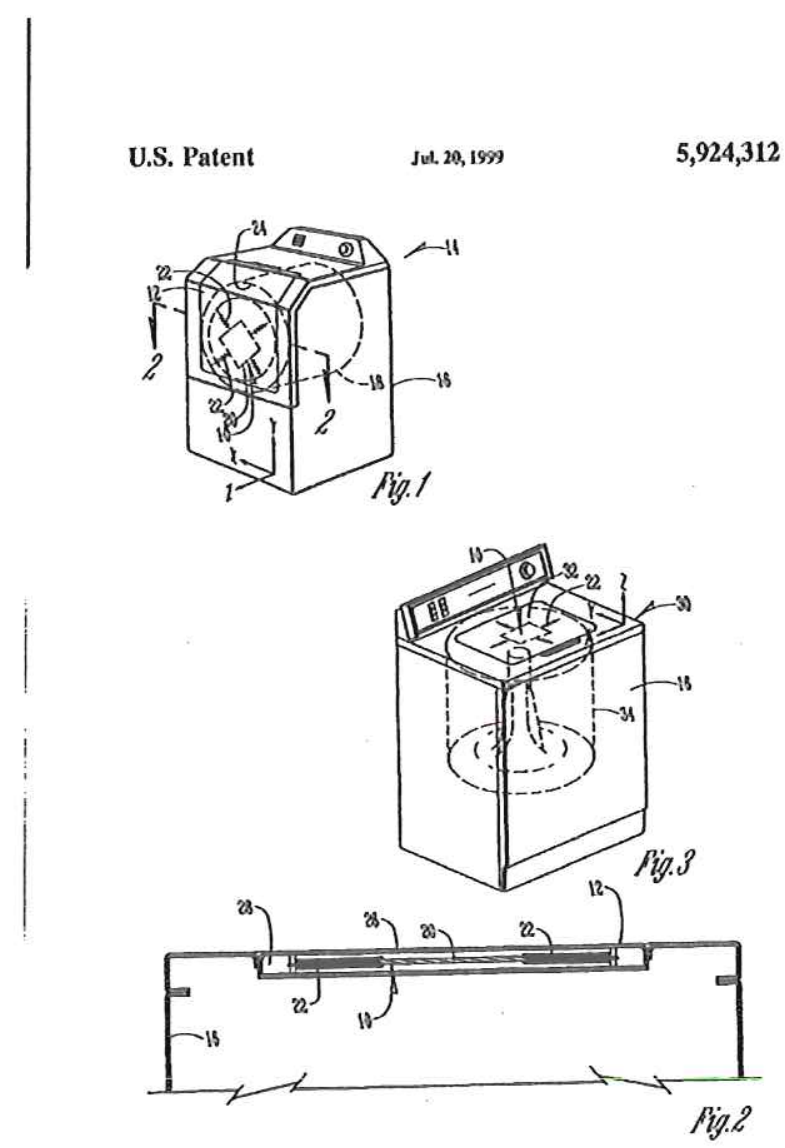

Figura 6.9 - Patente Maytag mostrando absorverdor de vibração em lavadoras - Fonte: Haar (1999)

Com o intuito de simular o sistema mecânico no modelo da lavadora comercial a ser estudada, um absorvedor de vibração foi desenvolvido a fim de absorver as vibrações laterais do gabinete durante centrifugação. As figuras abaixo (Figura 6.10, Figura 6.11) ilustram este mecanismo: 


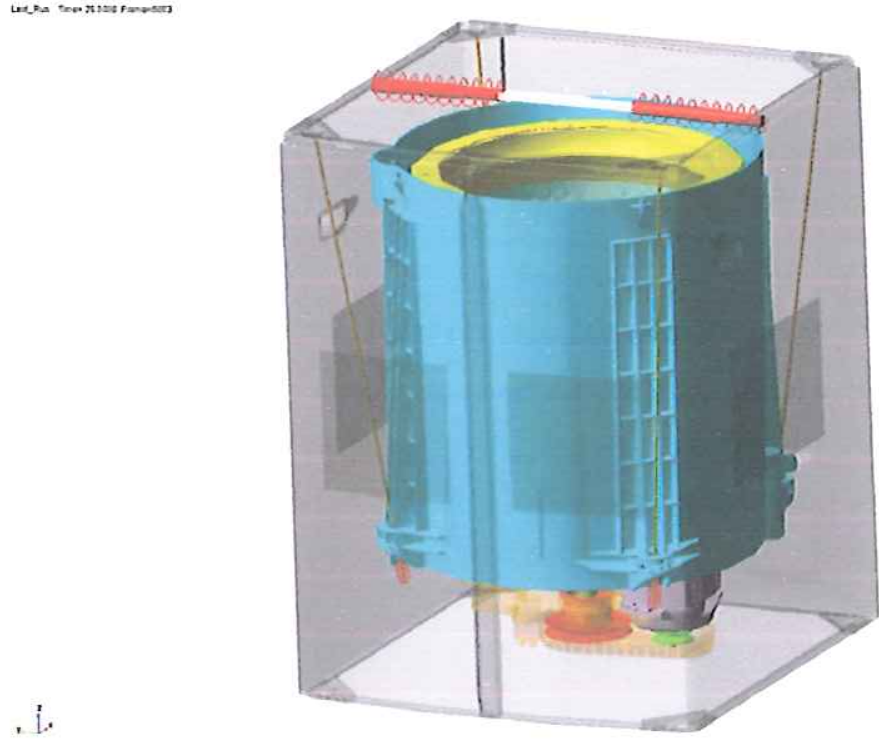

Figura 6.10 - Absorvedor de vibração aplicado ao modelo da lavadora

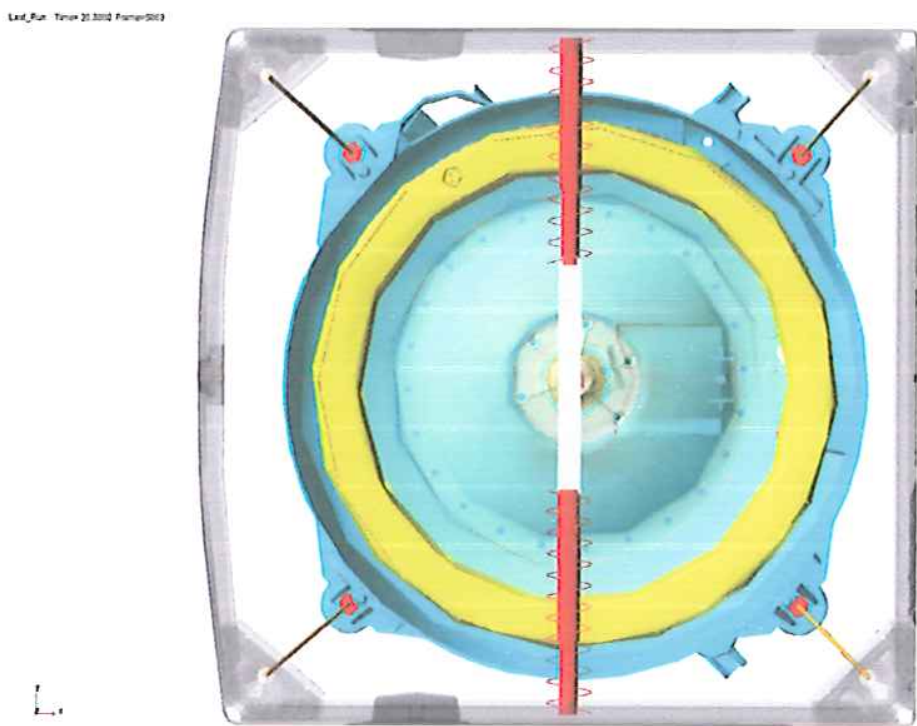

Figura 6.11 - Absorvedor de vibração - vista de topo

Neste estudo, comparou-se os resultados de deslocamento teórico do gabinete sem e com absorvedor de vibração. 


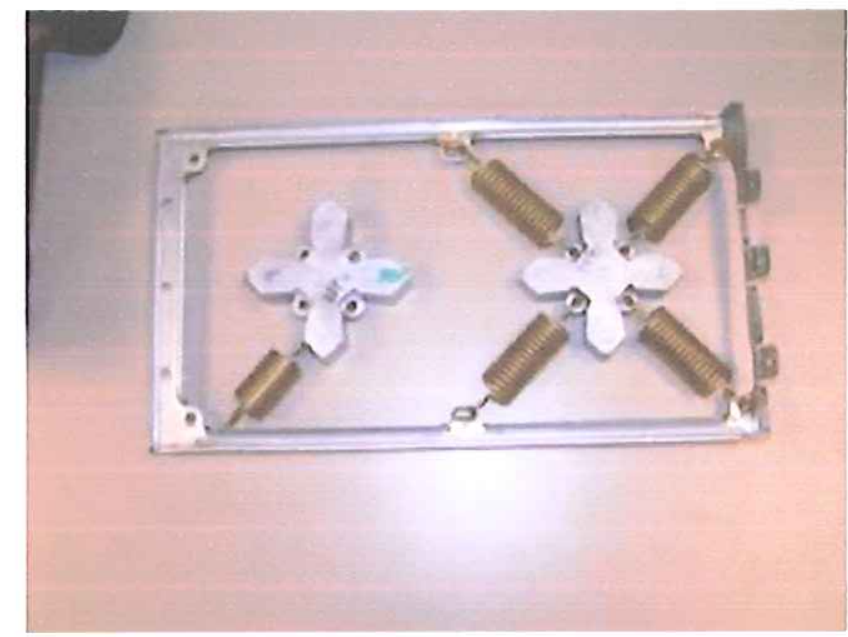

Figura 6.12 - Absorvedor de vibração de uma máquina de eixo horizontal Maytag

Os parâmetros do absorvedor de vibração, massa e rigidez, foram ajustados de forma a se obter uma freqüência natural idêntica `a freqüência de operação da lavadora em regime ( 760 rpm ).

O gráfico da figura abaixo mostra o resultados obtidos:

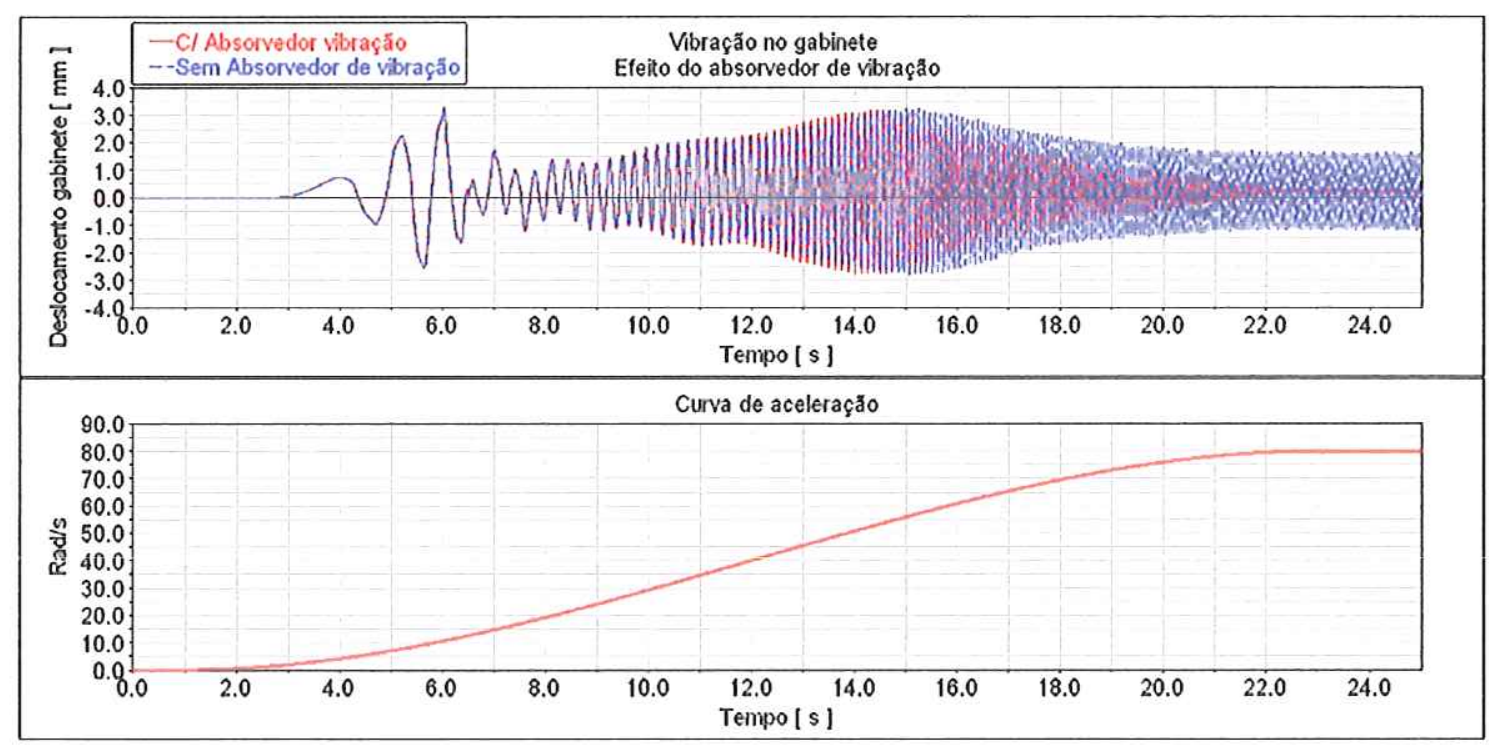

Figura 6.13 - Deslocamento lateral do gabinete

Observa-se, pelas curvas em vermelho e azul, uma grande melhoria de vibração do gabinete na região de regime. 


\section{Resultados e conclusões}

A inovação em produtos hoje é uma das principais armas das empresas para se manterem competitivas no mercado e atrativas aos investidores. Seguindo esta tendência, o desenvolvimento de produtos vem sofrendo uma grande mudança, aonde os inúmeros ciclos de Design - Construção - Teste vêm sendo substituídos por um processo muito mais enxuto de desenvolvimento, onde muitas vezes os primeiros protótipos reais já são capazes de atender grande parte dos requisitos de funcionamento e performance.

Esta mudança foi suportada principalmente por ferramentas computacionais que fizeram encurtar o tempo de desenvolvimento de produtos. Dentro deste grupo, se encontram as ferramentas de CAD/CAE e a construção de protótipos funcionais virtuais, foco deste trabalho.

A construção de um protótipo virtual, usando-se técnicas de Multicorpos e o software ADAMS, permitiu estudar o desempenho dinâmico de uma lavadora comercial durante o processo crítico de extração de água.

Os resultados teóricos de performance, comparados com dados experimentais e sumarizados abaixo (Figura 7.1), mostram correlação satisfatória, o que nos leva a confirmar a validade do modelo teórico. Este modelo, portanto, pode ser utilizado futuramente para estudos de mudança de design em parâmetros que influenciariam a performance dinâmica da lavadora.

Resultado Comparativo - Experimental versus Teórico

\begin{tabular}{lcccc}
\hline & \multicolumn{2}{c}{ Transiente } & \multicolumn{2}{c}{ Regime Estacionário } \\
\hline & $\begin{array}{c}\text { Deslocamento } \\
\text { Inferior }\end{array}$ & $\begin{array}{c}\text { Deslocamento } \\
\text { Superior }\end{array}$ & $\begin{array}{c}\text { Deslocamento } \\
\text { Inferior }\end{array}$ & $\begin{array}{c}\text { Deslocamento } \\
\text { Superior }\end{array}$ \\
Resultados Experimentais [ mm ] & 33,0 & 24,6 & 9,5 & 12,0 \\
Resultados Teóricos ADAMS [ mm ] & 33,5 & 33,5 & 9,0 & 12,5 \\
\hline \hline Erro \% & $1,5 \%$ & $36,2 \%$ & $-5,3 \%$ & $4,2 \%$
\end{tabular}

Figura 7.1 - Resultados comparativos - Teórico versus Experimental

O modelo ainda pode servir de base para estudo de otimização de performance ou mesmo para trabalhos de redução de custo e aumento de 
qualidade, uma vez que o modelo pode fornecer subsídios para cálculo de esforços em componentes e auxiliar o projeto do mesmo no ambiente virtual.

O modelo ainda serviu de meio para se entender as freqüências críticas do sistema, bem como o de ilustrar a aplicação de um absorvedor de vibração para se reduzir vibração do gabinete.

\subsection{Trabalhos futuros}

Investigações futuras relacionadas ao tema de lavadoras e Multicorpos podem incluir os seguintes tópicos:

- Estudo dos efeitos de corpos flexíveis na dinâmica da lavadora.

- Estudo paramétrico para otimização de desempenho dinâmico via Multicorpos

- Desenvolvimento de rotinas que simulem 0 efeito dos anéis de balanceamento de forma mais fidedigna durante o transiente na etapa de centrifugação

- Modelagem dos efeitos das massas variáveis em Multicorpos, simulando a extração de água do cesto da lavadora.

- Utilizar hardware in the loop para simular componentes de difícil caracterização ou com grande variação, como por exemplo anel hidrodinâmico ou suspensão, cujo amortecimento apresenta grande dispersão.. 


\section{REFERÊNCIAS BIBLIOGRÁFICAS}

BAE, S. ET AL. (2002). Dynamic analysis of an automatic washing machine with a hydraulic balancer. Journal of Sound and Vibration, v.257, p.3-18.

BAGEPALLI, B.S. (1987). Dynamic modeling of washing machine suspension system. In: ASME 11th BIANNUAL CONFERENCE OF MECHANICAL VIBRATIONS AND NOISE, Massachusetts, Sept 1987. Proceedings. p.13-18.

BARCHA,W. Estudo do Comportamento Dinâmico e do fenômeno de deslocamento em lavadora de eixo vertical. São Carlos: Departamento de Engenharia Mecânica EESC, Universidade de São Paulo, 2004. Tese de doutorado em Eng. Mecânica.

CALEJERO, M.E.; BELATEGUI, L.M.; GIMENEZ, B.C. (1988). Computer modeling of a guided Coulomb damping for a washing machine. Mini and Microcomputers and their Applications, p.13-16.

CONRAD, D.C. (1994). The fundamentals of automatic washing machine design based upon dynamic constraints. 261p. Ph.D. Thesis - School of Mechanical Engineering, Purdue University, West Lafayette. December 1994

CONRAD, D.C.; SOEDEL, W. (1995). On the problem of oscillatory walk of automatic washing machines. Journal of Sound and Vibration, v.188, p.301314.

CONRAD, D.C.; SOEDEL, W. (1998). Auxiliary mass dampers. Appliance Engineer, p.72-75, Jul.

CUNHA JR., S.S. (1999). Estudo teórico e numérico de absorvedores dinâmicos de vibrações. 99p. Dissertação (Mestrado) - Universidade Federal de Uberlândia, Uberlândia. Março 1999.

GENTA, G. (2005). Dynamics of Rotating Systems. 1a edição. Torino: Springer, 1994. 658 p.

HAAR, EVAN R. VANDE. Multiple direction vibration absorber. Unites States 
Patent, no. 5924312. 1999 julho 20.

HARDER, H.; LOEHR, A. (1981). Changes in domestic washing methods since 1945 - In German. Tenside Detergents, v.18, n.5, p.246-252, SepOct.

LEMON, J.R.; BURTON, S.L. (1972). Dynamic testing and analysis techniques as applied to appliance engineering problems. Appliance Suppliers Exhibit and Conference. Chicago.

MARQUES, R.F.A. (2000). Estudo teórico e numérico de absorvedores dinâmicos de vibrações ativos e adaptativos. 106p. Dissertação (Mestrado)

- Universidade Federal de Uberlândia, Uberlândia. Julho 2000.

NAUNIN, D.; SPECOVIUS, J. (1987). Electronic compensation of unbalanced mass forces in washing machines. In: SECOND EUROPEAN CONFERENCE ON POWER ELECTRONICS AND APPLICATIONS, France, 1987. Proceedings. v.2, p.1075-1078.

PAPADOPOULOS, E.; PAPADIMITRIOU, I. (2001). Modeling, design and control of a portable washing machine during the spinning cycle. ASME International Conference on Advanced Intelligent Mechatronics Systems. Italy, 2001.

PARK, G. R.; CHANG, J. W.; HWANG, J. S.;GUANGQING, L.. (2001). Development on a new damper for noise reduction of a fully automatic washer. Washing system tea, Home Appliance Laboratory, LG Eletronics Korea, 2006.

PEREIRA, J. C. Introdução à dinâmica de rotores. Florianópolis: UFSC, 2003.

SUN, J. Q.; JOLLY, M. R.; NORRIS, M. A. (1995). Passive, adaptative and active tuned vibration absorbers-a survey ASME, v.117,p.234-242, Jun 2005.

TENTOR, B. T. (2001). Characterization of an electromagnetic tuned vibration absorber. Ph.D. Thesis - Virginia Polytechnic Institute and State University. 2001.

VAN KIRK, J.W. (1971). Design of an automatic dynamic balancer for a 
vertical axis washing machine. Ph.D. Thesis - School of Engineering, University of Kansas, Kansas. 1971.

STEPHENS, L.S.; ROUCH, K.E.; TEWANI, S.G. (1991). Theory for an active vibration absorber. Advances Vibration and Acoustics ASME, 1991. DE-Vol. 34.

SUMER, I.T.; TUGCU, A.K.; TURKAY, O.S. (1992). The use of suspension system modeling and simulation in the manufacturing of washing machines. In: 43rd ANNUAL INTERNATIONAL APPLIANCE TECHNICAL CONFERENCE, Purdue University, West Lafayette, Indiana, 1992. Proceedings. p.117-126.

SUSUK, S. (2001). A study on the dynamic behavior of an automatic washing machine. SAMSUNG ELECTRONICS CO., LTD. Korea ADAMS user Conference. 2001. 11.8-9, p1 - 6.

TATSUMI, H. (1981). Analysis of vibration and noise of domestic automatic washing machines. Toshiba Corporation. Nagoya City, Japan.

THEARLE, E.L. (1950A). Automatic dynamic balancers - Part 1 - The Leblanc balancer. Machine Design, p.119-124, Sep.

THEARLE, E.L. (1950B). Automatic dynamic balancers - Part 2 - Ring, pendulum and ball balancers. Machine Design, p.102-106, Oct.

THEARLE, E.L. (1950C). Automatic dynamic balancers - Part 3 Designing for complete effectiveness. Machine Design, p.149-153, Nov. TÜRKAY, O.S.; SÜMER, I.T.; TÜGCU, A.K. (1992). Modeling and dynamic analysis of the suspension system of a front loaded washing machines. Advances in Design Automation Conference Trans ASME, p.383-390. TÜRKAY, O.S. ET AL. (1993A). Suspension design optimization of a washing machine: Part I- Modeling and validation results. Advances in Design Automation Conference Trans ASME, p.125-132.

TÜRKAY, O.S. ET AL. (1993B). Suspension design optimization of a washing machine: Part II - Formulation and implementation of parametric optimization. Advances in Design Automation Conference Trans ASME, p.133-144. 
VAKAKIS, A.F.; PAIPETS, S. A. (1998). The effect of viscously damped dynamic absorber on a linear multi-degree-of-freedom system. Journal of Sound and Vibration, 105(1), p.49-60.

WERKEMA, M.C.; AGUIAR, S. (1996). Planejamento e análise de experimentos: como identificar e avaliar as principais variáveis influentes em um processo. Belo Horizonte: Fundação Christiano Ottoni, Escola de Engenharia da UFMG.

ZUOXIN, P. (1991). A study of the vibration of a fully automatic washer and the optimizing of the structure parameters. In: 42ND ANNUAL INTERNATIONAL APPLIANCE TECHNICAL CONFERENCE, University of Wisconsin, Madison, May 1991. Proceedings. p.545-556. 